Maria Célia Vitor de Souza Brangioni

Efeitos da Modulação do Córtex Pré-Frontal através da Estimulação Transcraniana com Corrente Contínua no Tratamento do Tabagismo 


\author{
UNIVERSIDADE DE BRASÍLIA \\ FACULDADE DE CIÊNCIAS DA SAÚDE \\ PROGRAMA DE PÓS-GRADUAÇÃO EM CIÊNCIAS DA SAÚDE
}

Maria Célia Vitor de Souza Brangioni

\title{
Efeitos da Modulação do Córtex Pré-Frontal através da Estimulação Transcraniana com Corrente Contínua no Tratamento do Tabagismo
}

Dissertação apresentada como requisito parcial para a obtenção do Grau de Mestre em Ciências da Saúde pelo Programa de Pós-Graduação em Ciências da Saúde da Universidade de Brasília.

Orientador: Prof. Dr. Joaquim Pereira Brasil Neto Co-orientador: Prof. Dr. Raphael Boechat Barros 


\title{
Efeitos da Modulação do Córtex Pré-Frontal através da Estimulação Transcraniana com Corrente Contínua no Tratamento do Tabagismo
}

\begin{abstract}
Dissertação apresentada como requisito parcial para a obtenção do Grau de Mestre em Ciências da Saúde pelo Programa de Pós-Graduação em Ciências da Saúde da Universidade de Brasília.
\end{abstract}

Aprovado em 26 / 09/ 2016.

BANCA EXAMINADORA

Prof. Dr. Joaquim Pereira Brasil Neto (Presidente da Banca) Universidade de Brasília (UnB)

Prof. Dr. Gabriel Graça de Oliveira Universidade de Brasília (UnB)

Prof ${ }^{a}$. Dr ${ }^{\mathrm{a}}$. Maria Clotilde Henriques Tavares Universidade de Brasília (UnB)

Prof ${ }^{\mathrm{a}}$. Dr ${ }^{\mathrm{a}}$ Corina Elizabeth Satler (suplente) Universidade de Brasília (UnB) 


\section{Resumo}

Introdução: O tabagismo é atualmente uma das doenças crônicas mais comuns na população, estando desde 1990 inserida na Classificação Internacional de Doenças (CID10) da Organização Mundial da Saúde (OMS). É a principal causa de morte evitável em todo o mundo e uma das dependências de mais difícil tratamento. É considerado uma pandemia com um terço da população adulta fumante, cerca de 1,3 bilhão de pessoas, e estima-se que mate mais de 5 milhões de pessoas a cada ano em todo o mundo. É uma doença muito complexa que, embora $70 \%$ dos fumantes desejem parar de fumar, apenas $5 \%$ destes conseguem fazê-lo por si mesmos. As novas técnicas de neuromodulação por estimulação cerebral não invasiva (ECNI) tem se mostrado promissora no tratamento de várias condições neuropsiquiátricas e dentre elas a estimulação transcraniana por corrente contínua direta (ETCC) demonstrou efetividade na redução do desejo por consumo de cigarros e na redução do número de cigarros fumados em pacientes tabagistas em estudos prévios. Objetivo: analisar os efeitos da modulação do córtex pré-frontal dorso lateral esquerdo (CPFDLE) através da Estimulação Transcraniana por Corrente Contínua (ETCC) no tratamento do tabagismo. Metodologia: Foram randomizados 36 tabagistas: 19 receberam a ETCC (anódica no CPFDLE e catódica em região supraorbital direita) e 17 a Sham-ETCC com sessões de 20 minutos com $1 \mathrm{~mA}$, durante 5 dias. Foram aplicados: SCID-I, Questionário da História do Tabagismo, Teste de Fagerström, Escalas de Avaliação Analógica Visual de Motivação e Fissura (EVAs) e um cartão de automonitoramento do número de cigarros consumidos durante a pesquisa. As EVAs e a média de cigarros consumidos foram preenchidas no $1^{\circ}, 5^{\circ}, 7^{\circ}$ e $35^{\circ}$ dias. Resultados: Na ANOVA de medidas repetidas, foi verificado um efeito significativo sobre a vontade de fumar $(F=17,35 ; p<0,001)$ e o consumo de cigarros $(F=27,53 ; p<0,001)$, porém sem diferença significativa entre a interação desses fatores e grupo de tratamento (grupos ETCC e Sham-ETCC). Não houve diferenças na motivação $(F=1,65$; $p=0,187$ ) entre os grupos ETCC e Sham-ETCC. Conclusões: Nossos resultados não conseguiram confirmar a utilidade da ETCC no tratamento do tabagismo. Mais investigações com amostras maiores e outros parâmetros de estimulação são necessárias. Entretanto, a técnica se mostrou segura e de fácil manejo, o que incentiva novos estudos.

Palavras-chave: ETCC Anódica; CPFDL; Tabagismo; Tratamento. 


\section{Abstract}

Introduction: Smoking is currently one of the most common chronic diseases in the population, since 1990 being inserted in the International Classification of Diseases (ICD-10) of the World Health Organization (WHO). It is the leading cause of preventable death in the world and one of most difficult dependency treatments. It is considered a pandemic, with a third of the adult population being smokers, about 1.3 billion people, and it is estimated to kill more than 5 million people each year worldwide. It is a very complex disease since although $70 \%$ of smokers want to quit, only $5 \%$ of them can do it by themselves. The new techniques of neuromodulation by noninvasive brain stimulation have shown to be promising in treating various neuropsychiatric conditions, and among them the transcranial direct-current stimulation (tDCS) has shown effectiveness in reducing the craving for cigarette smoking and in reducing the number of cigarettes smoked in smokers in previous studies. Objectives: to study the effects of left dorsolateral prefrontal cortex modulation (DLPFC) with Transcranial Direct Current Stimulation (tDCS) on treatment of tobacco addiction. Methods: Thirty-six smokers were enrolled in the study: 19 were randomized to receive active tDCS (anode on the left DLPFC and cathode on the contralateral supraorbital region) and 17 sham stimulation. Treatment consisted of daily 20-minute tDCS sessions of $1 \mathrm{~mA}$ for five days. Each patient was evaluated with SCID I, a survey of smoking history, FTND Test, visual analog rating scales (VAS) of motivation and craving. They also were asked to fill a card for selfmonitoring of the number of cigarettes consumed during the search. VAS and the number of cigarettes were measured on the $1^{\text {st }}, 5^{\text {th }}, 7^{\text {th }}$ and $35^{\text {th }}$ days. Results: There was a significant effect on desire to smoke $(F=17,35 ; p<0,001)$ and number of smoked cigarettes $(F=27,53 ; p<0,001)$, but no significant difference was found in the interaction between these effects and treatment group. There was no difference in motivation $(F=1,65 ; p=0,187)$ between tDCS and sham groups. Conclusions: Our results failed to confirm the effects of tDCS treatment in tobacco dependence. Further research with larger samples and other stimulation parameters are required. However, the technique proved to be safe and easy to handle, which encourages further studies.

Keywords: Anodal tDCS; DLPFC; Smokers; Treatment. 


\section{Lista de figuras}

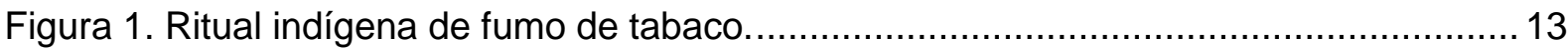

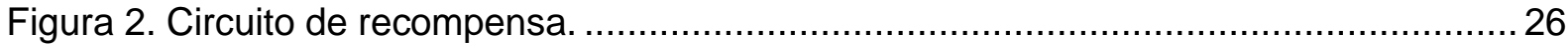

Figura 3. Sequência da dependência de substâncias psicoativas.........................................29

Figura 4. Experimentos de Luigi Galvani.................................................................. 40

Figura 5. Alessandro Volta e a pilha elétrica. ............................................................ 41

Figura 6. Aldini e os experimentos com estimulação elétrica. .......................................... 42

Figura 7. Homúnculos de Penfield. ...................................................................... 43

Figura 8. Circuito básico de um aparelho de ETCC: formado por um gerador, um amperímetro, um potenciômetro e dois eletrodos. ...................................................... 45

Figura 9. Estimulação Magnética Transcraniana (EMT)...............................................5 53

Figura 10. Estimulação Transcraniana por Corrente Contínua (ETCC)................................54

Figura 11. Delineamento do estudo da amostra de pacientes submetidos à ETCC e Sham-ETCC.............................................................. 64

Figura 12. Comorbidades psiquiátricas: autorrelato x SCID .......................................... 70

Figura 13. Grau de Motivação da amostra de tabagistas submetidos à ETCC e sham-ETCC no córtex pré-frontal dorso lateral esquerdo. ................................................. 72

Figura 14. Resultado do Teste de Fargeström da amostra de tabagistas submetidos à ETCC e sham-ETCC sobre o córtex pré-frontal dorso lateral esquerdo............................. 73

Figura 15. Boxplot da vontade/fissura dos grupos Sham-ETCC (0) e ETCC (1) ................. 74 Figura 16. Boxplot do consumo médio de cigarros dos grupos Sham-ETCC (0) e ETCC (1) .............................................................. 75

Figura 17. Boxplot da motivação dos grupos Sham-ETCC (0) e ETCC (1) ....................... 76

Figura 18. Diagrama de dispersão: cigarros $X$ fissura.................................................. 77

Figura 19. Diagrama de dispersão: cigarros X motivação. .................................................. 77 


\section{Lista de tabelas}

Tabela 1. Comparação da eficácia de medicações para cessão do tabagismo

Tabela 2. Características sociodemográficas da amostra submetidos à

ETCC ou sham-ETCC sobre o córtex pré-frontal dorso lateral esquerdo.

Tabela 3. Principais parâmetros clínicos e características do tabagismo dos pacientes

submetidos à ETCC ou sham-ETCC sobre o córtex pré-frontal dorso lateral esquerdo.......68

Tabela 4. Patologias psiquiátricas encontradas na SCID. ................................................... 71

Tabela 5. Estatísticas descritivas das medidas temporais entre os grupos de

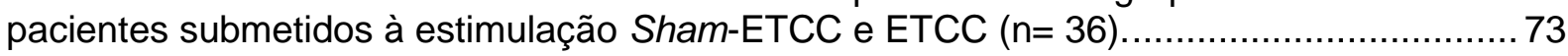

Tabela 6. ANOVA de medidas repetidas (efeitos entre sujeitos) da

vontade de fumar (fissura).

74

Tabela 7. ANOVA de medidas repetidas (efeitos entre sujeitos) da média de cigarros......... 75

Tabela 8. ANOVA de medidas repetidas (efeitos entre sujeitos) da

motivação para parar de fumar. 


\title{
Lista de abreviaturas e siglas
}

\author{
5-HT Serotonina \\ ACh Acetilcolina \\ AMPA Amino-3-hidroxi-5-metil-4-isoxazolpropiônico \\ AMPA-R Receptor de AMPA \\ AMS Assembleia Mundial de Saúde \\ ANOVA Análise de Variância \\ ANOVAmr Análise de Variância de medidas repetidas \\ ANVISA Agência Nacional de Vigilância Sanitária \\ APA American Psychiatric Association \\ ASL Arterial spin labeling \\ ATV Área Tegmental Ventral \\ AVC Acidente Vascular Cerebral \\ BOLD Blood Oxigenation Level Dependent \\ CAMK II Cinase dependente de cálcio e calmodulina II \\ CEP/FS/UNB Comitê de Ética em Pesquisa da Faculdade de Saúde da Universidade de Brasília \\ CID-10 Classificação Internacional de Doenças \\ CONICQ Comissão Nacional para a Implementação da Convenção-Quadro para o Controle do Tabaco \\ CPF Córtex pré-frontal \\ CPFDL Córtex pré-frontal dorso lateral \\ CPFDLE Córtex pré-frontal dorso-lateral esquerdo \\ CQCT Convenção-Quadro para o Controle do Tabaco \\ CREB Proteína ligante ao elemento de resposta do AMPc \\ DA Dopamina \\ DAT Transportador de DA \\ DSM Diagnostic and Statistical Manual of Mental Disorders \\ DTI Tensor de Difusão de Imagem \\ ECR Ensaios clínicos randomizados \\ EEG Eletroencefalografia \\ EMR Espectroscopia de ressonância magnética \\ ETCC Estimulação Transcraniana por Corrente Contínua \\ ETM Estimulação Magnética Transcraniana \\ ETMr Estimulação Magnética Transcraniana repetida \\ EVA Escala Visual Analógica \\ FDA Food and Drug Administration \\ FSC Fluxo sanguíneo cerebral \\ FSCr Fluxo sanguíneo cerebral regional \\ TFDN Teste de Fagerström para a Dependência de Nicotina
}




$\begin{array}{ll}\text { GABA } & \text { Ácido gama aminobutírico } \\ \text { HD-ETCC } & \text { ETCC de alta definição } \\ \text { HUB } & \text { Hospital Universitário de Brasília } \\ \text { IBGE } & \text { Instituto Brasileiro de Geografia e Estatística } \\ \text { INCA } & \text { Instituto Nacional de Câncer } \\ \text { LCR } & \text { Líquido céfalo-raquidiano } \\ \text { LTD } & \text { Depressão a longo prazo } \\ \text { LTP } & \text { Potenciação a longo prazo } \\ \text { MRI } & \text { Ressonância magnética } \\ \text { MRI } & \text { Ressonância magnética funcional } \\ \text { MVB } & \text { Morfometria baseada em voxel } \\ \text { NA } & \text { Noradrenalina } \\ \text { NAc } & \text { Núcleo accumbens } \\ \text { NMDA } & \text { N-metil-d-aspartato } \\ \text { NMDAR } & \text { Receptor de NMDA } \\ \text { OMS } & \text { Organização Mundial da Saúde } \\ \text { PET } & \text { Tomografia por emissão de pósitron } \\ \text { RCT } & \text { Estudo duplo-cego randomizado controlado } \\ \text { RENAME } & \text { Relação Nacional de Medicamentos Essenciais } \\ \text { SCID I } & \text { Entrevista Clínica Estruturada para Transtornos do Eixo I do DSM-IV } \\ \text { SNA } & \text { Sistema Nervoso Autônomo } \\ \text { SNC } & \text { Sistema Nervoso Central } \\ \text { SPECT } & \text { Tomografia computadorizada por emissão de fóton único } \\ \text { SUS } & \text { Sistema Único de Saúde } \\ \text { TRN } & \text { Terapia de reposição de nicotina } \\ \text { UNB } & \text { Universidade de Brasília } \\ \end{array}$




\section{Agradecimentos}

Agradeço primeiramente a Deus por estar presente em todos os momentos da minha vida, iluminando os meus caminhos e por ter me permitido desenvolver e concluir este trabalho.

A todos os meus familiares, em especial a minha mãe, Layce Vitor de Souza, por seu sempre imenso amor e carinho, ao meu pai, José Anacleto de Souza; ambos por incutirem em mim os meus mais caros valores morais e éticos.

Ao Professor Dr. Joaquim Brasil Neto, meu orientador, pelo seus preciosos ensinamentos, por sua imensa disponibilidade, serenidade, paciência, cordialidade e simpatia demonstradas, pelo contínuo e incansável auxílio que sem saber me proporcionavam segurança e conforto, pela confiança que sempre me concedeu, pelo permanente estímulo que, por vezes, se tornaram decisivos em determinados momentos da elaboração desta dissertação.

Ao Professor Dr. Raphael Boechat Barros, meu co-orientador, por ter me apresentado a Neuromodulação não Invasiva e com ela, a Estimulação Transcraniana por Corrente Contínua, me permitindo ampliar de forma significativa meus conhecimentos, contribuindo para o meu crescimento profissional; pela fundamental ajuda no início e ao longo de todo o trabalho, por estar sempre acessível, pelas opiniões, sugestões, conselhos e esclarecimentos, contribuindo para o meu contínuo caminhar na construção e conclusão do projeto.

Ao Dr. Danilo Assis Pereira e Alexandre Vasconcelos Lima pelos ensinamentos da análise estatística.

Ao Dr. Felipe Fregni pela importante contribuição na revisão do trabalho.

A todas as pessoas que participaram em diversos momentos ao longo desta pesquisa permitindo sua concretização.

Aos amigos que fizeram parte desses momentos sempre me ajudando e incentivando.

Aos pacientes tabagistas que participaram e me possibilitaram ampliar meu conhecimento nesta trajetória científica.

Ao Laboratório de Psiquiatria da Faculdade de Medicina da UnB e Hospital Universitário de Brasília da UnB, por me fornecerem a infraestrutura para a realização do projeto.

A todos, enfim, reitero o meu apreço e a minha eterna gratidão. 
A ciência é uma disposição de aceitar os fatos mesmo quando eles são opostos ao desejos. Burrhus Frederic Skinner

Se não houver frutos, valeu a beleza das flores; se não houver flores, valeu a sombra das folhas; se não houver folhas, valeu a intenção da semente. Henfil (Henrique de Souza Filho) 


\section{Sumário}

Resumo



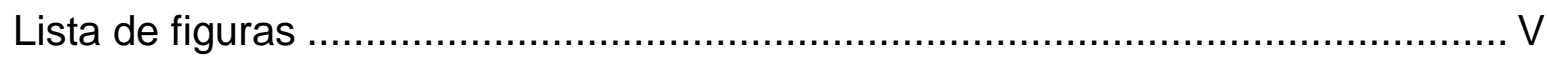

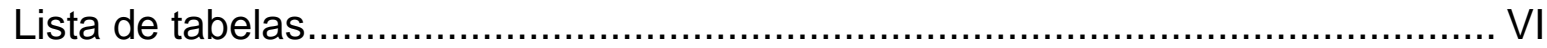

Lista de abreviaturas e siglas .................................................................. VII

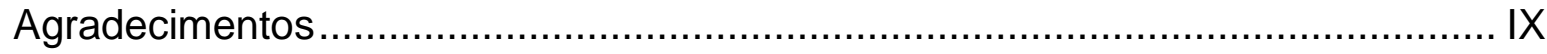

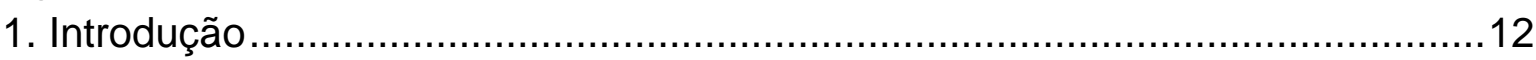

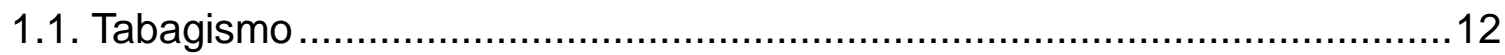

2. A Estimulação Transcraniana por Corrente Continua .......................................39

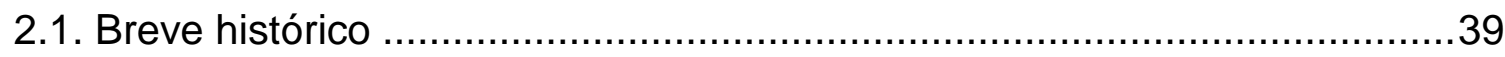

2.2. Mecanismos de funcionamento e ação ...................................................4

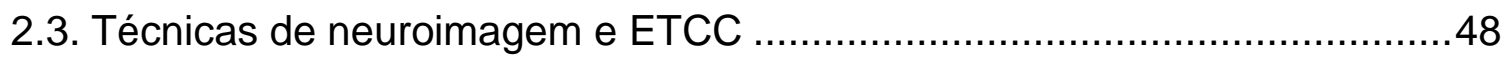

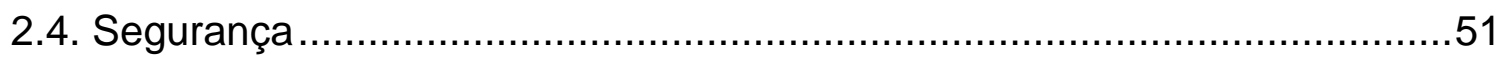

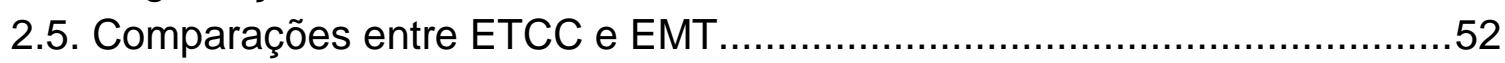

2.6. Estudos envolvendo tabagismo e ETCC .................................................54

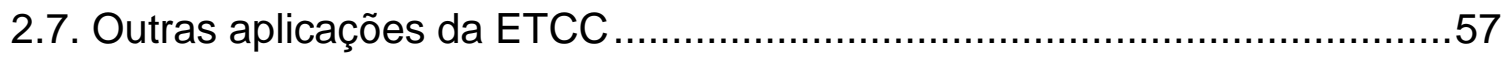

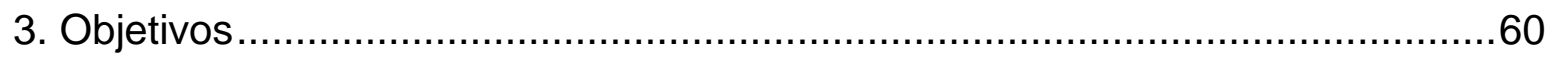

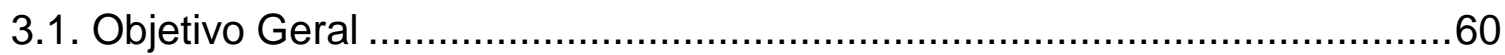

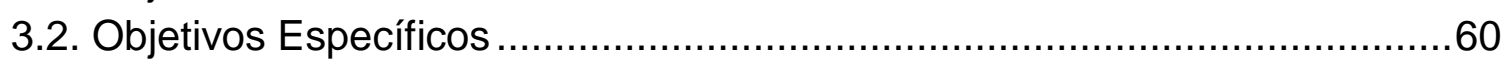



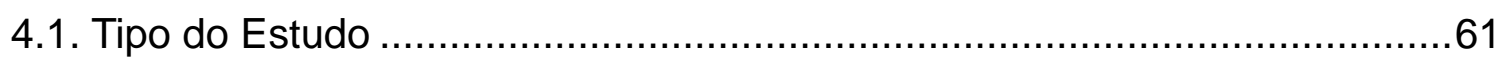

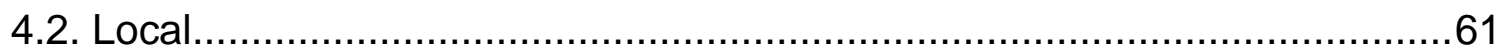

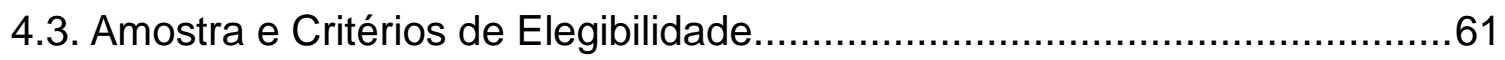



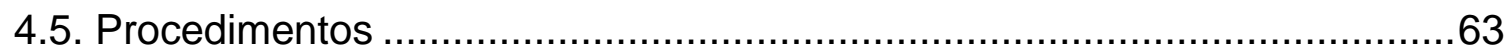

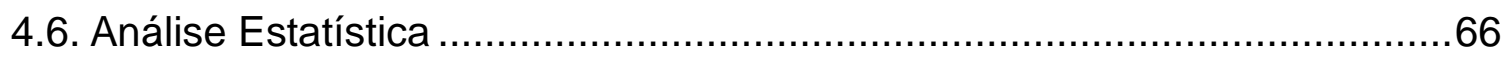



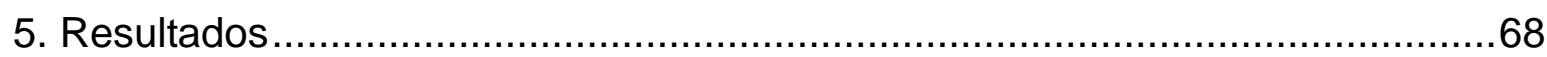

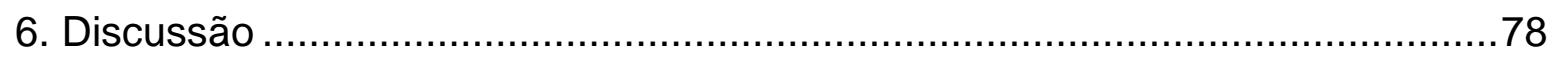

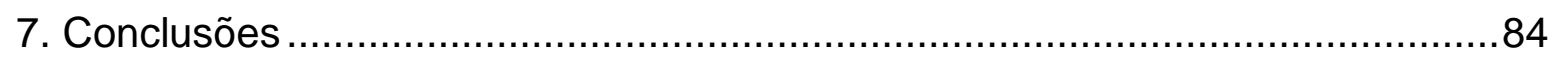



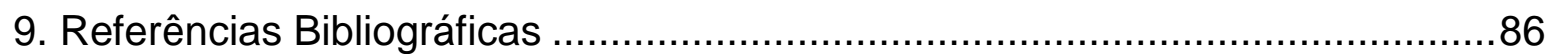

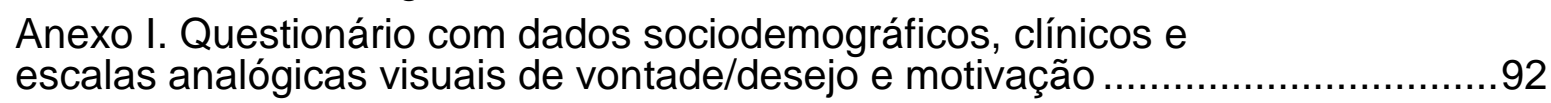

Anexo II. Questionário da história do tabagismo ..............................................94

Anexo III. Teste de Fargeström para a dependência de nicotina ...........................98

Anexo IV. Entrevista clínica estruturada para transtornos

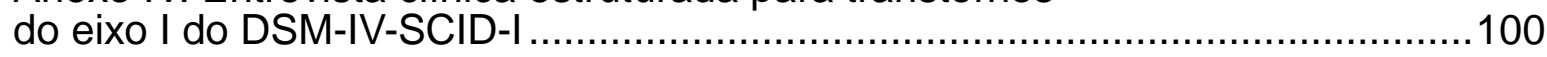

Anexo V. Documento de aprovação pelo Comitê de Ética.....................................102

Anexo VI. Termo de consentimento livre e esclarecido.......................................104 


\section{Introdução}

\subsection{Tabagismo}

\subsubsection{Breve histórico do Tabagismo}

O tabaco, a planta que ainda seduz e encanta milhões no mundo, se enraizou nas diversas culturas mundiais e se fez fortemente presente na sociedade contemporânea, atualmente matando aproximadamente 5,4 milhões de pessoas por ano no mundo (1). Arqueólogos e historiadores acreditam que o tabaco começou a ser cultivado no continente americano em torno de 6 mil a.C., tornando-se uma planta sagrada para os povos pré-colombianos, sendo utilizada em cerimônias religiosas $(2,3)$. O primeiro registro histórico do ato de fumar o tabaco foi encontrado em um vaso Maia do século 10 (3). As culturas indígenas espalhadas por este continente vivenciavam ritual semelhante mágico-religioso, sagrado, no qual o sacerdote, cacique ou pajé e seus circunstantes entravam em transe aspirando o fumo do tabaco (Figura 1) (2). Os astecas consideravam o sumo do tabaco como antídoto insuperável contra o veneno das cobras, os maias lhe atribuíam poderes milagrosos e por isso ofereciam a seus deuses o primeiro tabaco colhido. No Brasil, os aracujás ingeriam as folhas misturadas com outros alimentos. Os winnebagos, aborígenes norte-americanos, o consideravam um presente dos deuses ao primeiro dos seres humanos. Nativos do Amazonas iniciavam seus jovens no mundo adulto fazendo-os aspirar um aromático fumo (4). 

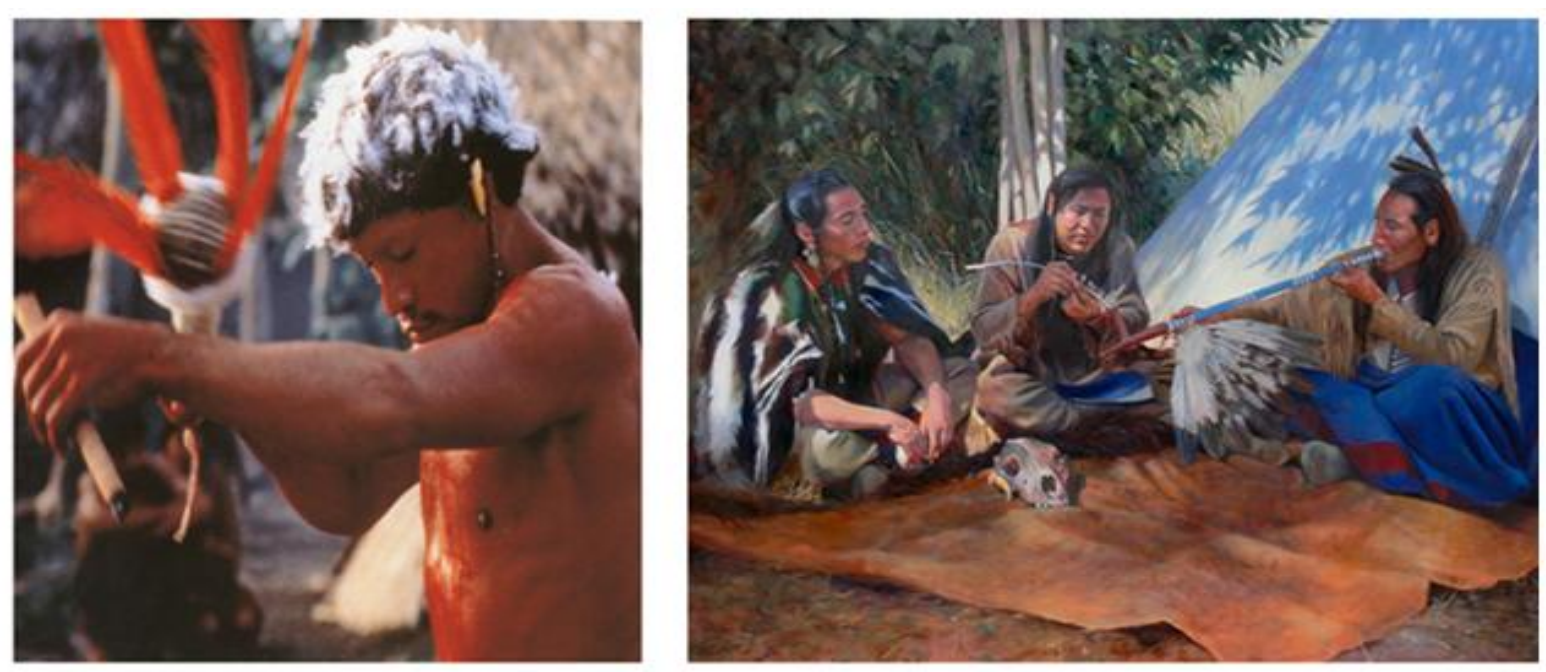

Figura 1. Ritual indígena de fumo de tabaco.

A América foi o berço a partir do qual se disseminou o tabaco. Quando Colombo aportou nestas paragens, plantava-se tabaco em todo o continente e em 1492 começou a ser levado para a Europa por quatros caminhos: Espanha, Portugal, França e Inglaterra (2,5). Espalhou-se pela Europa como rastilho de pólvora e se tornou uma "especiaria" rapidamente introduzida nas cortes europeias até alcançar a sociedade industrial emergente, em diversos formatos, de cachimbo a charuto, de rapé ao cigarro, sendo, em pouco tempo, um dos negócios mais lucrativos do planeta. Cinquenta anos após sua chegada, praticamente se fumava cachimbo em todo o continente: nobres, plebeus, soldados, marinheiros. Rapidamente o tabaco integrou-se a todas as populações do mundo civilizado. Em 1884, foi patenteada a primeira máquina para manufaturar cigarros, produzindo 120 mil cigarros a cada 10 horas. Apesar de ter havido alguns manifestos na época sobre possíveis malefícios do tabaco, seu consumo na forma de cigarro cresceu de forma assustadora, chegando a uma frequência de $80 \%$ nas coortes militares na Segunda Guerra Mundial. O cigarro e o cachimbo entraram para o rol das necessidades básicas do soldado na Segunda Guerra Mundial (3). Chegou a tal ponto de destaque, que um general americano, ao ser entrevistado sobre o que o havia levado a ganhar na guerra, disse: "a moral da minha tropa esteve elevada, pois havia balas, ração e cigarros"; ele ao final frisava que "os cigarros" fizeram a diferença (5). 
A história mostra também como a difusão do tabagismo foi rápida, se constituindo um dos maiores fenômenos de transculturação no mundo. $O$ tabaco está impresso em tapeçarias dos séculos 17 e 18, nas pinturas flamencas, francesas e de outros países, na música erudita, Bach escreve a cantata "Die Tabakpfeifer". A ópera "Carmen de Bizet" e a "Secreto de Susana", de Wolf-Ferrari, contêm temas sobre tabaco. Na literatura de ficção tem-se Graciliano Ramos, dos livros policiais, os detetives vivem com o cachimbo na boca: Sherlock Holmes, de Conan Doyle, e Maigret, de Simenon. Diversos filmes trazem o cigarro e o cachimbo como ostentações: Tobacco Road, de John Ford, tem a ação central voltada ao tabaco; Chaplin (Carlitos) conotou o charuto com a prepotência dos patrões, dos policiais e dos poderosos; outro exemplo é Casablanca, de Michael Curtiz. A filatelia possui selos com menção às folhas do tabaco e outros motivos (2).

Atualmente, não restam muitas dúvidas de que a maioria das pessoas que fumam tabaco, assim 0 fazem, para experimentar as propriedades psicofarmacológicas da nicotina; e que uma quantidade significativa de usuários habituais de tabaco acaba se tornando dependente da substância (6). No entanto, na década de 1950, não haviam as informações científicas de que se dispõe hoje sobre a dependência da nicotina, e nem sobre a relação causal entre tabagismo e doenças relacionadas ao tabaco. Havia uma grande difusão de motivações para fumar: estilo de vida, opção, charme, glamour; o cigarro era propagado e vendido pela mídia como um fator de sucesso. A comunicação pró-tabagismo era ostensiva e dirigida particularmente ao público jovem (5). Todavia, nas últimas décadas, essa visão foi sendo gradativamente substituída pela preocupação com os danos à saúde causados pelo tabagismo; o que era visto como um "hábito charmoso", atualmente é descrito como dependência ao tabaco, que se manifesta de diferentes modos no comportamento e nas atividades do indivíduo, sendo considerada uma doença crônica e recorrente (5).

A Nicotiana tabacum, a principal fonte do tabaco fumado, é uma das 40 espécies do gênero Nicotiana, que por sua vez tem quatro variedades: brasilensis, havanensis, virginica e purpurea. A nicotina é um alcaloide tóxico e a principal substância psicoativa responsável pela adição ao fumo (7). 
No mundo, mais de 6 trilhões de cigarros são consumidos anualmente, manufaturados a partir de mais de 6 milhões de toneladas de folha seca de tabaco. Dos 100 países produtores de tabaco mundialmente, o Brasil ocupa o 4 lugar, sendo responsável por 6\% da produção global (China: 34\%; EUA: 11\%, Índia: 10\%). Esses quatros países cobrem dois terços da produção total de tabaco no mundo. $O$ Brasil é o maior exportador, sendo responsável por $16 \%$ da exportação global de fumo (5).

Os conhecimentos e as concepções atuais sobre o tabagismo, levaram a uma grande conscientização e mobilização pela necessidade de controle desta dependência e a novos posicionamentos. Quando a Organização Mundial de Saúde (OMS) alertou que "o tabagismo é uma doença de dependência da nicotina", passou-se a organizar as intervenções terapêuticas por meio de programas de tratamento estruturados, com base em evidências científicas. Quando se descobriu que "o tabagismo passivo causava danos à saúde, capazes de gerar os mesmos problemas que o tabagismo ativo", expandiram-se as políticas para a proibição de fumar em ambientes fechados. E, quando as mensurações epidemiológicas da OMS constataram a existência de 1,3 bilhão de fumantes e a ocorrência de 5 milhões de mortes anuais por doenças relacionadas ao tabaco e que no ano de 2030 essa mortalidade dobraria se nada fosse feito para mudar o curso da epidemia do tabagismo, criou-se a Convenção-Quadro para o Controle do Tabaco (CQCT), primeiro tratado internacional de saúde pública para o controle do tabagismo no mundo (5). O Brasil participou ativamente do processo de elaboração da CQCT de 1999 a 2003 e ratificou o tratado em 5 de novembro de 2005. A CQCT tem como objetivo proteger as gerações presentes e futuras das devastadoras consequências sanitárias, sociais, ambientais e econômicas geradas pelo consumo da fumaça do tabaco. Atualmente, 40 países já ratificaram o Tratado (6).

\subsubsection{Epidemiologia do tabagismo}

O tabagismo é causa de múltiplas doenças e objeto de distintas especialidades. Por envolver múltiplos interesses e muita gente em todo o mundo, precisa ser observado como um fenômeno social, examinado como uma epidemia e estudado em escala populacional para ser melhor compreendido e tratado. A cadeia 
epidemiológica é enorme: desde a agregação de fatores de risco e a comorbidade frequente no domínio da psicopatologia (que faz os indivíduos buscarem a nicotina), até as intoxicações por agrotóxicos nas áreas de produção e manufaturados, sem contar as relações obscuras que 0 tabgismo envolve com 0 tráfico e a comercialização de outras substâncias aditivas, as agressões ecológicas, o desmatamento, etc. (8).

A prevalência de fumantes no mundo é de 1,3 bilhão, considerando-se pessoas de 15 ou mais anos, e isto constitui um terço da população global, sendo 900 milhões em países em desenvolvimento. O consumo anual é de 7 trilhões e 30 bilhões de cigarros, correspondendo a 20 bilhões por dia; cerca de 75.000 toneladas de nicotina são consumidas por ano, das quais 200 toneladas são diárias. No Brasil, há 27,9 milhões de fumantes, consumindo 110 bilhões de cigarros por ano, acrescidos de 48 bilhões procedentes de contrabando. Em relação ao gênero, no mundo, embora haja tendência de crescimento, ainda há menos mulheres fumantes que homens (9). Estima-se que o número de mulheres tabagistas esteja hoje em torno de 250 milhões (1 mulher/5 homens são fumantes) (5).

A mortalidade anual relacionada ao tabaco, no mundo, é de 5,4 milhões de pessoas, sendo um óbito a cada dez adultos, dos quais $70 \%$ em países em desenvolvimento e cerca de 1 milhão é do sexo feminino (dentro de um total de óbitos de 50 milhões, anualmente, por todas as causas) $(5,9)$. No Brasil, ocorrem 200 mil óbitos por ano. A previsão para o ano 2020 é ocorrerem, no mundo, 10 milhões de óbitos, sendo 7 milhões nos países em desenvolvimento. Persistindo essa tendência, no século 21, eventualmente, ocorrerão 1 bilhão de óbitos. A mortalidade nos adultos está sendo maior que o número de óbitos por HIV, malária, tuberculose, alcoolismo, causas maternas, homicídios e suicídios combinados $(9,10)$.

Há várias formas preparadas de tabaco, que têm a mesma ação nociva à saúde humana: cigarro, charuto, cachimbo, narquilé, uso oral de tabaco - tabaco sem fumaça (moído, mascado) e rapé $(9,10)$.

O tabagismo traz repercussões à saúde, socioeconômicas e ecológicas. Hoje, existem mais de 50 doenças relacionadas ao tabagismo, dentre elas o câncer de 
pulmão e em outros órgãos, o infarto do miocárdio, o acidente vascular e encefálico e as doenças obstrutivas pulmonares crônicas. Essas doenças limitam a capacidade do indivíduo, além de reduzirem o tempo de vida e a sua qualidade $(5,9,10)$.

Entre as repercussões socioeconômicas citamos: desvio de renda (menos gastos com as necessidades básicas) e perda de produtividade (por retenção no leito, absenteísmo no trabalho, pensões, acidentes, assistência médica, invalidez e mortes precoces) $(9,10)$.

Desde a década de 1970, a ameaça que a dinâmica de livre comércio e investimentos da Indústria fumageira colocava sobre iniciativas para o controle do consumo do tabaco, vinha sendo reconhecida pela Assembleia Mundial de Saúde (AMS) e em 1978 em sua 31a assembleia manifestou sua grande preocupação com essa dinâmica: "seriamente preocupados com o alarmante crescimento na produção e no consumo de cigarros durante as duas últimas décadas em países em desenvolvimento, nos quais o consumo não era anteriormente disseminado, e com o extensivo direcionamento promocional para as vendas de cigarros sendo desenvolvidos em meios de comunicações e da associação desses produtos com eventos culturais e esportivos, geralmente induzindo jovens a fumar" (7).

Diante deste cenário e das evidências de efetividade de medidas para 0 controle do tabagismo, em 1990 a AMS convocou os seus Estados Membros a adotá-las com urgência. Em 1999, 9 anos depois, acontecia o nascimento da Convenção-Quadro para o Controle do Tabaco (CQCT) (7).

Em 1999 o Banco Mundial publicou o livro Curbing the Epidemic governments and the economics of tobacco control, que sumarizava a tendência do uso global de tabaco e o grande e crescente peso das doenças e mortes prematuras atribuídas ao tabagismo. Nesta época já eram atribuídas ao tabagismo cerca de 4 milhões de mortes anuais em todo o mundo. Em função desses dados, o Banco Mundial, que nas décadas de 1970 e 1980 estimulava países a cultivarem tabaco como produto rentável para exportação, desde 1991 passou a reconhecer os efeitos nocivos do consumo e da produção de tabaco, ao mesmo tempo em que passou a estimular e até financiar os esforços para o controle do seu consumo em países em desenvolvimento (7). 
A CQCT é considerada um marco histórico para a saúde pública mundial, têm como objetivo proteger as gerações presentes e futuras das consequências sanitárias, sociais, ambientais e econômicas geradas pelo consumo e pela exposição à fumaça do tabaco; determina a adoção de medidas intersetoriais nas áreas de propaganda, publicidade, patrocínio, advertências sanitárias, tabagismo passivo, tratamento de fumantes, comércio ilegal e preços e impostos.

O Brasil tem avançado a passos largos para uma política intersetorial de peso no controle do tabagismo e para o fortalecimento e cumprimento efetivo das leis de controle do tabagismo.

O Programa Nacional de Controle do Tabagismo do Ministério da Saúde, coordenado pelo Instituto Nacional do Câncer (INCA), desde 1989, vêm articulando em nível nacional ações educativas, legislativas e econômicas com vistas a prevenir a iniciação do tabagismo, proteger a população da exposição involuntária às substâncias tóxicas da fumaça do tabaco e apoiar os fumantes no processo de cessação $(6,7,11)$.

A ação da CQCT tem garantido importantes avanços no combate ao tabagismo no Brasil, que têm registrado uma expressiva redução de fumantes nos últimos 25 anos (11).

Três grandes marcos estratégicos das ações nacionais para o controle do tabagismo têm sido a base do sucesso:

1. Um trabalho em rede articulado pelo Ministério da saúde/INCA através de parcerias com secretarias estaduais e municipais de saúde e educação e com a sociedade civil organizada, que tem permitido criar massa crítica nacional de apoio e proteção social às ações educativas e legislativas para o controle do tabagismo e na inclusão do tratamento para a cessação do tabagismo na rede do SUS.

2. Um trabalho de controle e fiscalização dos produtos do tabaco articulado pela Agência Nacional de Vigilância Sanitária, tendo dentre suas atribuições o mandato de regulamentar os produtos derivados do tabaco no que tange a seus conteúdos, emissões, embalagens e atividades de promoção. 
3. Um trabalho intersetorial formalizado através da Comissão Nacional para a Implementação da Convenção-Quadro para o Controle do Tabaco criada por Decreto Presidencial em 2003 que conta com a participação de representantes de 11 Ministérios tendo o Ministério da Saúde na sua Presidência e o INCA como sua secretaria executiva $(7,11)$.

Em 2015 (12) a CQCT completou 10 anos e o INCA noticiou os últimos dados sobre prevalência do tabagismo no país através de uma análise em parceira com o Instituto Brasileiro de Geografia e Estatística (IBGE): a prevalência de fumantes de cigarros diminuiu no País entre 2008 e 2013. Entre os homens, o percentual de fumantes acima de 18 anos caiu de 22,8\% em 2008 para 18,7\% em 2013. Entre as mulheres, a redução foi de $13,8 \%$ para 10,8\%. O número de fumantes masculinos reduziu de 43,3\% em 1989 para 18,9\% em 2013. Entre as mulheres o índice caiu de $27 \%$ para $11 \%$ no mesmo período.

O novo aspecto revelado pelo estudo citado, que destaca de forma positiva o Brasil na tendência mundial, se refere à redução do tabagismo entre homens com menos anos de instrução formal. Na maioria dos países, a redução do tabagismo é menor entre as pessoas com menos anos de escolaridade, por razões diversas, como uma maior dificuldade de acesso a informações e tratamento. Mas esta tendência não se confirma no Brasil, pelo menos entre os homens (12).

O estudo apontou outra evolução positiva na população masculina: 0 aumento da taxa de cessação entre os homens com menos de 25 anos (24,8\% em 2008 para $32,6 \%$ em 2013) foi muito maior do que entre os homens com mais de 25 anos $(52,9 \%$ para $55,1 \%)$. A taxa absoluta de cessação continua a ser menor entre os jovens, o que é esperado, porque esse grupo começou a fumar recentemente e é mais resistente a abandonar o cigarro (12).

Sobre os dados acima e o Programa o ex-Ministro da Saúde em 2015, Marcelo Castro, disse:

"No mundo inteiro o Brasil é referência pelo êxito nas políticas de combate ao tabagismo. A redução do número de fumantes, quando já tivemos quase $40 \%$ de fumantes no País, é uma vitória que devemos comemorar, mas ao mesmo tempo nos deixa alertas para continuar na luta. Ser membro da Convenção-Quadro é um desafio, mas temos a certeza que essas diretrizes são fundamentais para avançarmos na qualidade de vida e longevidade da população" (12). 
O INCA desenvolve papel importante como Centro Colaborador da Organização Mundial da Saúde (OMS) na América Latina, cujo objetivo é estimular e apoiar políticas e atividades de controle do tabagismo nessa região e na implementação da Convenção-Quadro para o Controle do Tabaco. Diversas áreas do INCA contribuem para o avanço da Política, a Direção-Geral/Secretaria-Executiva da CONICQ, a Divisão de Controle do Tabagismo, de Epidemiologia, de Comunicação, a Área de Câncer Ocupacional e Ambiental e o Departamento de Pesquisa do Instituto desenvolvem ações e programas de alcance nacional e reconhecimento mundial no controle do tabaco. No decorrer de sua história e atualmente para a internalização da CQCT no setor saúde, o Ministério da Saúde e o INCA atuam em rede e desenvolvem ações juntos às equipes coordenadoras dos estados (secretarias estaduais de Saúde e Educação), que, por sua vez, multiplicam junto às equipes coordenadoras dos municípios (secretarias municipais de Saúde e Educação), para desenvolverem atividades de coordenação/gerência operacional e técnica do Programa. Estes últimos multiplicam as ações junto aos profissionais que atuam nas diferentes instituições envolvidas no controle do tabagismo e prevenção de câncer, como escolas, unidades de saúde, universidades, dentre outras. É importante destacar que para efetivar as suas práticas de promoção da saúde o referido Instituto atua de forma integrada e articulada com Estados, Municípios e Distrito Federal (13).

É fundamental a continuidade das ações de prevenção e controle do tabagismo, papel que o Brasil através do INCA vem cumprindo de maneira exemplar, e com isto contribuindo para a redução das mortes e doenças tabacorelacionadas.

\subsubsection{A dependência de nicotina}

O conceito do tabagismo evoluiu consideravelmente nas últimas décadas. Considerado um hábito na década de 1960, o consumo do tabaco passou a ser visto como uma dependência química na década de 1970, e como adicção nos anos 1980 (14). 
Já em 1988 foi publicado o relatório do Surgeon General dos EUA, que concluiu que o cigarro e outras formas de tabaco geram dependência, que a droga que causa dependência é a nicotina, e que os processos farmacológicos e comportamentais que determinam a dependência de tabaco são similares àquelas que determinam dependência de outras drogas como heroína e cocaína (8).

A dependência ao Tabaco foi inserida pela primeira vez no Diagnostic and Statistical Manual of Mental Disorders (DSM-III) da American Psychiatric Association (APA) em 1980 e modificada para Dependência Nicotínica na terceira edição revisada (DMS-III-R) publicada em 1987, foi revisado recentemente em 2014 no DSM V e se encontra sob a denominação de Transtorno por Uso de Tabaco. Desde 1990 está inserida na Classificação Internacional de Doenças (CID-10) no grupo de Transtornos Mentais e de Comportamento decorrentes do uso de substancias psicoativas da OMS $(8,15,16)$.

Segundo DSM-V (16) os Critérios Diagnósticos para o Transtorno por Uso de Tabaco são:

A. Um padrão problemático de uso de tabaco, levando a comprometimento ou sofrimento clinicamente significativo, manifestado por pelo menos dois dos seguintes critérios, ocorrendo durante um período de 12 meses:

1. Tabaco é frequentemente consumido em maiores quantidades ou por um período mais longo do que o pretendido.

2. Existe um desejo persistente ou esforços malsucedidos no sentido de reduzir ou controlar o uso de tabaco.

3. Muito tempo é gasto em atividades necessárias para a obtenção ou uso de tabaco.

4. Fissura ou um forte desejo ou necessidade de usar tabaco.

5. Uso recorrente de tabaco resultando em fracasso em cumprir obrigações importantes no trabalho, na escola ou em casa (por exemplo, interferência no trabalho).

6. Uso continuado de tabaco apesar de problemas sociais ou interpessoais persistentes ou recorrentes causados ou exacerbados pelos seus efeitos (por exemplo, discussões com os outros sobre o uso de tabaco). 
7. Importantes atividades sociais, profissionais ou recreacionais são abandonadas ou reduzidas em virtude do uso de tabaco.

8. Uso recorrente de tabaco em situações nas quais isso representa perigo para a integridade física (por exemplo, fumar na cama).

9. O uso de tabaco é mantido apesar da consciência de ter um problema físico ou psicológico persistente ou recorrente que tende a ser causado ou exacerbado por ele.

10. Tolerância, definida por qualquer um dos seguintes aspectos:

a. Necessidade de quantidades progressivamente maiores de tabaco para atingir o efeito desejado.

b. Efeito acentuadamente menor com o uso continuado da mesma quantidade de tabaco.

11. Abstinência, manifestada por qualquer dos seguintes aspectos:

a. Síndrome de abstinência característica de tabaco (consultar os Critérios A e $\mathrm{B}$ do conjunto de critérios para abstinência de tabaco).

b. Tabaco (ou uma substância estreitamente relacionada, como nicotina) é consumido para aliviar ou evitar os sintomas de abstinência (16).

O CID-10 (8) define como dependência de tabaco (F17.2) os seguintes critérios:

Um padrão mal adaptativo de uso de substância, levando a prejuízo ou a sofrimento clinicamente significativo e manifestado por três ou mais dos seguintes critérios, ocorrendo a qualquer momento no mesmo período de 12 meses:

1. Tolerância:

a. uma necessidade de quantidades progressivamente maiores da substância para adquirir a intoxicação ou efeitos desejados;

b. acentuada redução do efeito com uso continuado da mesma quantidade de substância.

2. Abstinência:

a. síndrome de abstinência característica para substância;

b. a mesma substância é consumida para aliviar ou evitar sintomas de abstinência. 
3. A substância é frequentemente consumida em maiores quantidades, ou por um período mais longo do que o pretendido.

4. Existe um desejo persistente ou esforço malsucedido no sentido de reduzir ou controlar o uso da substância.

5. Muito tempo é gasto em atividades necessárias para a obtenção da substância, na utilização ou recuperação de seus efeitos.

6. Importantes atividades sociais, ocupacionais ou recreativas são abandonadas ou reduzidas em virtude do uso da substância.

7. O uso da substância continua, apesar da consciência de se ter um problema físico ou psicológico persistente ou recorrente, que tende a ser causado ou exacerbado pela substância.

Como outras dependências, a da nicotina é um transtorno progressivo, crônico e recorrente, mediada pela ação da nicotina em receptores centrais e periféricos e sustentada por fatores ambientais, biológicos e psicológicos $(15,17)$.

Fatores não farmacológicos são importantes para a determinação dos problemas relacionados ao uso do tabaco e sua prevalência, mas os fatores farmacológicos são aqueles que definem a tolerância e a dependência pela substância (8).

A queima de um cigarro produz monóxido de carbono e dezenas de outros produtos tóxicos, responsáveis pela alteração da oxigenação dos tecidos; libera nicotina, a substância responsável pela dependência do tabaco, uma amina terciária volátil capaz de estimular, deprimir ou perturbar o sistema nervoso central (SNC) e todo o organismo, dependendo da dose e da frequência com que é utilizada (15).

Cada cigarro contém 7-9 mg de nicotina, dos quais estima-se que pouco mais de $1 \mathrm{mg}$ seja absorvido pelo organismo. A nicotina é rapidamente absorvida pelos pulmões, atingindo o cérebro em dez segundos e sendo distribuída para todos os sistemas. A meia vida de eliminação da nicotina é de aproximadamente duas horas. Sua metabolização ocorre principalmente no fígado. Apenas $5 \%$ da nicotina é excretada em sua forma original através dos rins (8).

Apesar dos efeitos nocivos do uso do tabaco, a maior parte dos tabagistas mantém o hábito de fumar devido a três principais mecanismos: o reforço positivo 
(relacionado à ação da nicotina no SNC, liberando acetilcolina (ACh), noradrenalina (NA), dopamina (DA), serotonina (5-HT) e ácido gama aminobutírico (GABA), o que resulta em sensações prazerosas e redução do apetite, assim como no aumento da disposição, do estado de alerta e da atenção), o reforço negativo (representado pela manutenção do uso para evitar os sintomas da síndrome de abstinência, principalmente ansiedade, disforia, aumento do apetite, irritabilidade e dificuldade de concentração) e o condicionamento respondente (desencadeado por estímulos ambientais e emoções positivas e negativas associadas ao ato de fumar) (18).

O efeito farmacológico fundamental da nicotina ocorrerá nos receptores colinérgicos do tipo nicotínico (nAChRs). O mecanismo de ação da nicotina é muito complexo, tem ação bifásica sistêmica. Aproximadamente dez tipos diferentes de receptores de nAChRs já foram identificados. (6) Esses receptores são pentâmeros compostos por diferentes combinações de cadeias de polipeptídios, denominadas $\alpha$ e $\beta$, e estão presentes nos gânglios autonômicos, junção neuromuscular e SNC. Diferentes combinações dessas subunidades estão dispostas na membrana celular formando um canal iônico. A ligação da nicotina com esses receptores promove alterações conformacionais e abertura desses canais, promovendo o influxo de cátions ( $\mathrm{Na}+$ e $\mathrm{Ca} 2+)$. No SNC, a nicotina exerce seus efeitos interagindo com nAchRs pré e pós-sinápticos. A estimulação desses receptores resulta no aumento da liberação de vários neurotransmissores (19).

Os receptores nicotínicos periféricos estão em gânglios autonômicos, na suprarrenal, nos nervos sensitivos e na musculatura esquelética (8).

Os efeitos da nicotina sobre os nAChRs do Sistema Nervoso Autônomo (SNA) possivelmente não estão tão envolvidos na sensação subjetiva de prazer e na geração da dependência quanto o efeito desta substância nos mesmos receptores localizados no cérebro. (6) Os dois principais subtipos de receptores nicotínicos no cérebro são o subtipo a4ß2 e o subtipo a7. A ação da nicotina na Área Tegmental Ventral (ATV) são as que teoricamente estão ligadas a adicção. A ativação dos receptores pós-sinápticos de nicotina a4ß2 nos neurônios dopaminérgicos leva a uma liberação de DA no núcleo accumbens (NAc) e a ativação dos receptores présinápticos nicotínicos $\alpha 7$ nos neurônios glutamatérgicos causa liberação de GLU e, por sua vez, liberação de Da no NAc. A nicotina parece também dessensibilizar os 
receptores pós-sinápticos a4ß2 nos interneurônios inibitórios GABAérgicos na área ATV que também levaria à liberação de Da no NAc mediante a desinibição dos neurônios Da mesolímbicos. As ações da nicotina sobre os receptores nicotínicos pós-sinápticos $\alpha 7$ no córtex pré-frontal (CPF) podem estar ligadas as ações prócognitivas e de alerta mental da nicotina porém não nas aditivas. Os receptores nicotínicos $\alpha 4 \beta 2$ se adaptam à liberação pulsátil, crônica e intermitente de nicotina, se abrindo ao receber a nicotina, ficando em seguida dessensibilizados e se ressensibilizam. A inatividade dos receptores mediante sua dessensibilização leva os neurônios a tentar superar esta falta de receptores e regular o número dos mesmos, fazendo isto através de up-regulation. Se a administração da nicotina é interrompida, o sistema terá muitos $\mathrm{nAChRs,} \mathrm{o} \mathrm{que} \mathrm{pode} \mathrm{resultar} \mathrm{em} \mathrm{atividade}$ hipercolinérgica e sintomas de abstinência $(6,20)$.

O consumo do tabaco geralmente começa na adolescência. Nessa fase 0 cérebro ainda está em desenvolvimento, e é particularmente sensível aos efeitos da substância, um fator que contribui para o aumento da vulnerabilidade dos adolescentes que experimentam drogas. Quanto mais precoce este início, maiores serão a gravidade da dependência e os problemas a ela associados (8).

Estudos genéticos vêm indicando que a iniciação do tabagismo, o grau de dependência, a dificuldade de cessação e a manutenção da abstinência são substancialmente determinados por um tipo de herança complexa, a qual envolve múltiplos polimorfismos genéticos. (17,21) Estima-se que os fatores genéticos possam ser responsáveis por até $60 \%$ do risco de início e $70 \%$ da manutenção da dependência (21).

A neurociência apoia o modelo de doença cerebral da dependência e a investigação nesta área não só oferece novas oportunidades para a prevenção e tratamento delas, mas também nos ajuda a melhorar a nossa compreensão dos processos biológicos fundamentais envolvidos no controle do comportamento voluntário (22). 


\subsubsection{A Neurobiologia da dependência à Nicotina: o papel do córtex frontal e do sistema límbico}

Nas últimas duas décadas a investigação tem apoiado cada vez mais a opinião de que a adicção é uma enfermidade do cérebro. As drogas de abuso podem cooptar os mecanismos de plasticidade nos circuitos cerebrais envolvidos no reforço e recompensa (22). Evidências clínicas e experimentais sustentam a hipótese de que os efeitos centrais de diferentes drogas de abuso são mediados por um sistema de recompensa central. Este sistema é principalmente constituído pela via mesocorticolímbica dopaminérgica, tendo origem na ATV e projetando-se para o NAc e também para o CPF, sendo esta última estrutura cortical reconhecida como parte deste circuito apenas nos últimos 10 anos (Figura 2) (23). As alterações que ocorrem nesta via produzem, no CPF, uma diminuição do controle top-down (frontossubcortical) sobre as estruturas subcorticais, diminuindo a vigilância dessa estrutura cortical, de tal forma que as drogas se apoderam das funções subcorticais, deflagrando seu uso compulsivo e descontrolado $(22,23)$.

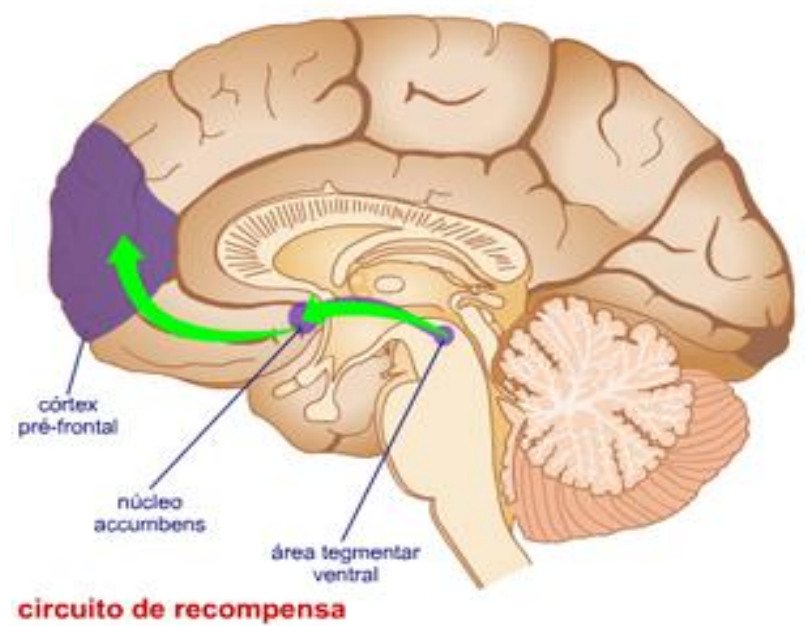

Figura 2. Circuito de recompensa.

Evidências de estudos pré-clínicos e clínicos sugerem que a dependência representa neuroadaptações sequenciais. Como resultado, uma ação impulsiva 
inicial se transforma em compulsiva e torna-se (eventualmente) crônica e recorrente. (24) Uma série de investigações em animais (23) provaram que a exposição repetida a cocaína, anfetamina, morfina ou nicotina apresentou efeitos de duração prolongada sobre a estrutura de dendritos e espinhas em regiões cerebrais que parecem mediar mudanças envolvidas com a motivação e a recompensa como o NAc e com as funções cognitivas como o CPF $(15,23)$. Trabalhos a partir de estudos de imagem $(15,24)$ forneceram evidências de que as mudanças neuroplásticas provocados pelas drogas ocorrem não só no NAc e no CPF, mas também em outras regiões do cérebro como, por exemplo, no corpo estriado dorsal, na amígdala e no hipocampo, dentre outras.

As mudanças plásticas e a subsequente reorganização de circuitos neurais em algumas regiões cerebrais que ocorrem durante a adicção podem estar envolvidas nos mecanismos celulares e moleculares implicados nos processos de aprendizagem e memória (23). Dependendo da experiência de aprendizagem (tais como a que ocorre nos episódios repetidos de uso de drogas) podem invocar tanto a potenciação a longo prazo (LTP), quando a transmissão de sinais entre os neurônios aumenta, como a depressão a longo prazo (LTD), quando a transmissão de sinais diminui (22). As cascatas moleculares induzidas por neurotransmissores dentro do núcleo celular dão lugar a mudanças não só na síntese de seus próprios receptores mas também em muitas outras proteínas pós sinápticas importantes, incluindo enzimas e receptores para outros neurotransmissores (20) A potenciação de longo prazo (LTP) requer a ativação de receptores n-metil-d-aspartato (NMDA) pelo GLU liberado pré-sinapticamente quando a membrana pós sináptica é significativamente despolarizada. Isto revela o bloqueio voltagem dependente do receptor de NMDA (NMDAR) por magnésio e permite que o Ca2+ entre nas espinhas pós-sinápticas. $\mathrm{O}$ ingresso do $\mathrm{Ca} 2+$ no compartimento pós-sináptico é crucial para a LTP e desencadeia complexas cadeias de sinalização intracelular, em particular a proteína cinase dependente de cálcio e calmodulina II (CAMK II). A potência sináptica é controlada pela inserção ou extração dos receptores que são estimulados pelo neurotransmissor excitatório GLU, que atua principalmente através de receptores $\alpha$ amino-3-hidroxi-5-metil-4-isoxazolpropiônico (AMPA) e NMDA e pelas mudanças na composição das subunidades destes receptores. A regulação dos receptores de AMPA que são altamente permeáveis ao cálcio aumenta a capacidade de resposta 
do NAc ao GLU que é liberado por terminais corticais e límbicas quando exposto a drogas $(15,24)$.

A base neurobiológica da dependência de substâncias psicoativas segue uma sequência nesta ordem $(25,26)$ (Figura 3):

Estágio1: Caracterizado por intoxicação/reforço positivo: As alterações da liberação suprafisiológica da dopamina, com o uso agudo de drogas, no circuito motivacional, induzem mudanças na sinalização celular com aumento na atividade do fator de transcrição da proteína ligante ao elemento de resposta ao AMPc (CREB) e indução de cFos com consequente aumento de GluR1, uma importante subunidade dos receptores glutamatérgicos AMPA. Estas alterações são de curta duração (poucas horas ou dias). Os neurotransmissores / neuromoduladores que têm sido identificados nesta etapa incluem DA, peptídeo opioide, GABA, GLU, endocanabinoides, e 5-HT.

Estágio 2: Caracterizado por afeto negativo/reforço negativo: Estágio de Transição. O uso repetido de drogas acumula mudanças na função neural, com surgimento de proteínas com meia vida longa, como o fator de transcrição $\Delta$ FosB. Este é o mecanismo através do qual drogas de abuso produzem alterações relativamente estáveis no cérebro. $O \Delta$ FosB é um regulador transcricional que modula a síntese de certas subunidades do receptor de AMPA (AMPA-R) e de certas enzimas sinalizadoras da célula (tirosina-hidroxilase, RGS9-2, autoR-D2, transportador de DA (DAT)). Estão envolvidos nesta fase a DA, GABA, GLU, CRF, NA, neuropeptídeo $\mathrm{Y}$, dinorfina e sustância $\mathrm{p}$.

Estágio 3: Caracterizado por preocupação/antecipação: neste estágio ocorrem o craving, automação e prejuízo da função executiva. As mudanças na expressão de proteínas conferem vulnerabilidade para recaída. Ocorre uma "Automaticidade" da resposta de procura frente a pista e estresse. Essas alterações são duradouras (anos). Estão envolvidos nesta fase o GLU, GABA, endocanabinoides e NA.

Essas alterações provavelmente se refletem na hipofrontalidade comumente observadas em dependentes químicos (25). 


\section{O ciclo da dependência}

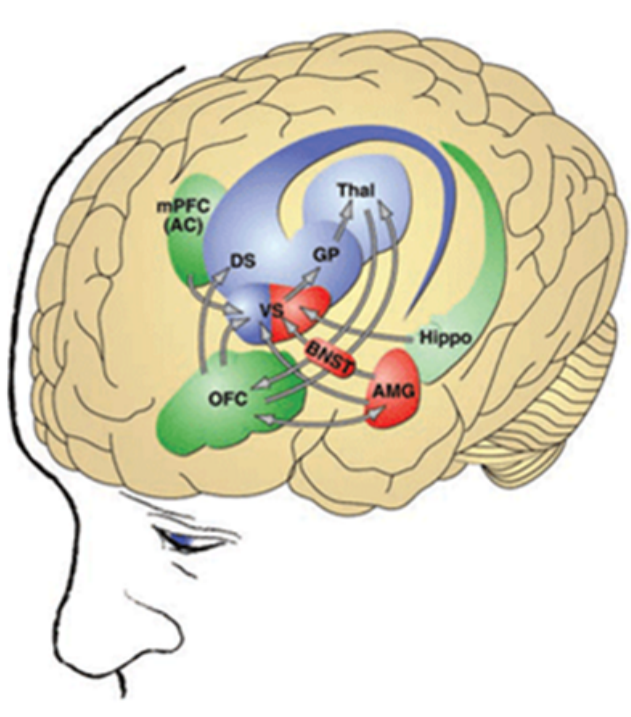

Binge/intoxicação:

Estriado Ventral(VS), incluindo Nac: euforia, recompensa.

Estriado Dorsal (DS), Global pálido(GP),

Tálamo(Thal): hábitos, perseveração .

Afeto negativo/reforço negativo:

Amígdala (AMG), núcleo leito da estria terminal (BNST):mal estar, disforia, estados emocionais negativos.

Estriado Ventral(VS): diminuição da recompensa.

\section{Preocupação / antecipação:}

Cingulado Anterior( $A C)$, córtex pré-frontal ( $\mathrm{mPFC}$ ), córtex orbito-frontal (OFC): efeitos subjetivos do craving, função executiva.

Amígdala (AMG): estímulos condicionados

Hipocampo (Hippo): estímulos condicionados

contextualizados

Koob,G.F. and Wolkow N. D. Neurocircuitry of addiction, Neuropsychopharmacology reviews, 35 (2010)

Figura 3. Sequência da dependência de substâncias psicoativas.

Koob (24) ressalta que as anormalidades neuronais que se manifestam em um dependente e que podem ser observados por exames de imagem e / ou estudos neuropsicofarmacológicos são um reflexo não só de uma determinada trajetória de exposição crônica à droga, mas também de uma base genética individual, do desenvolvimento, das características ambientais e suas interações dinâmicas, que irão determinar o curso e gravidade da dependência.

\subsubsection{Diagnóstico e tratamento do tabagismo}

O tabagismo é uma doença complexa e sua abordagem requer a integração de diversos componentes que interagem e se potencializam para dar conta desta complexidade (6). 
Estima-se que $70 \%$ dos pacientes querem parar de fumar, e cerca de $50 \%$ relatam uma tentativa de parar no ano anterior, mas apenas 4-7\% são bemsucedidos. Estas baixas taxas de abandono do cigarro mostram a importância do tratamento adequado para cessação do tabagismo através de meios comportamentais e farmacológicos (27).

Os tabagistas fumam por razões distintas, bem como consomem quantidades diferentes de nicotina, experimentam sintomas diferentes de abstinência particulares e são diferentes em diversos aspectos, como comorbidades clínicas ou psiquiátricas, grau de educação, nível socioeconômico, entre outros, por isto a importância de tratamentos individualizados (28).

A identificação da dependência de nicotina como um transtorno mental e o crescente conhecimento de sua neurobiologia levaram ao desenvolvimento, sobretudo nas últimas duas décadas, de terapias farmacológicas para esta doença. A importância dos medicamentos no tratamento tem aumentado consideravelmente e, nos dias atuais, os diferentes fármacos existentes desempenham papel fundamental na abordagem da maioria dos pacientes, sendo recomendados sempre que não houver contraindicações para seu uso (28).

É importante salientar que a cessação do tabagismo é um processo, mais que um evento específico; ele se inicia com a decisão de parar de fumar e só termina com a abstinência mantida por longo período (7).

Em 2000, o INCA, órgão do Ministério da Saúde (MS) responsável pela articulação do Programa Nacional de Controle do Tabagismo, juntamente com diferentes sociedades científicas e conselhos profissionais da área de saúde no Brasil elaboraram o "Consenso sobre Abordagem e Tratamento do Fumante" que contém as linhas gerais sobre métodos para deixar de fumar. Atualmente no Brasil, o tratamento do tabagismo está vinculado ao SUS, e é regulado pela Portaria do MS no 571, publicada em 5 de abril de 2013 (Portaria no 571/2013). O modelo de tratamento proposto pelo INCA é baseado na abordagem cognitivo-comportamental individual ou em grupo e uso de medicação quando necessário (11).

As intervenções medicamentosas liberadas pela Food and Drug Administration (FDA) e pela Agência Nacional de Vigilância Sanitária (ANVISA) 
disponíveis para tratamento do tabagismo são a terapia de reposição de nicotina (TRN) que inclui adesivo, goma de mascar ou pastilha mastigável; bupropiona e vareniclina (5).

$\mathrm{Na}$ abordagem do tabagista é importante definir junto com ele qual o tratamento mais adequado para o momento em que ele se encontra. A avaliação, além do diagnóstico da dependência à nicotina e dos sintomas de abstinência, deve contar com os seguintes itens: história do tabagismo, tentativas anteriores, comorbidades clínicas, comorbidades psiquiátricas, apoio social, grau de motivação, nível de dependência de nicotina que pode ser medida pelo Teste de Fargeström e dos aspectos psicológicos e comportamentais do consumo do tabaco (29).

A motivação é uma condição imprescindível para iniciar o tratamento, sua ausência praticamente elimina as expectativas de abstinência, sendo sua avaliação fundamental para determinar qual estratégia é mais adequada dentro de um processo de tratamento (6). Prochaska diz que o sucesso no tratamento está diretamente relacionado ao estágio em que o paciente está antes do tratamento e que tratar fumantes como se estivessem no mesmo estágio é simplório (30). Segundo Prochaska e DiClemente (30) podemos identificar diferentes estágios em que uma pessoa está, em relação à dependência à nicotina: 1. Pré-contemplativo: Não considera a possibilidade de parar de fumar, nem se preocupa com a questão; 2. Contemplativo: Admite o problema, é ambivalente e considera adotar mudanças eventualmente; 3. Preparação: Já decidiu parar e ensaia alguma atitude. Inicia algumas mudanças, planeja, cria condições para mudar, revisa tentativas passadas; 4. Ação: Põe em prática sua decisão e para de fumar. Investe tempo e energia na execução da mudança; 5. Manutenção: Processo de continuidade do trabalho iniciado com ação, para manter os ganhos e prevenir a recaída; 6. Recaída: Falha na manutenção e retomada do hábito ou comportamento anterior (6).

O uso de técnicas psicoterápicas específicas que contemplem os diversos estágios motivacionais auxilia os tabagistas em seus tratamentos (29).

Os exames complementares importantes são os de rotina básica: radiografia de tórax, espirometria antes e depois do broncodilatador, eletrocardiograma, hemograma completo, bioquímica sérica e urinária (21). 
Medidas de monóxido de carbono expirado e da cotinina (principal produto de biotransformação da nicotina) - urinária, sérica ou salivar - são úteis na avaliação e no seguimento do fumante, devendo ser utilizadas quando disponíveis (21).

Podemos dividir o tratamento do tabagismo em abordagem não farmacológica e abordagem farmacológica:

\section{Abordagem não farmacológica:}

Numerosas intervenções de mudança de comportamento para a cessação tabágica têm sido desenvolvidos e avaliados em ensaios clínicos randomizados (ECR). (31) Os diferentes modelos de tratamento das intervenções psicossociais variam de acordo com a base teórica e as técnicas utilizadas e podem ser diferenciadas pela intensidade (frequência ou duração do tratamento), pelo setting em que são utilizados (ambulatorial ou hospitalar), e pela forma em que são oferecidos (individual, grupo, ou por meio de outro canal de comunicação como, por exemplo, o telefone) (Baker e Lee, 2003). Podem ainda ser caracterizados como breves ou intensivos. As intervenções breves incluem material de autoajuda e aconselhamento face a face ou telefônico. As intervenções intensivas são geralmente oferecidas por profissionais especializados e têm formato individual ou em grupo (Lancaster \& Stead, 2005). Tanto a abordagem individual quanto a em grupo são eficazes, sendo ideal um tempo de abordagem de 90 minutos, e um mínimo de quatro sessões para resultados satisfatórios (6).

Inicialmente as intervenções psicossociais simples foram utilizadas para o tratamento do hábito de fumar. $\mathrm{O}$ aconselhamento foi a forma mais utilizada no cuidado do fumante, fazendo parte da maioria dos protocolos até hoje e qualquer profissional de saúde com um treinamento mínimo pode aplicá-lo (21).

A entrevista motivacional (EM) é uma técnica de abordagem que se propõe a ajudar a resolver as ambivalências relativas ao tabagismo e a mudar o estágio comportamental (21).

A abordagem cognitivo-comportamental é uma das principais técnicas utilizadas no tratamento do tabagismo e visa promover uma série de mudanças no estilo de vida do paciente bem como modificações de crenças e comportamentos 
relacionados ao ato de fumar. É breve e focal e pode ser desenvolvida por qualquer profissional de saúde, porém o trabalho multidisciplinar é o mais eficaz (6).

A literatura mostra que a combinação do aconselhamento com o uso de medicação é mais efetiva do que a utilização de um dos dois isoladamente, e o aconselhamento dado por qualquer profissional de saúde aumenta as taxas de cessação do tabagismo (21).

\section{Farmacoterapia:}

Diversos estudos demonstraram que o uso de medicações possibilita duplicar ou mesmo triplicar o resultado do tratamento para cessação do tabagismo em comparação com placebo $(5,6)$.

Os medicamentos são úteis na redução dos sintomas de abstinência, melhorando as taxas de cessação, e a integração de intervenções comportamentais, aumenta ainda mais a chance de sucesso do tratamento e podem ser úteis em todas as fases do tratamento da dependência de nicotina (21).

A escolha quanto à prescrição de medicamentos deve ser baseada no grau de dependência à nicotina, nas características individuais do paciente, incluindo comorbidades, devendo-se também conhecer os efeitos adversos e contraindicações de cada fármaco (21).

Os fármacos com evidências de eficácia são classificados em nicotínicos e não-nicotínicos. São considerados de primeira linha a TRN nas apresentações de goma de nicotina, pastilha, adesivo, spray nasal e inalador; bupropiona e vareniclina. Os de segunda linha incluem nortriptilina e clonidina. $(21,27,32)$

Evidências recentes sugerem um papel potencial para a citisina e naltrexona (27).

No Brasil, o cloridrato de bupropiona, em comprimidos, e nicotina, sob as formas de goma de mascar e adesivo transdérmico, foram incluídos na Relação Nacional de Medicamentos Essenciais (RENAME) desde 2006 (32) e são disponibilizados pelo Ministério da Saúde para o tratamento do tabagismo na Rede do SUS (13) 
II.1 Terapia farmacológica de $1^{\text {a }}$ linha

a) Medicamentos nicotínicos:

A TRN vem sendo usada desde 1984 para a cessação do tabagismo e tem como objetivo a substituição da nicotina do cigarro por meio de doses menores e seguras, reduzindo a fissura e outros sintomas de abstinência (21).

A opção por uma modalidade de TRN depende basicamente da escolha do paciente, da rota de administração e do perfil dos efeitos colaterais esperados, não havendo necessidade de prescrição para comprar a medicação (21).

Existem duas formas de apresentação da TRN: liberação lenta (adesivos transdérmicos) e liberação rápida (goma, inalador, spray nasal e pastilhas). No Brasil estão disponíveis os adesivos, a goma de mascar e as pastilhas mastigáveis (21).

A eficácia das diferentes apresentações é equivalente, mas a adesão ao tratamento é maior com o adesivo. Todas as formas de TRN liberam nicotina para o cérebro em quantidade e velocidade menores que o cigarro. Pacientes que utilizam TRN apresentam 1, 5 a 2 vezes mais chances de conseguir parar de fumar (28).

As apresentações dos adesivos de nicotina são $21 \mathrm{mg} ; 14 \mathrm{mg} ; 7 \mathrm{mg}$ em 24h e $15 \mathrm{mg}, 10 \mathrm{mg}, 5 \mathrm{mg}$ em 16h e da goma de nicotina ou pastilhas são de 4 e $2 \mathrm{mg}$ (32).

Recomenda-se a cessação do tabagismo ao iniciar a TRN, devido a risco de superdosagem de nicotina que pode causar sintomas como enjoo, náusea, taquicardia e crise de hipertensão arterial (21).

b) Medicamentos Não Nicotínicos: $(6,21,28,29,33)$

1. Cloridrato de Bupropiona: comprimidos de $150 \mathrm{mg} / \mathrm{dia}$.

Antidepressivo atípico de ação lenta que desde 1999 tem se mostrado eficaz na cessação do tabagismo através de inúmeros ensaios clínicos (21).

Seu mecanismo de ação poderia ser explicado pela redução do transporte neuronal dos neurotransmissores-dopamina e noradrenalina-ou do antagonismo aos 
receptores nicotínicos, levando à redução da compulsão pelo uso de cigarros. Foi introduzida pelo MS como terapia de primeira linha no tratamento do tabagismo em 2004, pela Portaria n. 442 de 13 de agosto de 2004.

O tratamento com a bupropiona deve se iniciar uma semana antes do paciente parar de fumar. A dose máxima recomendada na cessação do tabagismo é de $300 \mathrm{mg} / \mathrm{dia}$. Em caso de intolerância à dose preconizada, pode ser realizado ajuste posológico. Em pacientes idosos com insuficiência renal ou hepática a dosagem deve ser reduzida para $150 \mathrm{mg} / \mathrm{dia}$.

Suas contraindicações são: hipertensão arterial não controlada, epilepsia ou convulsões de qualquer natureza, gravidez e lactação. Como efeitos adversos, citam-se xerostomia, tremores de extremidades, insônia ou sonolência, alteração do apetite e aumento da pressão arterial, principalmente quando já existe hipertensão arterial prévia.

2. Tartarato de Vareniclina: Comprimidos de 0,5 e $1 \mathrm{mg}$ de tartarato de vareniclina.

O tratamento com vareniclina foi introduzido no Brasil em 2007, atuando como agonista parcial e seletivo dos receptores nicotínicos de acetilcolina $\alpha 4 \beta 2$, imitando os efeitos da nicotina. A ativação moderada dos receptores nicotínicos $\alpha 4 \beta 2$ explicam o alívio dos sintomas da abstinência e da fissura. Por outro lado, ao bloquear a ligação da nicotina ao receptor, reduzem a satisfação ao fumar e o reforço positivo naqueles que continuam fumando quando em uso da droga, configurando suas propriedades antagonistas.

A vareniclina tem sido considerada uma droga eficaz, segura e bem tolerada nas doses recomendadas para os pacientes em processo de cessação do tabagismo. Seu uso regular tem sido associado, em ensaios clínicos controlados, a taxas de abstinência significativamente maiores do que o placebo, a bupropiona e a TRN.

Pelo menos seis ensaios clínicos revelaram aumento nas taxas de abstinência com o uso de vareniclina no tratamento da dependência de nicotina, 
sendo que em alguns desses estudos, se observa também superioridade da vareniclina quando comparada à bupropiona e ao placebo.

Em geral, a probabilidade de se manter abstinente depois de 12 meses de tratamento com a vareniclina é de 3,22 (IC 95\% 2, 43-4,27) quando comparada ao placebo.

Em menos de 5\% dos casos, com o uso da Vareniclina, podem ocorrer náuseas, cefaleia, insônia e tontura. Deve-se ter precauções, no uso desta medicação, em pacientes com histórico de doenças psiquiátricas.

A terapia com bupropiona e vareniclina não requer cessação imediata do tabagismo. Recomenda-se a interrupção do tabagismo a partir do 8ำ dia após o início desses medicamentos.

Dantas et al. em 2016 (32), realizaram uma revisão sistemática na Biblioteca Virtual Cochrane sobre o tratamento do tabagismo com TRN, bupropiona ou vareniclina, em terapia isolada ou combinada, com métodos farmacológicos ou não farmacológicos no Brasil nos últimos 10 anos. Em 150 estudos mostrou que houve benefício no controle da abstinência por pelo menos seis meses, quando a TRN foi comparada ao uso de placebo ou não tratamento. Observou-se ordem decrescente de benefício com as seguintes formas farmacêuticas: aerossol nasal, nicotina inalada, comprimido ou pastilha sublingual, adesivos cutâneos e goma de mascar. A bupropiona demonstrou maior eficácia quando em sinergismo com a TRN, por ação em diferentes mecanismos. Em um estudo controlado randomizado, os autores compararam vareniclina a placebo e bupropiona de liberação sustentada, administrados a 1027 adultos fumantes, junto com sessão semanal de aconselhamento. Observaram como resultado abstinência em curto prazo em 43,9\% dos participantes do grupo com vareniclina em comparação com 29,8\% no grupo com bupropiona e $17,6 \%$ no grupo com placebo (32).

Segundo Dantas, apesar da relevância deste tema, não existe número significativo de ensaios clínicos que avaliem a perspectiva brasileira sobre o tratamento do tabagismo. 
Mike McDonough (34), em artigo recente de atualização (2015), comparou a eficácia dos medicamentos para cessação do tabagismo mostrando uma eficácia superior da vareniclina. A Tabela 1 abaixo mostra esta comparação.

Tabela 1. Comparação da eficácia de medicações para cessão do tabagismo.

\begin{tabular}{ll}
\hline Comparação & Odds ratio * \\
TRN vs placebo & $1.84(1.71-1.99)$ \\
Combinação TRN vs placebo & $2.04(1.25-2.38)$ \\
Bupropiona vs placebo & $1.82(1.6-2.06)$ \\
Vareniclina vs placebo & $2.88(2.4-3.47)$ \\
Combinação TRN vs monoterapia de TRN & $1.34(1.0-1.8)$ \\
Bupropiona vs TRN & $0.99(0.86-1.13)$ \\
Vareniclina vs TRN & $1.57(1.29-1.91)$ \\
Vareniclina vs Combinação TRN & $1.06(0.75-1.48)$ \\
Vareniclina vs bupropiona & $1.59(1.29-1.96)$ \\
TRN: Terapia de Reposição de Nicotina & \\
*odds ratio (com intervalo de confiança de 95\%) calculados sobre as taxas de parar durante \\
seis meses ou mais.
\end{tabular}

III. Terapia farmacológica de $2^{\mathrm{a}}$ linha $(6,21,29,33)$

Embora não tenham aprovação do Food and Drug Administration (FDA) para tratamento do tabagismo e provoquem muitos efeitos colaterais, existe evidência científica de que a nortriptilina e a clonidina sejam superiores ao placebo no tratamento do tabagismo, podendo contribuir em situações em que não se pode utilizar os medicamentos considerados de primeira linha acima mencionados.

III.1. Nortriptilina: é um antidepressivo tricíclico que bloqueia a recaptação de noradrenalina na pré-sinapse aumentando sua concentração na fenda sináptica. As evidências sugerem que o modo de ação da nortriptilina na cessação do tabagismo é independente de seu efeito antidepressivo e que sua eficácia é similar à obtida com a TRN ou com a bupropiona. Promove redução dos sintomas de abstinência, apresentando também ação ansiolítica e efeitos colaterais anticolinérgicos, como boca seca, tremores, visão turva e sedação. Aumenta em duas vezes a chance de cessar o tabagismo quando comparada a placebo (OR=2,34, Cl95\%: 1,61-3,41). Estudos recentes demonstram evidências de que a terapia combinada com a TRN possibilita um benefício adicional em longo prazo. A posologia recomendada é de 25 $\mathrm{mg} / \mathrm{dia}$, em dose única, com incremento gradual até atingir entre 75-100 mg/dia em três semanas. O uso não é recomendado em pacientes com infarto agudo do 
miocárdio (IAM) e arritmias devido ao potencial de induzir distúrbios de condução. É contraindicado em pacientes com insuficiência hepática, epilepsia, psicose e mulheres em amamentação.

III.2 Clonidina: é um agonista adrenoreceptor alfa-2 de ação central usado primariamente como anti-hipertensivo e também no controle dos sintomas de abstinência da dependência nicotínica. Estudos de meta-análise mostram que a clonidina aumenta em até duas vezes a chance de cessação do tabagismo comparada ao placebo. Comparativamente, apresenta a mesma eficácia que a TRN e a bupropiona. No entanto, seu uso é limitado pela elevada incidência de efeitos colaterais, tais como boca seca, sedação, sonolência, hipotensão ortostática, depressão, constipação e distúrbios do sono. A dose recomendada é de $0,1 \mathrm{mg} / \mathrm{dia}$, com incremento gradual até $0,4 \mathrm{mg} / \mathrm{dia}$. $O$ paciente deve ser orientado a parar de fumar de dois a três dias após o início da medicação, que deve ser mantida durante três a quatro semanas ou até que alcance o controle dos sintomas de abstinência. $A$ retirada da droga deve ser gradual para evitar hipertensão rebote e hipoglicemia.

IV - Outros medicamentos:

Naltrexona, reboxetina, selegilina, fluoxetina, rimonabant podem ser utilizados embora não tenham a mesma eficácia e segurança que os tradicionais (5). Outro medicamento utilizado é o Citisine, um agonista parcial nAchR a4ß2 semelhante à vareniclina, que tem sido utilizado em países do Leste Europeu e tem demonstrado eficácia e segurança. Os cigarros eletrônicos tornaram-se muito populares, parecem ser eficazes e são mais seguros do que fumar cigarros comuns, mas questões de dependência contínua e possíveis danos precisam ser considerados (35). As vacinas de nicotina estão em fase de pesquisa clínica mas ainda não existe uma posição sobre a viabilidade de seu uso na prática assistencial (5).

Fármacos em investigação: um estudo piloto com $\mathrm{N}$-acetilcisteína tem mostrado algum efeito promissor; baclofeno tem mostrado algumas evidências em ensaios pré-clínicos e clínicos; fármacos que atuam em receptores NMDA (memantina, cicloserina) estão em ensaios de Fase I; antagonistas do receptor D3 têm mostrado promessa em modelos animais (36). 


\section{A Estimulação Transcraniana por Corrente Continua}

\subsection{Breve histórico}

Mesmo antes de o homem ser capaz de armazenar e descarregar energia elétrica de maneira segura e confiável, há relatos do uso "medicinal" da estimulação elétrica no cérebro, os quais remontam à antiguidade. Scribonius Largus, médico do imperador romano Claudius (43-48 d.C.), descreveu a aplicação da descarga elétrica do "peixe torpedo" para aliviar dores de cabeça em seu livro Compositiones Medicae $(23,37,38)$.

As descargas produzidas por esse peixe podem variar em torno de 50 volts (V) e o fato desse peixe ser oriundo do mar e, portanto, apresentar solução salina no meio exterior fazia com que o contato entre o animal e o paciente apresentasse baixa resistência à corrente. Segundo descrições, o número de peixes necessários para produzir um torpor inicial com subsequente alívio da dor variava entre os casos; a variabilidade individual e posterior resposta a um determinado tratamento já podia ser observada (37).

No Império Muçulmano, o médico Ibn-Sidah também sugeriu em seus trabalhos, na virada do primeiro milênio, o uso de uma outra espécie de peixe torpedo para o controle de crises convulsivas $(23,38)$. Contudo, a história da estimulação elétrica como método de investigação do sistema nervoso começou quando o médico e fisiologista italiano Luigi Galvani (1737-1798) descobriu que os tecidos neurais são eletricamente excitáveis, por volta de 1786. Galvani, Professor da Universidade de Bolonha (Itália) e membro da Accademia delle Scienze, realizou diversos experimentos sobre eletricidade, sendo boa parte descrita em seu trabalho publicado em 1791 De Viribus Electricitatis in Motu Musculari Commentarius (39).

Em uma série de experimentos que iriam revolucionar a neurofisiologia, Galvani estimulava músculos e nervos de sapos e rãs, provocando respostas de contração muscular. Observações importantes foram realizadas em estudos com sapos, mas boa parte de suas interpretações seguiu na direção errada. A 
constatação de Galvani de que o contato de duas estruturas metálicas com o tecido muscular resultava em contração fez com que ele levantasse a hipótese da existência de uma eletricidade animal (39). A primeira observação foi acidental; um de seus assistentes tocou a ponta de um equipamento no nervo interno da coxa de uma rã e viu-se em seguida uma série de contrações. A partir disso, Galvani começou a alterar as condições experimentais chegando, inclusive, a considerar que as condições atmosféricas fossem capazes de interferir nas questões elétricas envolvidas.

A Figura 4 mostra alguns dos seus experimentos. Galvani poderia ter seguido na direção de uma hipótese eletrolítica, entretanto ele acreditava existir uma eletricidade animal inerente (37).

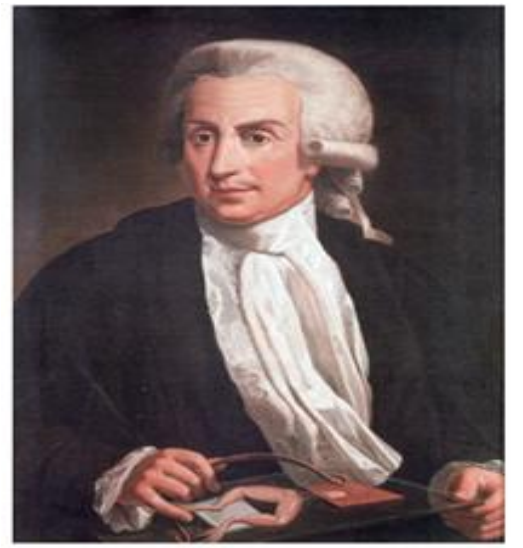

Luigi Galvani (1737-1798)



Experimentos de estimulação voltaica de nervos e músculos por Luigi Galvani em 1786

Figura 4. Experimentos de Luigi Galvani.

Com o progresso técnico a Física descobriu formas mais sofisticadas e mais bem controladas de estimulação elétrica, impulsionando o uso desta ferramenta, como uma metodologia sistemática de investigação da função nervosa. Um desses grandes progressos foi determinado pelo físico italiano Alessandro Volta (17451827) (Figura 5), que, inspirado pelas pesquisas de Galvani, desenvolveu um instrumento fundamental para a história da estimulação elétrica cerebral, a pilha elétrica. A hipótese de eletricidade animal defendida por Galvani foi calorosamente criticada por Volta. 


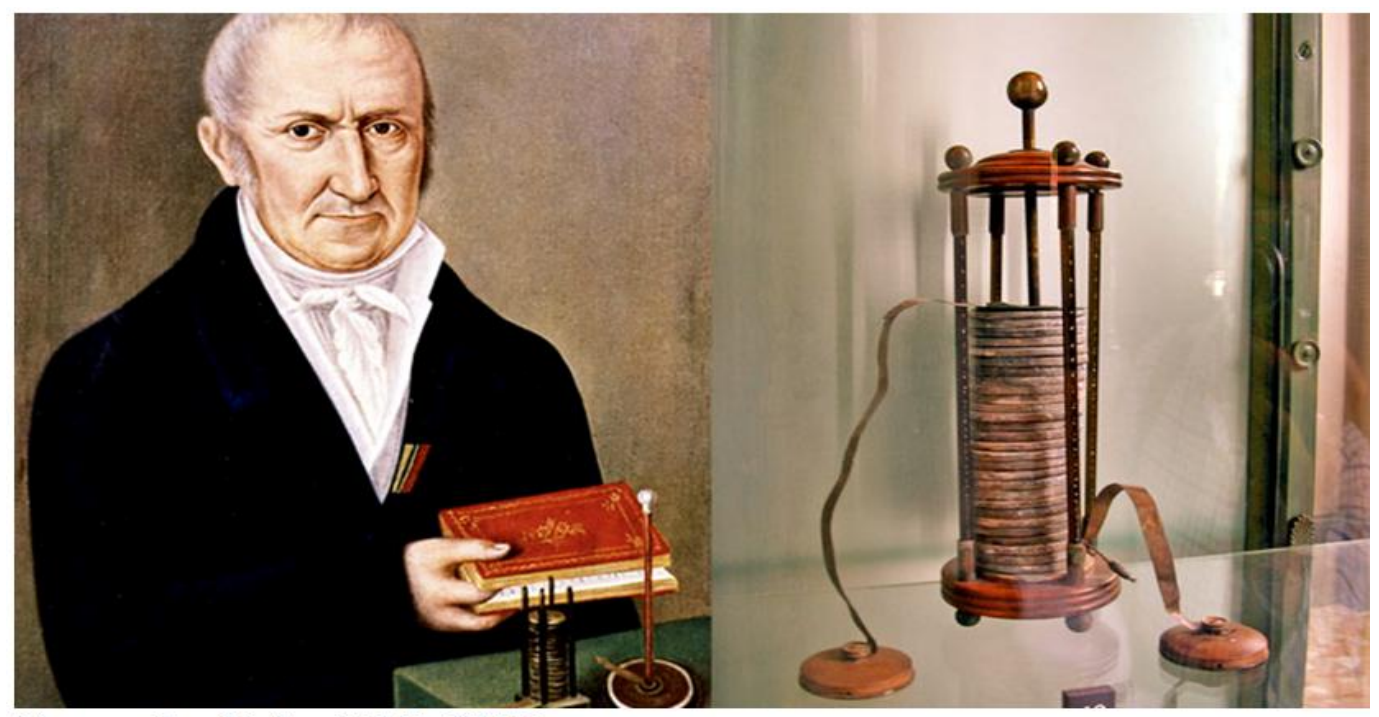

Alessandro Volta (1745-1827)

Pilha Voltaica- 1800

Figura 5. Alessandro Volta e a pilha elétrica.

Tentando replicar os experimentos de Galvani, Volta tinha descoberto que uma força eletromotriz podia ser gerada a partir de dois metais distintos, quando eles eram colocados em contato. Teve então a ideia, em 1800, de colocar vários discos metálicos empilhados em série, em uma coluna (daí o nome "pilha"), separados por discos de feltro embebido em solução condutora. A pilha voltaica revelou-se extremamente útil para gerar corrente elétricas constantes em um determinado valor de intensidade, e a partir desse momento ela tornou-se um dos dispositivos mais usados e mais fáceis de se controlar $(37,40)$.

Em 1802 o sobrinho de Galvani, Giovanni Aldini (1762-1834), dando continuidade aos trabalhos do tio, mas também considerando as colocações de Volta, realizou passos importantes na aplicação de eletricidade em seres humanos e forneceu elementos centrais para o desenvolvimento posterior de aspectos da fisiologia do Sistema Nervoso.

Aldini (Figura 6) aplicou corrente elétrica inicialmente em cadáveres observando durante as aplicações movimentos involuntários de membros, contrações de face, etc.; tais demonstrações impressionaram seus contemporâneos. Além disso, fez ensaios de aplicação de corrente elétrica em pacientes sofrendo de melancolia, observando resultados importantes nessa modalidade de tratamento. Entretanto, a carga aplicada, localização dos eletrodos, caracterização dos 
pacientes, entre outros fatores, não eram variáveis bem controladas nessa época $(37,40)$.

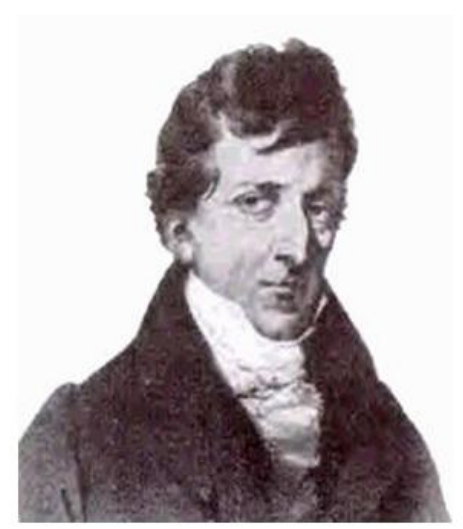

Giovanni Aldini (1762-1834)

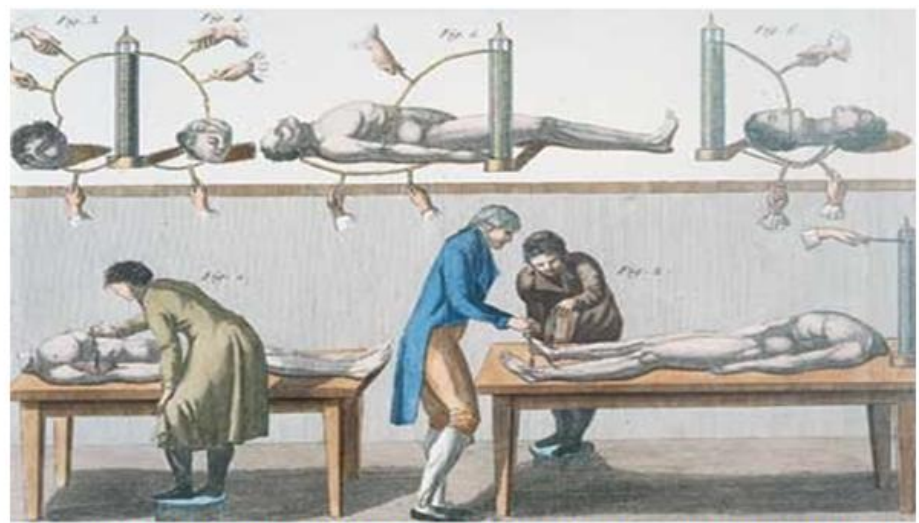

Experimentos feitos por Aldini e colaboradores com estimulação elétrica de cadáveres, utilizando pilhas voltaicas (1802).

Figura 6. Aldini e os experimentos com estimulação elétrica.

Em 1809 outro italiano, um médico e fisiologista chamado Luigi Rolando (1773-1831) fez experimentos sobre a função do cerebelo, expondo essa estrutura em animais vivos e ministrando estimulações elétricas do córtex cerebral, por meio de uma pilha voltaica. Como resultado, ele observou violentos efeitos motores, que ficavam maiores à medida em que ele aproximava os eletrodos do cerebelo. Erroneamente, Rolando concluiu que o cerebelo seria a fonte da "energia nervosa motora" (40).

A primeira estimulação experimental em seres humanos aconteceu em 1874, ou seja, cerca de 70 anos depois de Aldini e de Rolando. Um neurologista americano chamado Roberts Bartholow (1831-1904) estimulou uma paciente que estava com uma erosão no crânio, expondo seu córtex cerebral. Ele estimulou dois pontos, que por coincidência estavam no córtex pré-frontal, obtendo como resposta movimentos dos membros contralaterais ao córtex estimulado. Esta contralateralidade do movimento já era conhecida a partir do estudo dos efeitos de estimulação usando substâncias químicas feitos pelo fisiologista francês Pierre Flourens (1794-1867), o qual, entre 1824 a 1827, realizou experimentos de lesão e estimulação em cérebros de pombos e de coelhos (23).

No início do século 20 as primeiras estimulações elétricas sistemáticas em pacientes sob anestesia local foram conduzidos no famoso Instituto de Neurologia 
de Montreal, Canadá, pelo neurocirurgião Wilder G. Penfield (1891-1976) (Figura 7), entre os anos de 1930 a 1950. Penfield com valiosos colaboradores, como Herbert H. Jasper (1906-1999) e Theodore Brown Rasmussen (1910-2002) quando ia fazer uma cirurgia do cérebro aproveitava para estimular o córtex do paciente e solicitava que ele descrevesse o que estava sentindo. Mapeou o córtex cerebral tanto motor quanto sensorial e descreveu os "homúnculos corticais". Observou, além dos efeitos motores e sensoriais já esperados, também respostas cognitivas complexas, envolvendo vários sentidos, como visão e audição, que representavam memórias de fatos passados (40).

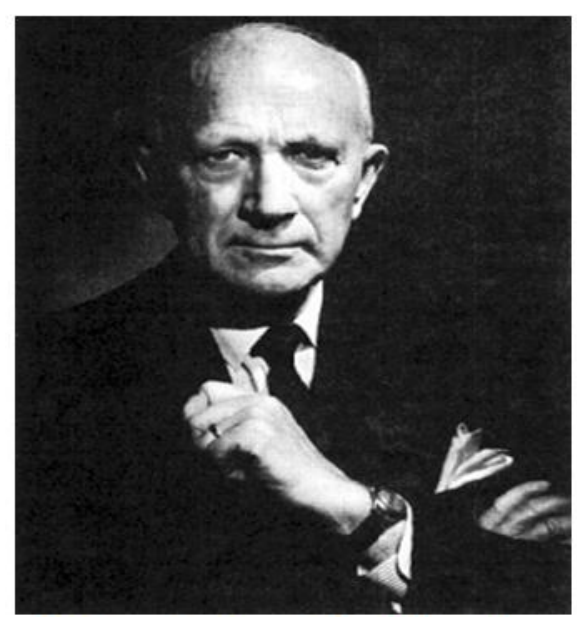

Wilder G. Penfield (1891-1976

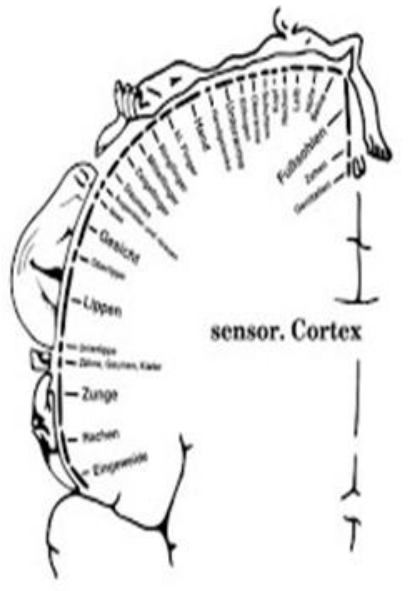

Homúnculos de Penfield

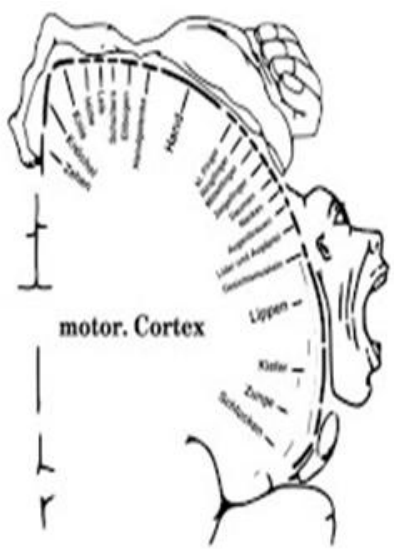

Figura 7. Homúnculos de Penfield.

Em meados de 1960, Bindman foi o responsável pela descoberta de que o gradiente de potenciais elétricos produzido por correntes contínuas de baixa intensidade era capaz de alterar a excitabilidade neural de ratos e que estes efeitos duravam por horas após o fim da estimulação. Em 1964, Purpura e McMurtry observaram, em células do trato piramidal de gatos, um aumento da atividade neuronal espontânea após a aplicação de corrente contínua anódica e o inverso, após a aplicação catódica. A partir de então, vários estudos foram realizados na tentativa de verificar o potencial terapêutico da polarização cerebral, porém seu interesse perdeu força devido às limitações tecnológicas da época e ao incremento da indústria farmacológica $(23,41)$. 
No final da década de 1990, o interesse acerca do efeito da aplicação transcraniana de corrente galvânica de baixa intensidade sobre o sistema nervoso central humano reapareceu. Em 1998, Priori e colaboradores observaram uma supressão da excitabilidade cortical no córtex motor humano após a aplicação de uma estimulação positiva (ânodo) alternada com uma negativa (cátodo) (41).

A ETCC, como aplicada atualmente, foi introduzida por Paulus e Nitsche, apenas em 2000. Os autores demonstraram em um estudo pioneiro, o efeito polaridade dependente da ETCC sobre excitabilidade cortical no córtex motor de sujeitos saudáveis. Desde então, a ETCC tem sido largamente empregada com objetivo terapêutico ou de análise das funções cerebrais de indivíduos conscientes (37).

\subsection{Mecanismos de funcionamento e ação}

Equipamento: o aparelho de ETCC é constituído basicamente por quatro componentes principais: eletrodo (ânodo e cátodo), amperímetro (medidor de intensidade de corrente elétrica), potenciômetro (resistor variável que controla a tensão entre os eletrodos permitindo com isso a manipulação da intensidade da corrente aplicada) e um jogo de baterias. A Figura 8 demonstra esquematicamente $o$ circuito básico do equipamento (23). 


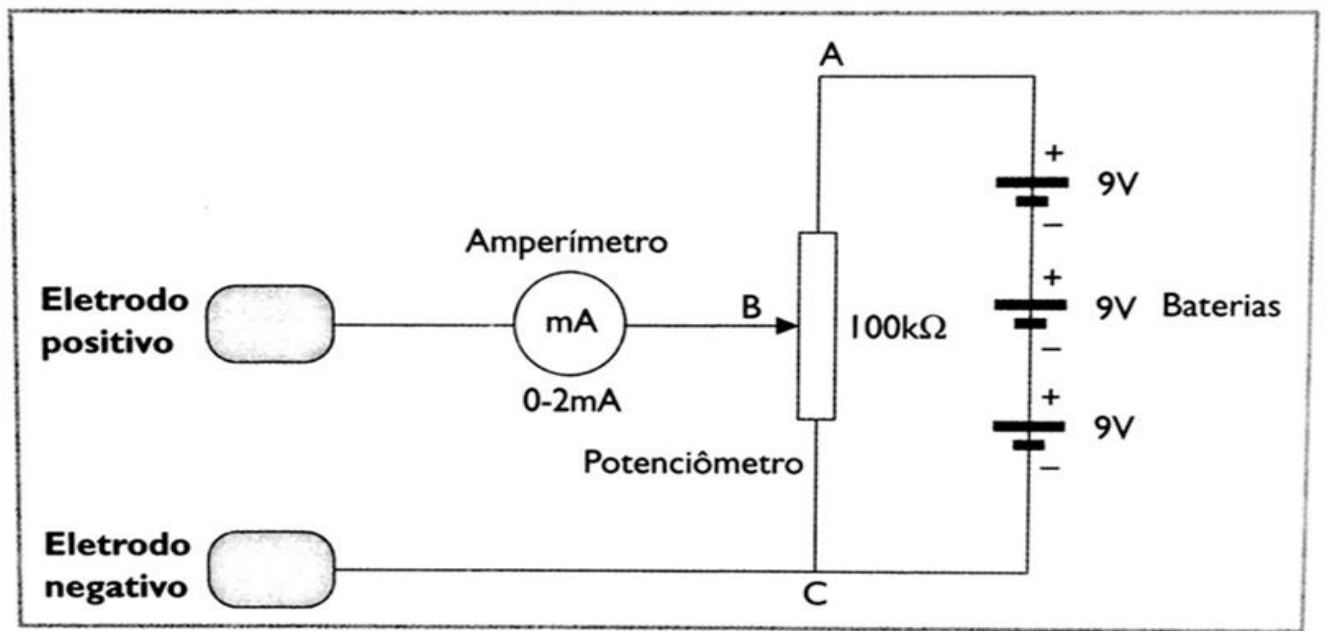

Figura 8. Circuito básico de um aparelho de ETCC: formado por um gerador, um amperímetro, um potenciômetro e dois eletrodos.

Considerando o uso em pesquisas, alguns aparelhos de ETCC permitem realizar dois tipos de estimulação: ativa ou sham (simulada). Na estimulação ativa, a intensidade da corrente é elevada gradativamente (rampa de subida) à taxa de aproximadamente $100 \mu \mathrm{A} / \mathrm{s}$ até atingir a intensidade desejada, a qual permanece constante até o final da sessão, quando também é diminuída gradativamente (rampa de descida). Já com relação à estimulação simulada, realiza-se a rampa de subida até atingir a intensidade da corrente desejada, mas em seguida a corrente é gradativamente reduzida; o aparelho então é desligado. Com esse procedimento, os efeitos iniciais de formigamento leve na área onde o eletrodo está posicionado é percebido pelo voluntário, porém não há estimulação ativa propriamente dita (23).

Os parâmetros de estimulação da ETCC podem ser ajustados em relação a: 1) posicionamento e tamanho dos eletrodos; 2) intensidade da corrente elétrica; 3) duração da estimulação; 4) número total de sessões; e 5) intervalo entre elas. A combinação de tais elementos resulta em variadas cargas de corrente atingindo a área-alvo, gerando efeitos fisiológicos distintos (23).

O posicionamento dos eletrodos na área cortical normalmente é baseado no sistema 10 x 20 da classificação internacional de EEG, podendo a montagem dos mesmos ser "unipolar" (cefálica) ou "bipolar" (extracefálica) (23). Os eletrodos mais utilizados são com esponjas de tamanho de 25 ou $35 \mathrm{~cm}^{2}$, com corrente de $1 \mathrm{~mA}$ a 2 
$\mathrm{mA}$, sendo que sua densidade no córtex varia entre 0,28 e 0,80A/m e com tempo de duração entre 20 a 40 minutos $(23,38)$.

O número total de sessões é um importante aspecto a ser considerado. Sessões sucessivas de ETCC podem ter efeito cumulativo, associados a maior magnitude e duração dos efeitos comportamentais. No entanto, o número necessário e /ou máximo de sessões ainda não foi estabelecido. O intervalo de tempo entre duas sessões pode interferir no resultado final (23).

Um estudo recente demonstrou que, quando uma sessão extra de ETCC é aplicada durante o período de uma hora após a primeira sessão, os efeitos duraram por mais tempo (120 min), se comparados ao efeito de apenas uma sessão ou de duas sessões de ETCC consecutivas (sem intervalos), enquanto uma sessão extra de ETCC aplicada além desse período (por exemplo, após 3 horas) não interfere no efeito da primeira sessão (23).

Diversos fatores fisiológicos, além dos metodológicos, podem alterar a dosagem total da corrente que atinge o córtex cerebral, como, por exemplo, resistência da calota craniana, estruturas intracranianas (vasos sanguíneos, líquido cefalorraquidiano (LCR), meninges), tecido cerebral, dentre outros. Defeitos ósseos, lesões cerebrais, uso de substâncias psicoativas, idade, gênero, tabagismo, também podem influenciar na neuromodulação da ETCC (23).

A característica da ETCC é uma corrente de baixa intensidade, com fluxo direto e contínuo. Este padrão de eletricidade é capaz de modular a atividade cortical, sem, contudo, agir diretamente sobre os neurônios. Esta é uma das várias vantagens desta técnica: uma vez que os neurônios não são afetados diretamente, minimizam-se os efeitos adversos, ao contrário do que ocorre com a convulsoterapia. Ela é polaridade dependente, onde a estimulação anódica geralmente aumenta a excitabilidade cortical e a catódica resulta em efeitos opostos (42).

Os mecanismos pelos quais a ETCC produz efeitos biológicos ainda não estão totalmente esclarecidos. (42) Os estudos mostram que durante o período de aplicação da corrente elétrica na ETCC, se observam efeitos essencialmente 
neuromodulatórios e após cessada a aplicação os efeitos são essencialmente neuroplásticos (23).

Desde 1950 os estudos em animais já demonstravam o efeito da ETCC na modulação do potencial de repouso da membrana neuronal. Goldring e O'Leary verificaram que a polarização superficial positiva aplicada na superfície do córtex resultou no desenvolvimento de descargas paroxísticas e que a corrente necessária para isto variava de experimento para experimento, sendo encontrada no geral com correntes variando de 1 a 3 mA após a polarização de 20 - 30 segundos. Terzuolo e Bullock (1956) observaram aumento no disparo espontâneo após estimulação com corrente anódica e redução após a catódica em crustáceos Cambarus clarkii e Panulirus interruptus. Púrpura e McMurry (1964) observaram em células do trato piramidal de gatos, aumento da atividade neural espontânea após a passagem de corrente anódica e redução após a catódica (23).

Mais recentemente, estudos em humanos começaram a investigar a ação da ETCC ao ser aplicada concomitantemente com drogas bloqueadoras dos canais de sódio e cálcio, ocorrendo inibição dos efeitos decorrentes da estimulação anódica, enquanto que, quando associada a drogas agonistas e antagonistas de NMDA ou moduladores de receptores do GABA, não há apresentação de interferência nestes efeitos provocados pela corrente $(23,42,43)$.

No período pós-modulatório as sinapses GABAérgicas e glutamatérgicas são fundamentais na indução de neuroplasticidade relacionadas à ETCC. Outros neurotransmissores, como acetilcolina e serotonina também exercem efeito modulatório neste período. O efeito de longa duração da ETCC depende também de síntese proteica e alterações dos níveis de cálcio e AMP cíclico (23).

É Importante destacar o papel dos receptores glutamatérgicos e GABAérgicas na manutenção dos efeitos ao longo do tempo, visto que é conhecido o papel destes receptores na plasticidade cortical, a exemplo da potenciação a longo prazo (LTP) e depressão a longo prazo (LTD) $(42,43)$. Contudo, embora a plasticidade seja um fator prognóstico positivo, plasticidade ilimitada poderia desestabilizar as redes neuronais; desse modo, mecanismos homeostáticos têm sido propostos para controlar as modificações de redes desequilibradas (42). 
Há evidências que a ETCC exerce influência sobre áreas que estão conectadas àquelas diretamente estimuladas. A ETCC aplicada no córtex motor primário altera a atividade de estruturas como o próprio córtex motor primário, mas atinge também o córtex pré-motor, a área motora suplementar, o córtex cingulado anterior, o tálamo, o cerebelo, e o córtex somatossensorial. Estudo recente utilizando tomografia eletromagnética cerebral de baixa resolução, demonstrou que a ETCC aplicada no córtex pré-frontal dorso lateral (CPFDL) altera a atividade da região subgenual do córtex pré-frontal, no córtex cingulado anterior e no giro frontal medial (23).

A ETCC influência vários tecidos diferentes (vasos, tecido conjuntivo) e mecanismos fisiopatológicos (em inflamação, migração celular, motilidade vascular); além disso, os seus efeitos são observados em várias estruturas celulares (citoesqueleto, mitocôndria, membrana) (38).

\subsection{Técnicas de neuroimagem e ETCC}

As técnicas de neuroimagem têm a vantagem de medir correlatos da atividade neuronal, não somente sob ou em estreita proximidade com o local onde o eletrodo foi colocado, mas também em regiões do cérebro mais remotos antes, durante e depois estimulação (44). Vários estudos envolvendo neuroimagem confirmaram os efeitos da ETCC (45).

Os métodos de neuroimagem para estudo da ETCC podem ser divididos em dois tipos: o primeiro que utiliza radiomarcadores é representado pela tomografia por emissão de pósitron (PET) e a tomografia computadorizada por emissão de fóton único (SPECT), que avaliam o metabolismo cerebral através da emissão de raios gama. A vantagem de PET / SPECT em investigação na ETCC é que o radiomarcador pode ser injetado durante a estimulação do cérebro, proporcionando assim "em tempo real" a imagiologia cerebral. No entanto, a resolução espacial de tais métodos é pobre. Além disso, esses métodos requerem obrigatoriamente a utilização de radiomarcadores, e a dose de radiação tem de ser cuidadosamente controlada e monitorizada (38). 
O segundo, é a ressonância magnética (MRI). Esta técnica apresenta alta resolução espacial. Há várias abordagens metodológicas para ressonância magnética, que permite a avaliação dos diferentes aspectos da atividade cerebral. Por exemplo, a ressonância magnética funcional (fMRI) explora as propriedades paramagnéticas de hemoglobina para inferir o metabolismo cerebral (com base na saturação de oxigênio no sangue) enquanto a espectroscopia de ressonância magnética (EMR) analisa os campos magnéticos de moléculas relevantes (por exemplo, o glutamato, GABA) e fornece um método não invasivo "biópsia química" do cérebro. Algumas destas técnicas, tais como fMRI não têm resolução temporal, uma vez que não mede alterações na atividade elétrica diretamente (ele faz indiretamente, através de mudanças no fluxo cerebral).

O Tensor de Difusão de Imagem (DTI) enfoca as fibras de substância branca, revelando a conectividade neural entre áreas do cérebro.

A morfometria baseada em voxel (MVB) é uma análise computacional de imagens morfológicas que faz inferências sobre a atividade do cérebro com base nas diferenças de concentração de tecido cerebral entre as áreas.

Para ETCC, esses métodos apresentam a vantagem de alta resolução espacial e permitem avaliar mudanças sutis na área estimulada (38).

Apenas duas décadas atrás, a aplicação simultânea de métodos de ETCC e de neuroimagem foram consideradas inviáveis (aquecimento sob os eletrodos, qualidade dos dados adquiridos) e somente nos últimos dois anos, ela tornou-se tecnicamente viável e segura para estimular simultaneamente o cérebro e medir o fluxo de sangue cerebral com ressonância magnética (46).

Clark et al. em 2011 (47), com a hipótese de que a ETCC anódica conduz ao aumento da atividade metabólica no cérebro, e com isto o aumento dos processos cognitivos e da memória; avaliaram os mecanismos neuronais pelo qual a ETCC influencia a aprendizagem. Os autores observaram aumento de glutamato e glutamina sob o eletrodo anódico da ETCC aplicada no córtex parietal, com intensidade de 2,0mA, por 30 minutos, usando espectroscopia de prótons por ressonância magnética. 
Zheng et al. em 2011 (44), avaliaram em 14 voluntários saudáveis o fluxo sanguíneo cerebral regional (FSCr) através do arterial spin labeling (ASL), variando a polaridade (anódica e catódica), bem como a intensidade da corrente (0,82,0mA) utlizada. O anodo foi posicionado no córtex motor direito e o catodo na região supraorbital contralateral. A estimulação anódica induziu um aumento significativo do FSCr durante e após a estimulação. Já a catódica induziu um aumento menor durante a estimulação e uma redução contínua no período pós-estimulação. Foi verificado também que a ETCC não modula apenas a atividade na região subjacente à área estimulada, como também uma rede de regiões corticais que são funcionalmente relacionadas com o local onde o eletrodo se encontra posicionado. Embora apresente resultados mais discretos, os estudos iniciais com ressonância magnética funcional (fMRI) também confirmam os efeitos neuromodulatórios da ETCC (44).

Antal et al. em 2011 (48), investigaram os efeitos on-line de curtos períodos de ETCC anódica e catódica sobre a região motora primária (M1) em 20 indivíduos saudáveis associados à resposta BOLD (Blood Oxigenation Level Dependent). Na região motora primária não foram observadas alterações, nem com estimulação anódica, nem catódica. Contudo, a ETCC anódica resultou em uma diminuição na resposta BOLD na área motora suplementar (a estimulação catódica não produziu efeitos nesta região, embora uma tendência também para diminuição tenha sido observada).

Bachtiar et al. em 2015 (49), avaliaram a ETCC anódica aplicada a M1 em doze participantes saudáveis. Usando Espectroscopia por Ressonância Magnética observaram um aumento significativo da conectividade funcional nesta região e uma redução significativa nos níveis de GABA conforme estudos anteriores. No entanto, pela primeira vez, mostrou que a magnitude destas alterações não se correlaciona entre os indivíduos, sugerindo que eles podem ser acionados por mecanismos subjacentes diferentes. Este estudo também proporcionou novos dados sobre a evolução no tempo da mudança de GABA com ETCC anódica e demonstrou que a redução anteriormente descrita em GABA é mais proeminente no período de 30 min após a estimulação. 
Estudo recente (2016) de Gbadeyan et al. (50) avaliou a ETCC convencional e a ETCC de alta definição comparando segurança, tolerabilidade, e compatibilidade com uso simultâneo de ressonância magnética funcional simultânea (fMRI). Foi avaliado também o potencial de aquecimento e impacto sobre a qualidade de imagem da HD-ETCC durante o uso simultâneo de fMRI. Este estudo confirmou a segurança, tolerabilidade, eficácia e compatibilidade do uso simultâneo de ETCC de alta definição e ressonância magnética funcional simultânea (fMRI).

\subsection{Segurança}

Estudos sobre segurança no uso da ETCC indicam ser uma técnica segura. Os protocolos experimentais atuais que usam tamanhos de eletrodo entre 25 e 35 $\mathrm{cm}^{2}$ e na aplicação de correntes de 1-2 mA para durações de até 20 min (resultando em densidades de carga de cerca de 0,03-0,09 C / cm²) são considerados seguros em humanos (51). No entanto as particularidades de cada protocolo precisam ser consideradas e a monitorização dos possíveis efeitos adversos fortemente encorajada (23).

Em uma recente revisão sistemática dos efeitos adversos associados com ETCC ( 2011) (52) foram analisados 209 estudos que avaliaram 3.836 indivíduos. O objetivo foi identificar os principais eventos adversos relacionados a essa técnica. Os eventos adversos mais comuns foram, no grupo ativo (117 estudos), prurido ( $n=46$, $39,3 \%)$, formigamento $(n=26 ; 22,2 \%)$, cefaleia $(n=17,14,8 \%)$, queimação $(n=10$, $8,7 \%)$ e desconforto ( $n=12,10,4 \%)$. No grupo sham (82 estudos), os eventos adversos mais comuns foram prurido $(n=27,32,9 \%)$, cefaleia $(n=13,16,2 \%)$, formigamento ( $n=15,18,3 \%)$, queimação $(n=10,8,7 \%)$, e desconforto $(n=8,10 \%)$.

No entanto, embora a ETCC pareça ser segura em voluntários saudáveis, um cenário diferente é observado em amostras neuropsiquiátricas. Os 35 estudos em Fase II com populações neuropsiquiátricas, todos eram compostos por amostras heterogêneas (diversas condições neuropsiquiátricas e uma ampla gama de medicamentos) e apenas 8 destes foram adequados para análise; porém, conclusões definitivas sobre os efeitos adversos não poderiam ser tiradas, em função da heterogeneidade dos mesmos (52). 
Marinho Andrade et al. em 2015 (45), em uma revisão recente da literatura da ETCC para o Tratamento do Acidente Vascular Cerebral (AVC) identificaram 62 artigos, sendo 54 considerados relevantes. Foram analisados os procedimentos com ETCC, tendo sido verificado que uma sensação de formigamento leve foi o efeito adverso mais comum relatado pelos pacientes (70,6\%), seguida por fadiga moderada, sentida por 35,3\% dos participantes, e uma sensação de coceira leve, ocorrendo em 30,4\% dos casos. Episódios de dor de cabeça $(11,8 \%)$, náusea $(2,9 \%)$ e insônia $(0,98 \%)$.

Brunoni et al. em 2011 (52) ressaltam a importância de monitorar ativamente os efeitos adversos e sugerem o uso de questionários estruturados e avaliadores treinados quando da aplicação dos mesmos. Ressaltam ainda a importância da tradução e teste em diferentes línguas e dos critérios objetivos que devem ser usadas/desenvolvidos para avaliar os efeitos adversos como, por exemplo, medir e relatar a dimensões da vermelhidão quando observados.

\subsection{Comparações entre ETCC e EMT}

A Estimulação Magnética Transcraniana (ETM) e ETCC são os dois tipos mais comuns de estimulação cerebral não invasiva. (38) Nenhuma destas estimulações são novas para a prática médica, EMT tem sido utilizado clinicamente desde 1985, e o uso de ETCC pode ser rastreada em 1800. Trata-se de técnicas com amplo espectro de aplicações em doenças do campo da neurociência, englobando transtornos psiquiátricos, doenças neurológicas e condições dolorosas agudas e crônicas (38).

EMT: Inicialmente a EMT (Figura 9) tinha como propósito ser uma ferramenta diagnóstica. Eram realizados pulsos únicos e media o tempo de condução motora. Com a introdução dos pulsos repetidos (EMTr), seu uso expandiu-se para a pesquisa básica e clínica em animais, voluntários saudáveis e pacientes com diversas condições neuropsiquiátricas. Seus efeitos devem-se à indução eletromagnética focal que produz modificações na atividade elétrica neuronal. A estimulação de baixa frequência (1 Hz ou menos) é inibitória e a estimulação de alta frequência (5 Hz ou mais) é excitatória. Na EMTr a carga elétrica armazenada em 
capacitor é liberada por uma bobina que produz corrente de pulso, que gera campo magnético nas áreas próximas a ela. A bobina sobre a cabeça gera campo magnético que penetra no escalpo e induz o campo elétrico cerebral. $O$ fluxo de íons nesse campo elétrico nos dois lados da membrana despolariza ou hiperpolariza os neurônios (38). Como método de tratamento, a ETM pode atuar em doenças provenientes de desordens motoras, reabilitação de um AVC, demência, depressão, enxaquecas, dor crónica e epilepsia (53). Em 2012 o Conselho Federal de Medicina (Resolução 1986/2012) regulamentou o uso da EMT para depressão uni e bipolar, alucinação auditiva e neuronavegação (54).

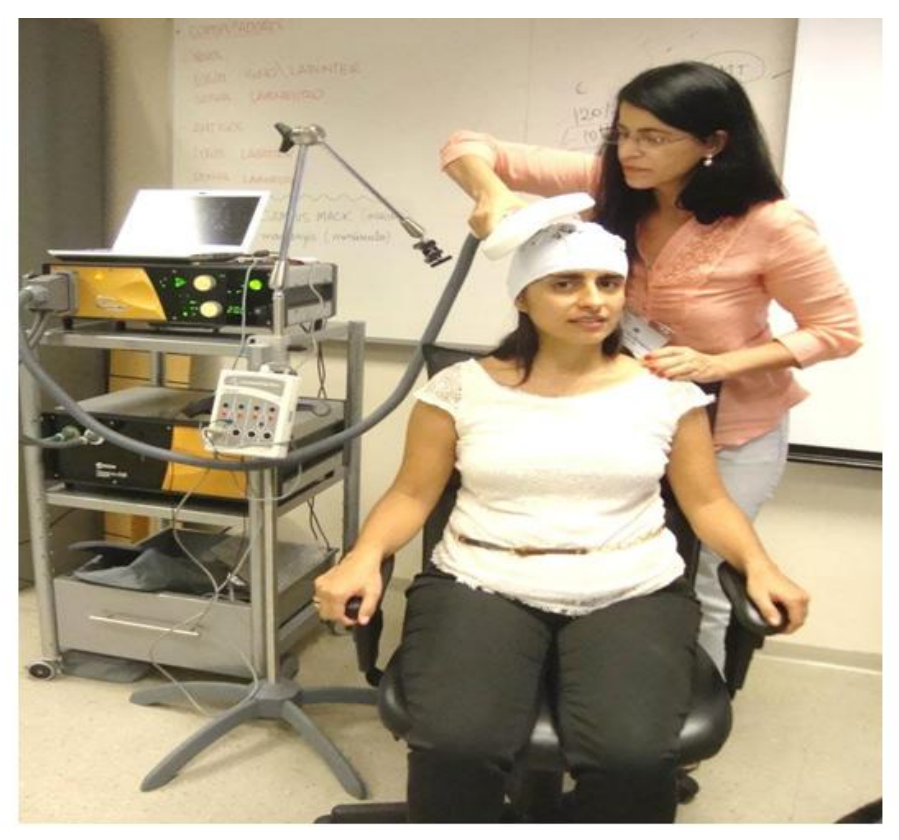

Figura 9. Estimulação Magnética Transcraniana (EMT).

ETCC: Na ETCC (Figura 10), correntes de baixa intensidade são aplicadas no cérebro via eletrodos no couro cabeludo de maneira simples e indolor, deslocandose para cima ou para baixo a excitabilidade cortical de acordo com a polaridade da corrente. Certas características atraentes da ETCC (não invasivo, bem tolerada, efeitos adversos leves e transitórios) provocaram um aumento nos estudos clínicos em particular para distúrbios neuropsiquiátricos tais como transtorno depressivo, dor crônica e aguda, reabilitação acidente vascular cerebral, dependência de drogas, e outras condições neurológicas e psiquiátricas. Embora os efeitos relatados tenham sido heterogêneos e sejam necessários mais estudos clínicos, os resultados têm sido geralmente promissores (38). Nenhum efeito adverso sério foi observado as 
pessoas submetidas à ETCC. Os efeitos colaterais mais comuns incluem prurido e formigamento local, que tendem a desaparecer ao término das sessões (55).

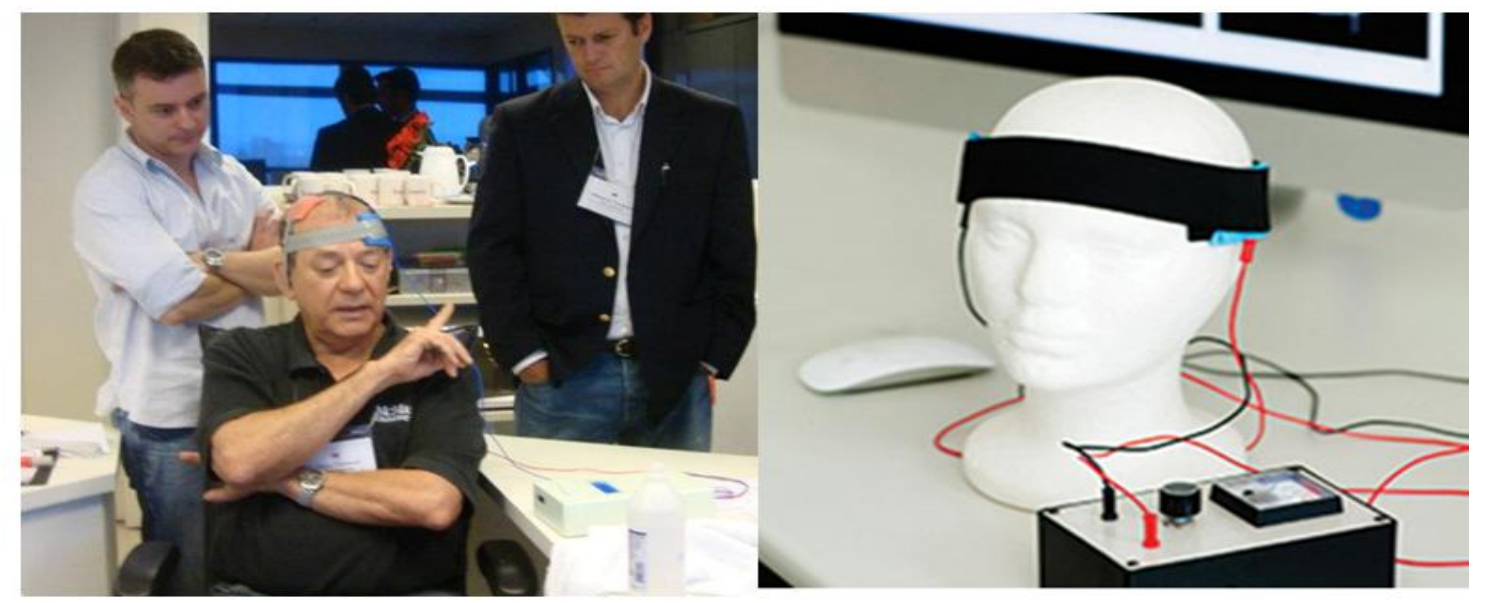

Figura 10. Estimulação Transcraniana por Corrente Contínua (ETCC).

Em contraste com a EMT, que é administrada através de um dispositivo sofisticado, a ETCC pode ser administrada com dispositivos já fabricados e utilizados para o tratamento da dor e na medicina estética. O baixo custo do aparelho da ETCC comparativamente ao aparelho de EMT, a simplicidade da técnica, o fácil transporte do material necessário, poucos feitos colaterais, a ausência de dor, alta tolerabilidade, segurança da aplicação e potencial eficácia em diversas especialidades como neurologia, psiquiatria e reabilitação física assim como reabilitação neuropsicológica, são fatores que tornam a ETCC uma técnica vantajosa comparativamente a outros métodos neuromodulatórios.

\subsection{Estudos envolvendo tabagismo e ETCC}

Na literatura, até o presente momento, poucos estudos têm aplicado a ETCC para a dependência do cigarro. Estudos de imagem e de EMTr sugerem que o aumento da ativação e a integridade do CPFDL podem ser associada ao aumento da resistência aos sinais relacionados com o tabagismo. Os trabalhos existentes sugerem que a ETCC é uma promessa para alterar o complexo sistema pelo qual estímulos ambientais interagem com o desejo e o comportamento de fumar em 
usuários de tabaco (56). ETCC anódica no CPFDL, acredita-se aumentar a ativação deste e consequentemente reduzir o desejo do cigarro em resposta a estes sinais (56). No entanto, estes estudos são altamente heterogêneos, tanto nos parâmetros da estimulação da ETCC, quanto no desenho do estudo, tipo de amostra, dentre outros; o que prejudica tanto a comparação dos resultados obtidos quanto sua generalização (23).

Usando os termos "transcranial direct current stimulation", "treatment", "Tobacco Addiction", "smoking" e "craving" foram encontrados 9 artigos através de pesquisa no Pubmed. Deste, apenas três estão relacionados a ETCC e fissura em tabagistas, 4 estão relacionados à ETCC e número de cigarros. Não há registros de estudos de ETCC avaliando motivação em tabagistas.

O primeiro estudo clínico avaliando os efeitos da ETCC em tabagistas foi em 2008 realizado por Fregni et al. (57). Participaram 24 pacientes. Três tipos de montagens dos eletrodos: 1) eletrodo anodo (esponja $35 \mathrm{~cm}^{2}$ ) em CPFDL esquerdo no F3 (sistema EEG 10/20) e eletrodo catodo (esponja $100 \mathrm{~cm}^{2}$ ) em F4 (sistema EEG 10/20); 2) eletrodo anodo (esponja $35 \mathrm{~cm}^{2}$ ) em CPFDL direito no F4 (sistema EEG 10/20) e eletrodo catodo (esponja $100 \mathrm{~cm}^{2}$ ) em F3 (sistema EEG 10/20); 3) sham: o eletrodo foi colocado na mesma posição de uma aplicação e era desligado após 30 segundos de estimulação. A corrente foi de $2 \mathrm{~mA}$ aplicada por 20 minutos em uma única sessão. A fissura foi avaliada inicialmente por Escala Analógica Visual (EVA) ao que se seguia exposição a pistas relativas ao cigarro (manipulação do cigarro e vídeo com cenas de pessoas fumando) e, em seguida, uma nova avaliação da fissura. Após este procedimento, os pacientes eram submetidos à estimulação e então o procedimento inicial se repetia. Notou-se que a estimulação do CPFDL em uma sessão de ETCC, tanto à esquerda quanto à direita, reduziu significativamente a fissura nos pacientes do grupo ativo em comparação com o grupo placebo.

Em 2009, o estudo pioneiro de Boggio et al. (58) foi estendido para investigar o efeito cumulativo de cinco sessões de ETCC sobre o CPFDL esquerdo em tabagistas. A fissura e número de cigarros foram avaliados. Vinte e sete pacientes participaram do estudo. O eletrodo anodo (esponja $35 \mathrm{~cm}^{2}$ ) em CPFDL esquerdo no F3 (sistema EEG 10/20) e eletrodo catodo (esponja $100 \mathrm{~cm}^{2}$ ) em F4 (sistema EEG 10/20), e no grupo sham: o eletrodo foi colocado na mesma posição do grupo 
aplicação e era desligado após 30 segundos de estimulação. A corrente foi de $2 \mathrm{~mA}$ aplicada por 20 minutos por cinco dias consecutivos. Vídeos com pistas relacionados ao cigarro e EVA foram utilizados para avaliar a fissura antes e depois de cada sessão. Após cinco sessões de ETCC, houve uma redução significativa do desejo por cigarro e do número de cigarros no grupo aplicação comparado ao grupo placebo.

Em outro estudo em 2013, Xu et al. (59) avaliaram o efeito da ETCC anódica no CPFDL esquerdo sobre o humor, atenção e vontade de fumar cigarros em 24 tabagistas. Neste estudo os pacientes eram solicitados a não fumar na noite anterior à aplicação da ETCC. Os participantes receberam ETCC (real ou simulada) depois de assistir as pistas do cigarro. Eletrodo ânodo com esponja de $35 \mathrm{~cm}^{2}$ foi colocado sobre o CPFDL esquerdo e o eletrodo cátodo foi colocado sobre a área supraorbital contralateral. A corrente foi de $2 \mathrm{~mA}$, durante $20 \mathrm{~min}$. Houve uma redução do afeto negativo no grupo ETCC comparada com o grupo sham-ETCC. Já em relação ao desejo pelo cigarro e o desempenho em uma tarefa de atenção visual não houve efeito significativo no grupo ETCC comparada com o grupo sham-ETCC.

Fecteau et al. em 2014 (60) avaliaram vontade de fumar, consumo de cigarros e de tomada de decisão em 12 adultos tabagistas que desejam parar de fumar (estágio motivacional contemplador). O eletrodo anodo foi posicionado no CPFDL direito e o catodo no CPFDL esquerdo. A corrente foi de $2 \mathrm{~mA}$ durante $30 \mathrm{~min}$ durante cinco dias. Observaram diferença significativa tanto no desejo de cigarro quanto no número de cigarros fumados no grupo ETCC comparada com o grupo sham-ETCC.

Meng et al. (61) examinaram os efeitos da ETCC catódica na área de associação frontal-parietal-temporal (FPT) em 30 homens tabagistas. Três montagens de eletrodos: 1) catódica bilateral ambos em FPT; 2) catódica sobre FPT direita; e 3) sham-ETCC. A corrente utilizada foi de $1 \mathrm{~mA}$ durante 20 minutos, uma única estimulação. Foram avaliados atenção visual aos sinais relacionados com o tabagismo, utilizando um sistema de rastreamento dos olhos, e número de cigarros consumidos diariamente antes e após o tratamento ETCC. Como resultado o estudo mostrou que, após a estimulação catódica bilateral da área da FPT, a atenção aos sinais relacionados com o tabagismo mostrou uma tendência de diminuição, porém 
os efeitos não foram significativamente diferentes da estimulação sham. O consumo diário de cigarros foi reduzido para um nível significativo. Esses efeitos não foram observados sob ETCC catódica individuais ou sham-ETCC.

Recentemente em 2015, Falcone et al. (62) avaliaram o tempo de latência para fumar cigarros após a aplicação da ETCC. Vinte e cinco pacientes tabagistas participaram do estudo. Eletrodo anódico foi colocado sobre a área de F3 (sistema EEG 10/20 ) para a estimulação sobre o CPFDL esquerda e o cátodo foi colocado sobre a área supraorbital direita. Corrente de $1 \mathrm{~mA}$ por 20 minutos, uma única estimulação. Pacientes eram orientados a ficar sem fumar durante a noite e no dia seguinte eram submetidos a aplicação de ETCC na presença de sinais relacionados com o cigarro; eles tinham a opção de fumar a qualquer momento ou receber US\$1 para cada 5 minutos que ficassem sem fumar. Tempo para o primeiro cigarro (latência de fumar) e número total de cigarros fumados foram registrados. ETCC ativas (em comparação com sham) aumentou significativamente a latência de fumar $(p=0,02)$ e reduziu o número total de cigarros fumados $(p=0,014)$ durante a sessão.

\subsection{Outras aplicações da ETCC}

O campo de estimulação cerebral não invasiva teve um aumento rápido e exponencial nos últimos 10 anos. Esta "velha nova" técnica, como a estimulação transcraniana elétrica cerebral com correntes elétricas que foi recorrentemente descrita na literatura médica desde os tempos antigos, foi reavaliada apenas recentemente após os fundamentais estudos de Priori et al. (1998) e Nitsche e Paulus (2000) (63).

A ETCC é uma ferramenta interessante nas Neurociências, pois, possibilita o estabelecimento de relações entre atividade motora, sensorial, cognitiva e áreas corticais estimuladas ou inibidas, além do uso como potencial terapêutico para uma variedade de desordens neurológicas e psiquiátricas (23).

De 1998 em diante, vários estudos mostraram a capacidade neuromodulatória da ETCC em uma infinidade de efeitos nas áreas comportamental, sensorial e motora, de acordo com parâmetros de estimulação e características dos sujeitos. No entanto, ensaios clínicos com ETCC estão em estágios iniciais (63) e os estudos não 
são amplamente padronizado em relação às variáveis e amostras populacionais, estando as descobertas limitadas a amostras pequenas e design experimental, limitando conclusões (64).

Brunoni et al. em um artigo de Revisão em 2012 (63), citam artigos originais sobre os efeitos eletrofisiológicos da ETCC na memória de trabalho visuo-espacial (Heimrath et al., 2012), discriminação de cor em humanos (Costa et al., 2012), excitabilidade do córtex motor (Chaieb et al., 2012); artigos originais que exploram os efeitos comportamentais do ETCC na excitabilidade do campo ocular frontal nos movimentos sacádicos (Kanai et al., 2012), processos verbais automáticos (Vannorsdall et al., 2012), memória de trabalho (Jones e Berryhill, 2012), processamento emocional (Nitsche et al., 2012), produção de respostas falsas (Fecteau et al., 2012); e artigos originais sobre os efeitos clínicos da ETCC sobre zumbido (De Ridder e Vanneste, 2012), transtorno depressivo maior (Blumberger et al., 2012; Knotkova et al., 2012), dor (Dossantos et al., 2012), e revisões sobre aprendizado e memória (Brasil-Neto, 2012), doença de Alzheimer (Hansen, 2012), acidente vascular cerebral (Adeyemo et al., 2012; Madhavan e Shah, 2012), e dependência de tabaco (Fraser e Rosen, 2012) mostrando a diversidade dos campos de pesquisa de investigação com a ETCC.

Apesar de inúmeras pesquisas com ETCC, a maior parte dos ensaios clínicos foram realizados investigando-se a depressão, com resultados positivos e promissores, porém o número de estudos ainda é pequeno. Para tratamento de esquizofrenia os resultados são menos consistentes, e os métodos são mais heterogêneos (63).

Shiozawa et al. em 2013 (65) em artigo de Revisão sinalizaram que alguns ensaios clínicos iniciais com ETCC para o tratamento de Depressão Maior mostraram melhora significativa dos sintomas depressivos para pacientes submetidos a tratamento complementar com ETCC. Ferrucci et al. avaliaram pacientes com depressão grave usando duas sessões diárias de ETCC (2mA, 20 minutos por sessão), duas vezes por dia durante 5 dias consecutivos. Os autores encontraram melhora de cerca de $20 \%$ nos sintomas depressivos para o grupo ativo. Brunoni et al., num estudo com 31 pacientes utilizando do mesmo protocolo, 
encontraram resultados semelhantes para pacientes com diagnóstico de depressão bipolar, com uma redução de cerca de $18 \%$ dos sintomas clínicos.

Outro estudo de impacto foi conduzido por um grupo australiano que teve por objetivo investigar a eficácia do ETCC em um ensaio duplo-cego, placebocontrolado, onde 64 participantes com depressão maior receberam ETCC anódica ativa ou simulada no córtex pré-frontal dorsolateral esquerdo ( $2 \mathrm{~mA}, 15$ sessões divididas em 3 semanas), seguido de uma fase de 3 semanas de tratamento ativo para todos os grupos. Foram avaliados sintomas depressivos e desempenho em escalas cognitivas. Houve melhora significativa do humor no grupo ativo versus sham $(p<0,05)$, embora nenhuma diferença nas taxas de resposta tenha sido verificada (13\% em ambos os grupos). Atenção e memória de trabalho apresentaram melhora após uma única sessão de tratamento ativo, mas não para o grupo sham $(p<0,05)$. Não houve declínio do desempenho neuropsicológico após 36 semanas de estimulação ativa (65).

Brunoni et al. em 2013 (63) realizaram um grande estudo duplo-cego randomizado controlado (RCT) implementado no Brasil com 120 pacientes deprimidos. Foram aleatorizados com um design fatorial $2 \times 2$ a sertralina, um inibidor da recaptação da serotonina usado como antidepressivo, ou placebo, e ETCC ativa ou sham. Em comparação com os grupos sham-ETCC, grupos ETCC mostrou melhorias significativamente maiores de sintomas depressivos após 10 estimulações em 2 semanas. O benefício de ETCC foi ainda indicado no final de um período de extensão de 4 semanas em que foram administradas duas estimulações (em semanas) (64).

$\mathrm{Na}$ esquizofrenia, há poucos dados disponíveis sobre o efeito do ETCC até o momento. Brunelin et al. em 2012 randomizaram 30 pacientes esquizofrênicos com alucinações auditivas persistentes para receber estimulação ativa versus simulada. Neste estudo o cátodo foi colocado sobre a região temporo-parietal esquerda e o ânodo sobre o córtex pré-frontal dorsolateral esquerdo. Com estimulação duas vezes ao dia, por 5 dias, os autores demonstraram que houve melhora dos sintomas alucinatórios (desfecho primário) logo após o término da estimulação, efeitos que se mantiveram após 1 e 3 meses de tratamento. Houve também melhora significativa dos sintomas negativos e tendência a melhoria dos sintomas positivos (65). 
$\mathrm{Na}$ doença de Alzheimer existem na literatura ensaios clínicos randomizados, duplo-cegos investigando os efeitos de sessão única (Ferrucci et al., 2008; Boggio et al. 2009) e cinco ou mais sessões de ETCC (Boggio et al., 2012; Cotelli et al., 2014; Suemoto et al., 2014; Kherd et al., 2014). Os estudos realizados até agora são, em grande parte heterogêneos, com números de participantes pequenos e resultados diversos (64).

A ETCC tem sido uma ferramenta terapêutica progressivamente estudada para transtornos psiquiátricos. Os resultados de diferentes estudos clínicos têm mostrado evolução clínica favorável para pacientes submetidos à ETCC x placebo, com ênfase para pacientes com depressão maior e esquizofrenia. Ensaios clínicos mais amplos são necessários para o estabelecimento mais robusto desta técnica no cenário da psiquiatria atual (38).

\section{Objetivos}

\subsection{Objetivo Geral}

O presente estudo teve como objetivo geral analisar os efeitos da modulação do córtex pré-frontal dorso lateral esquerdo através da estimulação transcraniana com corrente direta contínua no tratamento de tabagistas.

\subsection{Objetivos Específicos}

1. Avaliar se são estatisticamente significativas as diferenças entre os grupos ETCC e sham-ETCC quanto à redução no desejo de fumar;

2. Avaliar se são estatisticamente significativas as diferenças entre os grupos ETCC e sham-ETCC quanto à quantidade de cigarros consumidos durante a pesquisa;

3. Avaliar se são estatisticamente significativas as diferenças entre os grupos ETCC e sham-ETCC quanto à motivação. 


\section{Materiais e Métodos}

\subsection{Tipo do Estudo}

O estudo realizado foi do tipo clínico experimental, exploratório, randomizado e placebo controlado.

\subsection{Local}

O estudo foi desenvolvido no Hospital Universitário de Brasília com apoio do Laboratório de Psiquiatria da Faculdade de Medicina da Universidade de Brasília (UNB).

\subsection{Amostra e Critérios de Elegibilidade}

Os voluntários foram recrutados através de cartazes no próprio HUB, divulgação no website da UNB e mídia local. Os interessados eram agendados pela secretaria do Laboratório de Psiquiatria da Faculdade de Medicina da UNB.

Para que fossem incluídos no estudo, os voluntários deveriam preencher os seguintes critérios de inclusão:

(1) ter idade entre 18 e 65 anos;

(2) não ser analfabeto;

(3) ser fumante, de pelo menos, 10 cigarros por dia, há no mínimo um ano;

(4) não estar, no momento, em tratamento para o tabagismo (medicamentoso ou não) - pacientes que já fizeram tratamentos prévios estavam aptos a participar;

(5) ser capaz de entender substancialmente o projeto ao qual está se submetendo;

(6) não estar grávida ou em risco de engravidar durante as aplicações; 
(7) não ser portador de comorbidade clínica e/ou psiquiátrica importante que possa interferir no seguimento do projeto.

\subsection{Instrumentos}

Em todos os 36 sujeitos que fizeram parte da amostra foram aplicados:

1. Questionário com dados sócios demográficos (idade, sexo, estado civil, profissão, escolaridade) e clínicos (lateralidade, doenças clínicas e psiquiátricas) (ANEXO I).

2. Escalas de Avaliação Analógica Visual (EVA) de Vontade/Desejo pelo cigarro. Composta da pergunta "Qual a sua vontade/desejo pelo cigarro?" seguida de uma linha de $10 \mathrm{~cm}$ que tem como extremos as frases "Sem vontade/desejo" e “Intensa vontade/desejo". Pontuação máxima de 10. Pouca vontade/desejo se 0-3; Vontade/Desejo moderada se 4-7; Vontade/Desejo elevada se $\geq 8$ (ANEXO I).

3. Escalas de Avaliação Analógico Visual (EVA) de Motivação para parar de fumar. Composta da pergunta "Qual a sua motivação para deixar de fumar?" seguida de uma linha de $10 \mathrm{~cm}$ que tem como extremos as frases "Sem nenhuma vontade" e "Francamente decidido a parar". Pontuação Máxima de 10. Pouca motivação se 0-3; Motivação moderada se 4-7; Motivação elevada se $\geq 8$ (ANEXO I).

4. Questionário da História do Tabagismo, do qual constavam informações sobre o uso do cigarro (idade do início do uso, idade de fumar regularmente, quantidade do uso médio por dia, tentativas anteriores e sucesso de parada, tratamentos anteriores, hábitos relacionados ao uso, perguntas relacionadas aos estágios motivacionais, etc.) (ANEXO II).

5. Teste de Fagerström para a Dependência de Nicotina (TFDN) que é um dos instrumentos mais utilizados de avaliação da dependência. Traduzido e adaptado para o português por Carmo e Pueyo (2002) (22). A versão aqui utilizada é a mesma utilizada pelo Ministério da Saúde/INCA (2001) composta de 6 itens com pontuação de 0 a 10 . Os escores para dependência de nicotina permitem a 
classificação da dependência em cinco níveis: muito baixo (0 a 2 pontos); baixo (3 a 4 pontos); moderado (5 pontos); alto (6 a 7 pontos); muito alto (8 a 10) $(66,67)$ (ANEXO III).

6. Entrevista Clínica Estruturada para Transtornos do Eixo I do DSM-IV SCID I (versão clínica traduzida para o português) que é um instrumento que permite bons índices de confiabilidade do diagnóstico psiquiátrico. Esta entrevista é composta por rígidos critérios diagnósticos que guiam o atendimento, mostrando-se um instrumento com resultados confiáveis, sendo reconhecida internacionalmente (15) (ANEXO IV).

7. Adicionalmente, os pacientes receberam da pesquisadora um cartão de auto monitoramento para controlar o número de cigarros fumados durante o período da pesquisa.

\subsection{Procedimentos}

A triagem, aplicação dos questionários e escalas foram realizadas por 04 Residentes do segundo ano de psiquiatria do HUB previamente treinados. Participaram das aplicações da Estimulação Transcraniana por Corrente Contínua, no início da pesquisa, 2 Graduandos de Medicina, 2 Residentes de Psiquiatria do segundo ano do HUB e a autora da pesquisa; sendo que na maioria dos pesquisados a aplicação da estimulação foi realizada pela autora da pesquisa.

Todos os pesquisadores que participaram da aplicação da ETCC foram devidamente treinados e supervisionados pela autora da pesquisa.

A aplicação das escalas no $5^{\circ}, 7^{\circ}$ e $35^{\circ}$ dia foram realizadas pela autora da pesquisa.

Os voluntários eram agendados pela Secretaria do Laboratório de Psiquiatria da Faculdade de Medicina da UnB e encaminhados para o HUB-UnB. Os Residentes do Psiquiatria do segundo ano do HUB faziam a triagem, aplicavam os questionários e escalas; e em seguida conduziam os voluntários ao Laboratório do 
Sono no próprio HUB, para serem submetido à aplicação da ETCC. No Laboratório do Sono do HUB, os pesquisadores explicavam os procedimentos da ETCC aos voluntários, após uma randomização por ordem de chegada; e havendo concordância, assinavam o termo de Consentimento Livre e Esclarecido, iniciando a aplicação (Figura 11).

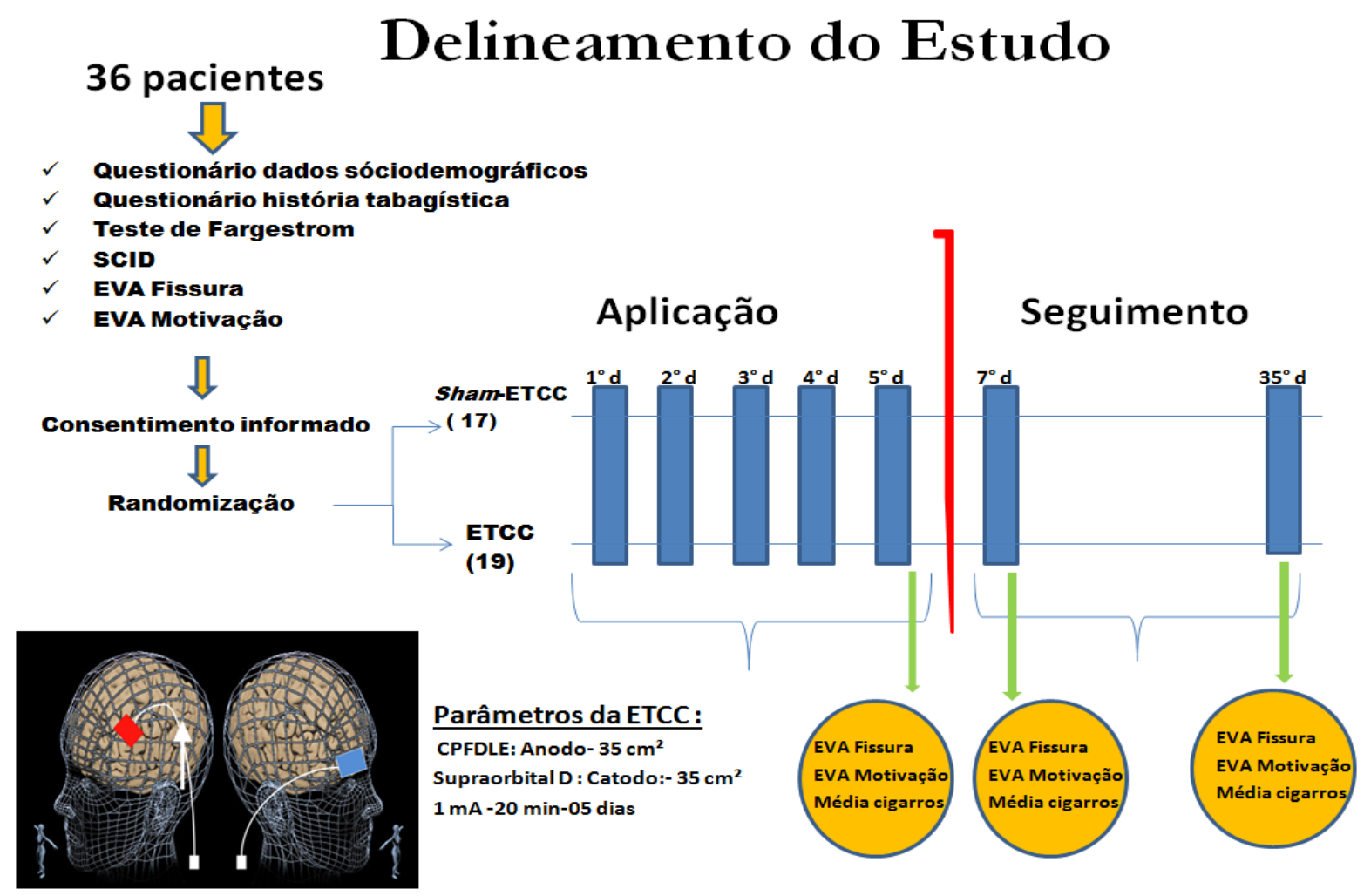

Figura 11. Delineamento do estudo da amostra de pacientes submetidos à ETCC e ShamETCC. 
Sessenta e dois (62) pacientes tabagistas foram triados, sendo 26 excluídos deste estudo por diversos motivos: 10 por apresentarem questionários incompletos com uma das variáveis, 6 por readequação do ponto de estimulação, 2 por fumarem 6 cigarros/dia, 2 desistiram após triagem (1 alegou não ser possível participar dos 5 dias de aplicação e outro alegou receio de se submeter às aplicações), 2 desistiram após a primeiro dia de aplicação (1 alegou morar longe e o outro não conseguimos contato), 2 pacientes desistiram após o $2^{\circ}$ dia de aplicação (1 alegou irritabilidade e cefaleia e com o outro não conseguimos contato), 1 paciente desistiu após a $3^{\circ}$ terceira aplicação alegando estar sem disponibilidade para ir nos outros dias, 1 foi excluída por ser analfabeta.

Nos primeiros pacientes a área FP1 de acordo com o sistema internacional para EEG 10-20 era o ponto estimulado. Após consultoria com o Centro de Neuromodulação de Harward, EUA, foi sugerido estimular o ponto F3, sendo todos os pacientes da amostra desta dissertação estimulados no ponto F3.

Tanto os pacientes com estimulação em FP1, bem como os outros com questionários incompletos, serão objeto de outro estudo posterior.

A amostra apresentada na dissertação é composta de 36 pacientes tabagistas, sendo 21 mulheres e 15 homens. Todos os 36 tabagistas completaram o protocolo de 5 dias consecutivos de aplicação da ETCC, 1 não compareceu ao seguimento de 7 dias e 8 não compareceram ao seguimento de 35 dias.

Nenhum efeito colateral foi observado nas aplicações. Todos os participantes toleraram bem as estimulações e não houve nenhuma queixa de dor ou desconforto.

Foi utilizado um estimulador produzido especialmente para o estudo, constituído basicamente por quatro componentes principais: eletrodo (anodo e catodo), amperímetro (medidor de intensidade de corrente elétrica), potenciômetro (resistor variável que controla a tensão entre os eletrodos permitindo com isso a manipulação da intensidade da corrente aplicada) e um jogo de baterias.

O estimulador foi aferido pelo Departamento de Engenharia Elétrica da Universidade de Brasília. 
Dos 36 participantes do estudo, 19 tabagistas receberam a ETCC ativa e 17 a sham-ETCC.

Para fins de aplicação da ETCC, foram utilizados eletrodos revestidos com esponjas, medindo $35 \mathrm{~cm}^{2}(7 \times 5 \mathrm{~cm})$, embebidos em solução salina com a seguinte montagem: anodo em córtex pré-frontal dorsolateral esquerdo (área F3 de acordo com o sistema internacional $10-20$ de posicionamento de eletrodos para eletroencefalografia-EEG) e catodo na região supra orbital contralateral direita. Durante o experimento, os pacientes ficavam sentados confortavelmente em uma poltrona em um quarto iluminado e silencioso. $O$ aparelho era colocado estrategicamente atrás da poltrona, oculto do paciente durante a estimulação. Foi aplicada uma corrente constante de $1 \mathrm{~mA}$, com uma rampa de subida de 10 segundos no início e uma rampa de descida de 10 segundos no final de todas as estimulações, com duração de 20 minutos cada, por cinco dias consecutivos. Os pacientes deveriam sentir a corrente ao redor dos eletrodos no início da estimulação.

Para a Sham-ETCC a mesma montagem dos eletrodos foi usada, nas mesmas condições da ETCC ativa, inclusive as rampas de subida e descida, por um período de 10 segundos. Mas, nesta condição, a corrente era reduzida após aproximadamente 20 segundos e em seguida uma rampa de descida da corrente até o aparelho ficar desligado, sem o conhecimento dos pacientes. Entretanto, os pacientes sentiam as sensações iniciais do começo do procedimento, mas não recebiam o restante da corrente durante o período da estimulação. Este procedimento permitiu manter os indivíduos ingênuos para a respectiva condição de estimulação. Assim todos os participantes experimentaram o prurido inicial produzido pela estimulação e acreditaram estar recebendo a ETCC ativa $(23,67)$.

\subsection{Análise Estatística}

O Banco de Dados foi gerado no programa Excel e exportado para 0 programa Statistical Package for Social Sciences (SPSS) 18.0 software (SPSS Inc., Chicago, EUA) onde a análise foi realizada. Foi considerado o valor de $p<0,05$ para significância estatística. 
As variáveis qualitativas foram apresentadas por meio de tabelas e gráficos. Para verificar associação entre as variáveis qualitativas e grupos ETCC e ShamETCC, utilizou-se o teste Qui-Quadrado $\left(\mathbf{X}^{2}\right)$. Quando o valor esperado foi inferior a cinco, aplicou-se o teste exato de Fischer. Para as variáveis quantitativas foram calculadas medidas de posição e dispersão. A análise de variância de medidas repetidas (ANOVAmr) foi utilizada para avaliar se houve efeito significativo da ETCC entre o grupo ETCC e Sham-ETCC quanto a vontade de fumar, ao número de cigarros consumidos e a motivação, conforme os dias analisados. A fim de verificar se a redução do número de cigarros poderia ser explicada pela fissura ou motivação no $35^{\circ}$ dia, utilizou-se um teste de regressão linear.

\subsection{Aspectos Éticos}

Os procedimentos experimentais do estudo foram elaborados seguindo as diretrizes da resolução 196/96 do Conselho Nacional de Saúde e conduzidos de acordo com a declaração de Helsinki (1964).

O estudo foi aprovado pelo Comitê de Ética em Pesquisa envolvendo seres humanos da Faculdade de Ciências da Saúde da Universidade de Brasília (UnB), CEP/FS/UnB Registro N:080/10 (ANEXO V).

Este ensaio clínico foi registrado no Sistema de Registro http://ClinicalTrials.gov sob o número TAB-69168.

Todos os indivíduos participaram voluntariamente e através do termo de Consentimento Livre e Esclarecido (ANEXO VI), estiveram cientes dos objetivos e procedimentos do estudo, assim como dos riscos e benefícios da sua participação e que a qualquer momento durante a realização do estudo poderiam retirar-se do mesmo, sem nenhum prejuízo em sua relação com o pesquisador ou a instituição que apoiou este estudo. 


\section{Resultados}

As características sociodemográficas e clínicas do grupo total de tabagistas $(n=36)$ foram subdivididos em grupos Sham-ETCC $(n=17)$ e ETCC $(n=19)$ e são apresentadas na Tabela 2 e na Tabela 3.

Os grupos Sham-ETCC e ETCC foram relativamente homogêneos em relação às variáveis demográficas e clínicas. Nenhuma diferença foi encontrada $(p>0,05)$, exceto em relação à média de cigarros consumidos (carga tabágica) $(p=0,008)$.

Tabela 2. Características sociodemográficas da amostra submetidos à ETCC ou shamETCC sobre o córtex pré-frontal dorso lateral esquerdo.

\begin{tabular}{|c|c|c|c|}
\hline $\begin{array}{l}\text { Variáveis Demográficas } \\
\qquad n=36\end{array}$ & $\begin{array}{c}\text { Sham-ETCC } \\
(n=17)\end{array}$ & $\begin{array}{l}\text { ETCC } \\
(n=19)\end{array}$ & Valor de $p$ \\
\hline \multicolumn{4}{|l|}{ Faixa Etária } \\
\hline Até 39 anos & $6(35,3 \%)$ & $6(31,6 \%)$ & \multirow{2}{*}{$0,813^{*}$} \\
\hline 40 anos ou mais & $11(64,7 \%)$ & $13(68,4 \%)$ & \\
\hline \multicolumn{4}{|l|}{ Sexo } \\
\hline Masculino & $7(41,2 \%)$ & $8(42,1 \%)$ & \multirow{2}{*}{$0,955^{\star}$} \\
\hline Feminino & $10(58,8 \%)$ & $11(57,9 \%)$ & \\
\hline \multicolumn{4}{|l|}{ Escolaridade } \\
\hline Até ensino médio & $6(35,3 \%)$ & $5(26,3 \%)$ & \multirow{2}{*}{$0,559^{*}$} \\
\hline Ensino superior ou mais & $11(64,7 \%)$ & $14(73,7 \%)$ & \\
\hline \multicolumn{4}{|l|}{ Estado Civil } \\
\hline Solteiro & $8(47,1 \%)$ & $8(42,1 \%)$ & \multirow{3}{*}{$0,914^{\star *}$} \\
\hline Casado/União Estável & $5(29,4 \%)$ & $7(36,8 \%)$ & \\
\hline Divorciado/Separado/Viúvo & $4(23,5 \%)$ & $4(21,1 \%)$ & \\
\hline
\end{tabular}

Tabela 3. Principais parâmetros clínicos e características do tabagismo dos pacientes submetidos à ETCC ou sham-ETCC sobre o córtex pré-frontal dorso lateral esquerdo.

\begin{tabular}{lccc}
\hline \multicolumn{1}{c}{ Variáveis $\mathrm{n=36}$} & $\begin{array}{c}\text { Sham-ETCC } \\
(\mathrm{n}=17)\end{array}$ & $\begin{array}{c}\text { ETCC } \\
(\mathrm{n}=19)\end{array}$ & Valor de $\mathbf{p}$ \\
\hline Lateralidade & & & \\
\hline Destro & $15(88,2 \%)$ & $16(84,2 \%)$ & $0,727^{\star}$ \\
Canhoto & $2(11,8 \%)$ & $3(15,8 \%)$ & \\
Comorbidade clínicas & & & \\
\hline Não & $7(41,2 \%)$ & $11(57,9 \%)$ & $0,255^{\star \star *}$ \\
Sim & $10(58,8 \%)$ & $8(42,1 \%)$ & \\
\hline
\end{tabular}




\begin{tabular}{|c|c|c|c|}
\hline Variáveis $\mathrm{n}=36$ & $\begin{array}{c}\text { Sham-ETCC } \\
(n=17)\end{array}$ & $\begin{array}{l}\text { ETCC } \\
(n=19)\end{array}$ & Valor de $p$ \\
\hline \multicolumn{4}{|c|}{ Comorbidades psíquicas (SCID) $^{(1)}$} \\
\hline Não & $5(29,4 \%)$ & $8(44,5 \%)$ & \multirow{2}{*}{$0,358^{*}$} \\
\hline $\operatorname{Sim}$ & $12(70,6 \%)$ & $10(55,6 \%)$ & \\
\hline \multicolumn{4}{|l|}{ Medo de engordar } \\
\hline Não & $10(58,8 \%)$ & $11(57,9 \%)$ & \multirow{2}{*}{$0,955^{*}$} \\
\hline Sim & $7(41,2 \%)$ & $8(42,1 \%)$ & \\
\hline \multicolumn{4}{|l|}{ Idade de início } \\
\hline Até 16 anos & $7(41,2 \%)$ & $12(63,2 \%)$ & \multirow{2}{*}{$0,187^{\star}$} \\
\hline 17 anos ou mais & $10(58,8 \%)$ & $7(36,8 \%)$ & \\
\hline \multicolumn{4}{|l|}{ Carga tabágica } \\
\hline 10 a 20 cigarros & $10(58,8 \%)$ & $9(47,4 \%)$ & \multirow{4}{*}{$0,008^{\star *}$} \\
\hline 21 a 30 cigarros & $1(5,9 \%)$ & $9(47,4 \%)$ & \\
\hline 31 a 40 cigarros & $4(23,5 \%)$ & $1(5,3 \%)$ & \\
\hline Mais de 40 cigarros & $2(11,8 \%)$ & $0(0,0 \%)$ & \\
\hline \multicolumn{4}{|l|}{ Anos de uso do cigarro } \\
\hline 1 a 10 anos & $1(5,9 \%)$ & $1(5,3 \%)$ & \multirow{5}{*}{$0,817^{\star *}$} \\
\hline 11 a 20 anos & $4(23,5 \%)$ & $5(26,3 \%)$ & \\
\hline 21 a 30 anos & $5(29,4 \%)$ & $5(26,3 \%)$ & \\
\hline 31 a 40 anos & $5(29,4 \%)$ & $3(15,8 \%)$ & \\
\hline Mais de 40 anos & $2(11,8 \%)$ & $5(26,3 \%)$ & \\
\hline \multicolumn{4}{|l|}{ Tentativas de parar } \\
\hline Nunca tentou & $4(23,5 \%)$ & $4(21,1 \%)$ & \multirow{4}{*}{$0,620^{\star *}$} \\
\hline Tentou, mas não conseguiu & $4(23,5 \%)$ & $2(10,5 \%)$ & \\
\hline 1 a 3 vezes & $7(41,2 \%)$ & $8(42,1 \%)$ & \\
\hline Mais de 3 vezes & $2(11,8 \%)$ & $5(26,3 \%)$ & \\
\hline \multicolumn{4}{|l|}{ Pensando em parar } \\
\hline Sem planos para parar & $2(18,8 \%)$ & $3(15,8 \%)$ & \multirow{5}{*}{$0,885^{\star *}$} \\
\hline Sim, nos próximos 6 meses & $0(0,0 \%)$ & $1(5,3 \%)$ & \\
\hline Sim, nos próximos 30 dias & $4(23,5 \%)$ & $3(15,8 \%)$ & \\
\hline Sim, nos próximos dias & $10(58,8 \%)$ & $12(63,2 \%)$ & \\
\hline Sim, inclusive já parei & $1(5,9 \%)$ & $0(0,0 \%)$ & \\
\hline \multicolumn{4}{|l|}{ Quanto Motivado } \\
\hline Pouco motivado & $1(5,9 \%)$ & $4(21,1 \%)$ & \multirow{3}{*}{$0,402^{\star *}$} \\
\hline Motivado & $4(23,5 \%)$ & $5(26,3 \%)$ & \\
\hline Bastante motivado & $12(70,6 \%)$ & $10(52,6 \%)$ & \\
\hline \multicolumn{4}{|l|}{ Já parou? } \\
\hline Não & $11(64,7 \%)$ & $13(68,4 \%)$ & \multirow{2}{*}{$0,813^{\star}$} \\
\hline Sim & $6(35,3 \%)$ & $6(31,6 \%)$ & \\
\hline \multicolumn{4}{|l|}{ Escala de Fargeström } \\
\hline Mediana (mínimo-máximo) & $6,5(1-9)$ & $5,0(1-8)$ & $0,461^{\star \star *}$ \\
\hline \multicolumn{4}{|c|}{ (1) 1 paciente teve SCID inconclusivo } \\
\hline \multicolumn{4}{|l|}{ **Teste Exato de Fisher } \\
\hline${ }^{\text {**} T e s t e ~ d e ~ M a n n-W h i t n e y ~}$ & & & \\
\hline
\end{tabular}


A amostra foi constituída de 58,3\% $(n=21)$ do gênero feminino, apresenta média de idade de 45 anos (DP=11), 69,4\% ( $n=25)$ com escolaridade superior ou mais, sendo $44,5 \%(n=16)$ solteiros e $86,1 \%(n=31)$ destros.

Metade da amostra $(50 \% \mathrm{n}=18)$ apresentava comorbidades clínicas. A maioria (62\% ( $n=22)$ possuía um ou mais diagnóstico de patologias psiquiátricas (Figura 12 e Tabela 4) na SCID, enquanto no autorrelato apenas $25 \%(n=9)$ diziam possuir algum tipo de patologia psiquiátrica.



Figura 12. Comorbidades psiquiátricas: autorrelato x SCID. 
Tabela 4. Patologias psiquiátricas encontradas na SCID.

\begin{tabular}{lcc}
\hline \multicolumn{1}{c}{ SCID } & $\mathbf{n}$ & \% \\
\hline Transtorno de ansiedade generalizada & 11 & 30,6 \\
Fobia específica & 9 & 25,0 \\
Transtorno alimentar & 7 & 19,4 \\
Fobia social & 6 & 16,7 \\
Agorafobia sem pânico & 5 & 13,9 \\
Dependência de álcool & 5 & 13,9 \\
Abuso de álcool & 4 & 11,1 \\
Abuso não álcool & 4 & 11,1 \\
Dependência não álcool & 2 & 5,6 \\
Transtorno dismórfico corporal & 1 & 2,8 \\
Transtorno de estresse pós-traumático & 1 & 2,8 \\
Transtorno bipolar & 1 & 2,8 \\
Transtorno depressivo maior & 1 & 2,8 \\
Transtorno somatoforme indiferenciado & 1 & 2,8 \\
\hline
\end{tabular}

Considerando as características específicas do tabagismo da amostra, 19 (52\%) iniciaram o uso de cigarro antes dos 16 anos, a média do tempo de tabagismo era de 28,2 (DP=11,3) anos, o número de cigarros ao dia de 24,2 (DP=11,5).

Em relação a questões motivacionais, o autorrelato mostrou que a maioria (23 pacientes ou 63\%) pensava em parar nos próximos dias e 22 (61,1\%) se diziam bastante motivados

(Figura

\section{Grau de Motivação}

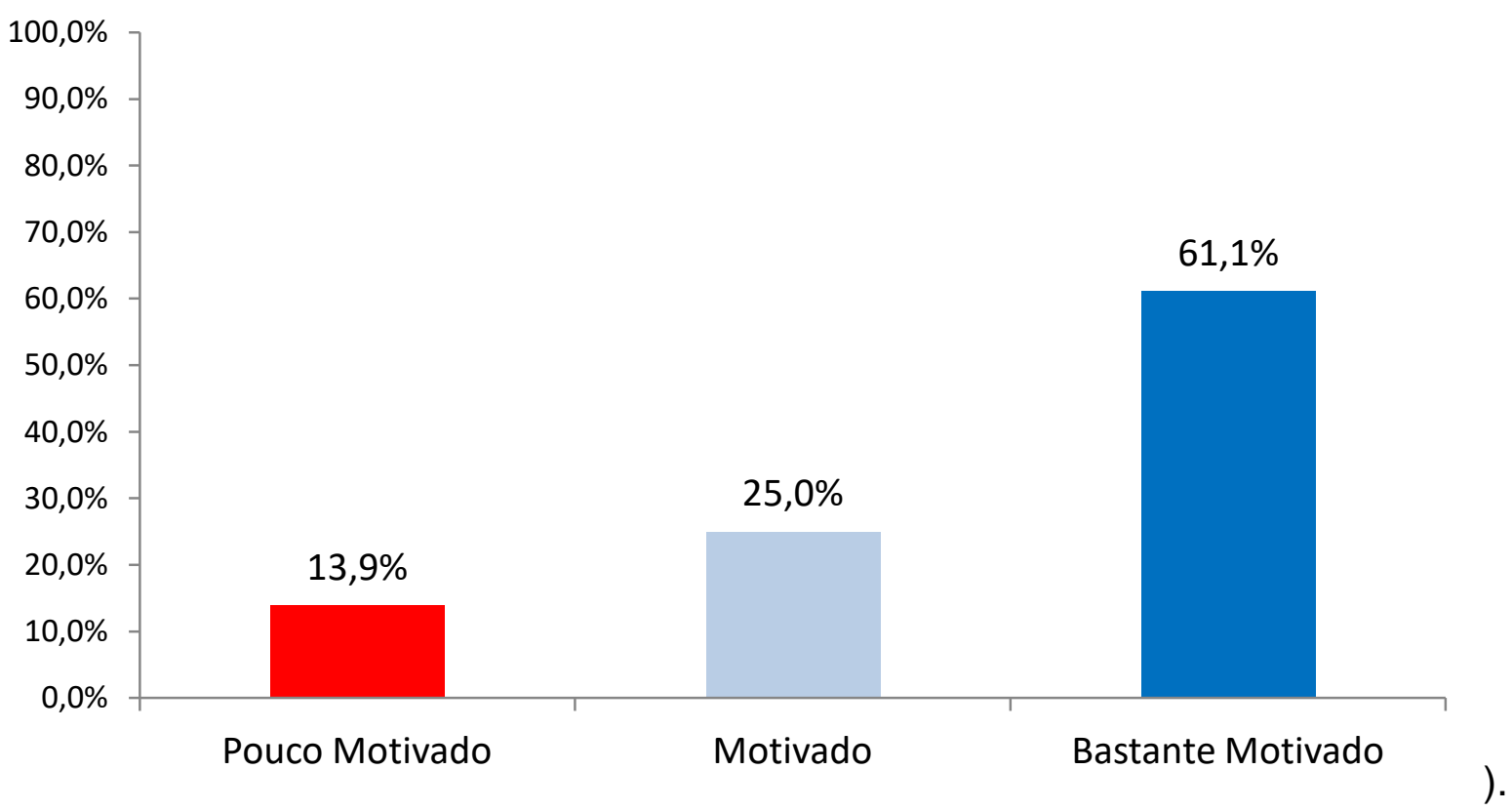




\section{Grau de Motivação}



Figura 13. Grau de Motivação da amostra de tabagistas submetidos à ETCC e sham-ETCC no córtex pré-frontal dorso lateral esquerdo.

Das tentativas de cessação do tabagismo, 15 (41,6\%) relataram de 1 a 3 tentativas prévias para parar de fumar e 24 (66,6\%) nunca tinham parado de fumar completamente.

A dependência nicotínica medida pelo TFDN foi considerada moderada em sete $(19,0 \%)$ dos tabagistas (escore de Fagerström=5) e considerada elevada ou muito elevada (escore de Fagerström $\geq 6$ ) em 19 (52,8\%) dos tabagistas (Figura 14). 


\section{Teste de Fargestron}

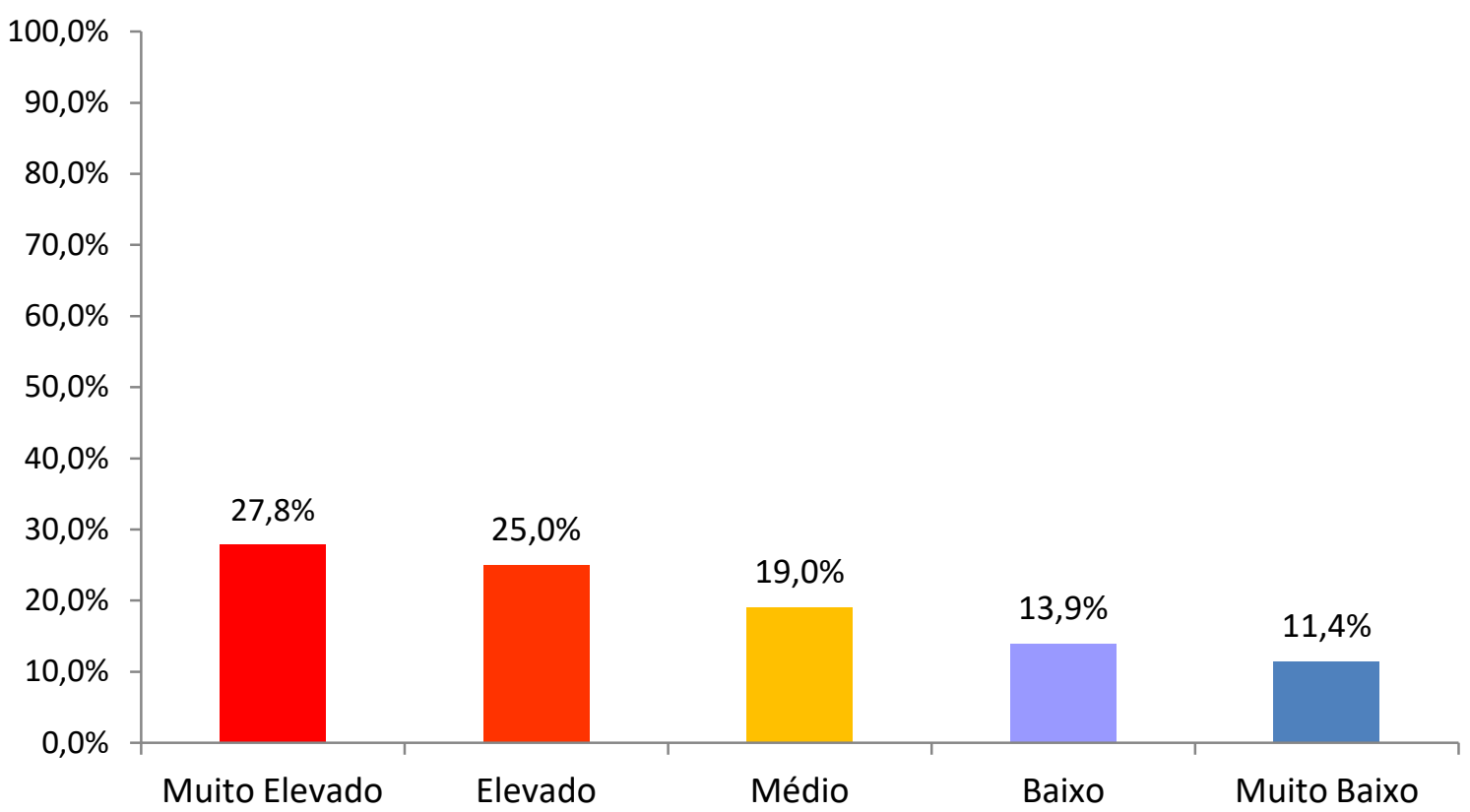

Figura 14. Resultado do Teste de Fargeström da amostra de tabagistas submetidos à ETCC e sham-ETCC sobre o córtex pré-frontal dorso lateral esquerdo.

A pontuação do Teste de Fargestrom considera: Muito baixo: 0 a 2 pontos; Baixo: 3 a 4 pontos; Moderado: 5 pontos; Alto: 6 a 7 pontos; Muito alto: 8 a 10.

A Tabela 5 mostra as estatísticas descritivas (média, desvio-padrão e valores mínimo e máximo) de cada medida temporal (1ํㅜㄴ $5^{\circ}, 7^{\circ}$ e $35^{\circ}$ dias) separadas por grupo (ETCC e Sham-ETCC). As variáveis avaliadas foram: vontade de fumar (fissura), motivação para parar de fumar e média de cigarros consumidos por dia.

Tabela 5. Estatísticas descritivas das medidas temporais entre os grupos de pacientes submetidos à estimulação Sham-ETCC e ETCC $(n=36)$.

\begin{tabular}{lcccccccccc}
\hline & \multicolumn{4}{c}{ Grupo Sham-ETCC } & \multicolumn{5}{c}{ Grupo ETCC } \\
\hline & N válido & Média & D.P. & Min. & Máx. & N válido & Média & D.P. & Min. & Máx. \\
\hline Vontade $1^{\mathbf{o}}$ dia & 17 & 7,4 & 3,0 & 0,3 & 10 & 18 & 8,0 & 1,5 & 5,1 & 10 \\
Vontade $5^{\mathbf{o}}$ dia & 16 & 4,9 & 2,3 & 1,9 & 9,6 & 18 & 5,6 & 2,6 & 1,4 & 10 \\
Vontade $7^{\circ}$ dia & 16 & 4,6 & 2,7 & 0 & 10 & 18 & 5,4 & 2,3 & 0,6 & 10 \\
Vontade $35^{\circ}$ dia & 13 & 4,7 & 2,8 & 0,5 & 8,6 & 15 & 5,1 & 2,3 & 1.7 & 9,1 \\
Média de cigarros $1^{\circ}$ dia & 17 & 26,1 & 14,6 & 10 & 60 & 19 & 22,1 & 7,5 & 10 & 40 \\
Média de cigarros $5^{\circ}$ dia & 17 & 16,5 & 10,9 & 0 & 42 & 18 & 11,6 & 7,3 & 0 & 24 \\
Média de cigarros $7^{\circ}$ dia & 16 & 16 & 10,9 & 0 & 30 & 18 & 11,2 & 7,9 & 0 & 22 \\
Média de cigarros $35^{\circ}$ dia & 13 & 17,2 & 11 & 0 & 31 & 15 & 9,9 & 8,8 & 0 & 23 \\
Motivação $1^{\mathbf{o}}$ dia & 17 & 8,3 & 2,4 & 3,2 & 10 & 19 & 7,7 & 2,9 & 1,5 & 10 \\
Motivação $5^{\mathbf{o}}$ dia & 17 & 9,0 & 1,5 & 5,2 & 10 & 18 & 8,4 & 2,2 & 3.8 & 10 \\
Motivação $7^{\mathbf{o}}$ dia & 16 & 8,3 & 2,2 & 2,9 & 10 & 18 & 8,6 & 2,0 & 3.8 & 10 \\
Motivação $35^{\circ}$ dia & 13 & 9,0 & 1,5 & 5,4 & 10 & 15 & 8,4 & 2,2 & 4.3 & 10 \\
\hline
\end{tabular}


A análise de variância de medidas repetidas (ANOVArm) mostrou um efeito principal do momento de avaliação nos resultados quanto à vontade de fumar. Os dados sugerem que houve uma queda significativa na vontade de fumar do $1^{\circ}$ para 0 $5^{\circ}$ dia $\left(F=17,35 ; p<0,001\right.$ com tamanho de efeito médio: $\left.\eta^{2}=0,44\right)$. Estas reduções se mantiveram no seguimento de 30 dias, porém não houve diferença entre os grupos Sham-ETCC e ETCC $(F=0,32 ; p=0,810)$, com tamanho de efeito nulo $\left(\eta^{2}<0,01\right)$ (Tabela 6 e Figura 15).

Tabela 6. ANOVA de medidas repetidas (efeitos entre sujeitos) da vontade de fumar (fissura).

\begin{tabular}{|c|c|c|c|c|c|c|c|c|c|}
\hline & $\begin{array}{l}\text { Correção de } \\
\text { Esfericidade }\end{array}$ & $\begin{array}{c}\text { Soma dos } \\
\text { Quadrados }\end{array}$ & df & $\begin{array}{l}\text { Média dos } \\
\text { Quadrados }\end{array}$ & $\mathrm{F}$ & $\mathrm{p}$ & $\eta^{2}$ & $\eta^{2} \mathrm{p}$ & $\omega^{2}$ \\
\hline \multirow[t]{3}{*}{ Vontade de Fumar } & None & 163.426 & 3.000 & 54.475 & 17.352 & $<.001$ & 0.437 & 0.441 & 0.409 \\
\hline & Greenhouse-Geisser & 163.426 & 2.545 & 64.221 & 17.352 & $<.001$ & 0.437 & 0.441 & 0.409 \\
\hline & Huynh-Feldt & 163.426 & 2.906 & 56.246 & 17.352 & $<.001$ & 0.437 & 0.441 & 0.409 \\
\hline \multirow[t]{3}{*}{ Vontade de Fumar $*$ grupo } & None & 3.020 & 3.000 & 1.007 & 0.321 & 0.810 & 0.008 & 0.014 & 0.000 \\
\hline & Greenhouse-Geisser & 3.020 & 2.545 & 1.187 & 0.321 & 0.778 & 0.008 & 0.014 & 0.000 \\
\hline & Huynh-Feldt & 3.020 & 2.906 & 1.039 & 0.321 & 0.804 & 0.008 & 0.014 & 0.000 \\
\hline \multirow[t]{3}{*}{ Residual } & None & 207.205 & 66.000 & 3.139 & & & & & \\
\hline & Greenhouse-Geisser & 207.205 & 55.984 & 3.701 & & & & & \\
\hline & Huynh-Feldt & 207.205 & 63.923 & 3.242 & & & & & \\
\hline
\end{tabular}

Nota. Tipo III Soma dos

Quadrados.

Estimativa de tamanho de efeito $=\eta^{2}, \eta^{2}$ parcial e $\omega^{2}$.

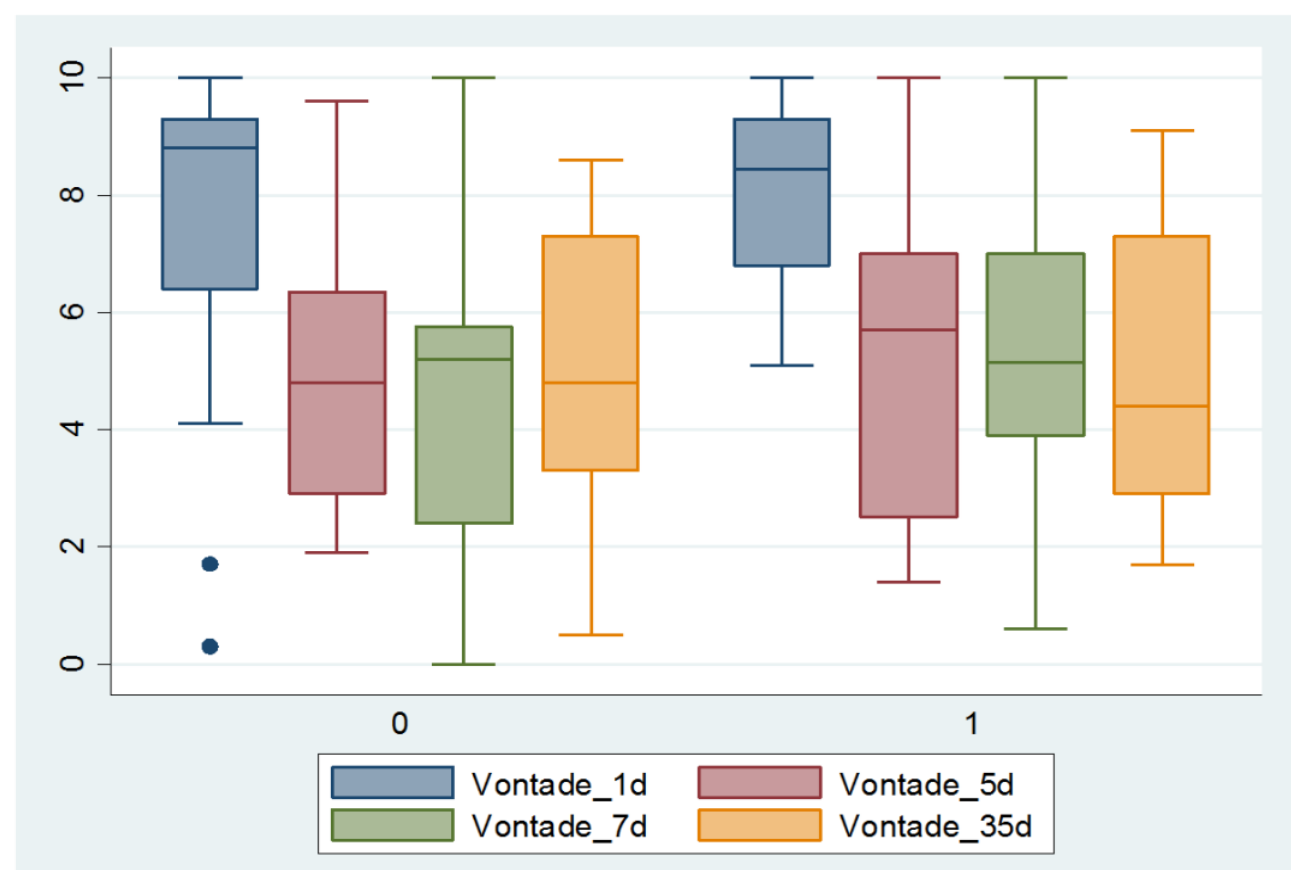

Figura 15. Boxplot da vontade/fissura dos grupos Sham-ETCC (0) e ETCC (1). 
Em relação ao número de cigarros (Tabela 7 e Figura 16) pode-se notar que houve um efeito significativo entre as médias de cigarros consumidos nas diferentes medidas temporais $\left(1^{\circ}, 5^{\circ}, 7^{\circ}\right.$ e $35^{\circ}$ dias; $F=27,53 ; p<0,001$, com tamanho de efeito médio: $\left.\eta^{2}=0,53\right)$, sugerindo que ao longo do tempo os indivíduos consumiram menos cigarros que no momento inicial. No entanto, esta diferença não foi significativa para a interação entre momento e grupo (grupos Sham-ETCC e ETCC - $F=0,233$; $p=0,873$ com tamanho de efeito nulo: $\left.\eta^{2}<0,01\right)$, mostrando que o grupo Sham-ETCC também diminuiu consideravelmente o consumo médio de cigarros ao longo do tempo.

Tabela 7. ANOVA de medidas repetidas (efeitos entre sujeitos) da média de cigarros.

\begin{tabular}{|c|c|c|c|c|c|c|c|c|c|}
\hline & $\begin{array}{l}\text { Correção de } \\
\text { Esfericidade }\end{array}$ & $\begin{array}{l}\text { Soma dos } \\
\text { Quadrados } \\
\end{array}$ & df & $\begin{array}{l}\text { Média dos } \\
\text { Quadrados } \\
\end{array}$ & $\mathrm{F}$ & $P$ & $\eta^{2}$ & $\eta^{2} p$ & $\omega^{2}$ \\
\hline \multirow[t]{3}{*}{ Média de Cigarros } & None & 2842.49 & 3.000 & 947.496 & 27.543 & $<.001$ & 0.532 & 0.534 & 0.509 \\
\hline & Greenhouse-Geisser & 2842.49 & 2.284 & 1.244 .643 & 27.543 & $<.001$ & 0.532 & 0.534 & 0.509 \\
\hline & Huynh-Feldt & 2842.49 & 2.537 & 1.120 .405 & 27.543 & $<.001$ & 0.532 & 0.534 & 0.509 \\
\hline \multirow[t]{3}{*}{ Média de Cigarros $*$ grupo } & None & 24.03 & 3.000 & 8.009 & 0.233 & 0.873 & 0.004 & 0.010 & 0.000 \\
\hline & Greenhouse-Geisser & 24.03 & 2.284 & 10.521 & 0.233 & 0.821 & 0.004 & 0.010 & 0.000 \\
\hline & Huynh-Feldt & 24.03 & 2.537 & 9.471 & 0.233 & 0.842 & 0.004 & 0.010 & 0.000 \\
\hline \multirow[t]{3}{*}{ Residual } & None & 2476.86 & 72.000 & 34.401 & & & & & \\
\hline & Greenhouse-Geisser & 2476.86 & 54.811 & 45.189 & & & & & \\
\hline & Huynh-Feldt & 2476.86 & 60.888 & 40.679 & & & & & \\
\hline
\end{tabular}

Nota. Tipo III Soma dos Quadrados. Estimativas de tamanho dos efeitos $=\eta^{2}, \eta^{2}$ parcial e $\omega^{2}$

Teste de Mauchly indicou que pressuposto da esfericidade foi violado $(p<.05)$, foi utilizado Teste de Greenhouse-Geisser para correção da esfericidade.

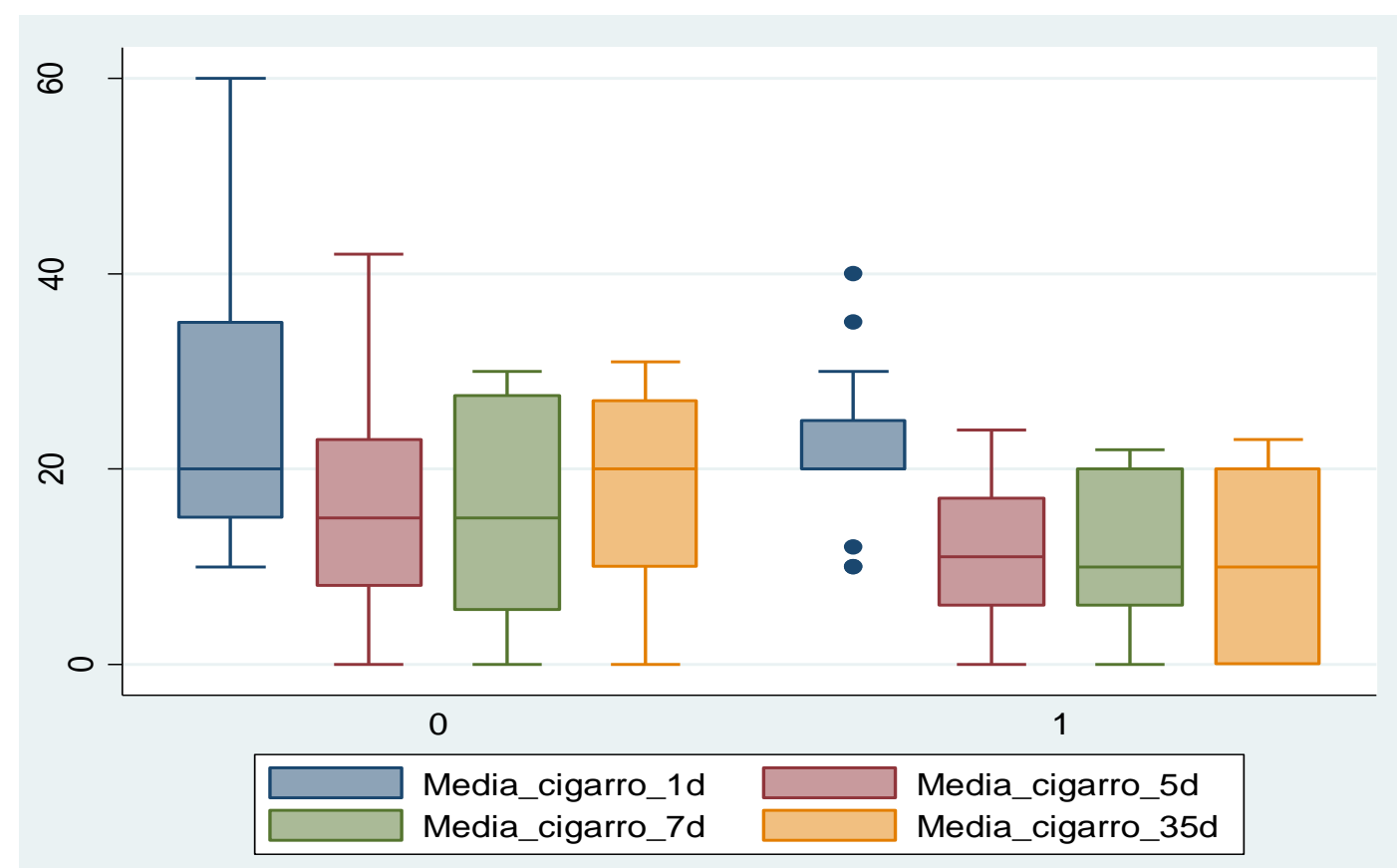

Figura 16. Boxplot do consumo médio de cigarros dos grupos Sham-ETCC (0) e ETCC (1). 
Em relação à motivação dos pacientes para deixar de fumar, os resultados mostraram que não houve diferença entre os grupos Sham-ETCC e ETCC ( $F=1,65$; $p=0,187$ com tamanho de efeito nulo: $\eta^{2}=0,06$ ) e que também não houve diferença ao longo do tempo ( $F=1,18 ; p=0,324$ com tamanho de efeito nulo: $\left.\eta^{2}=0,05\right)$, o que sugere que não houve alteração desta variável por efeito da estimulação (Tabela 8 e Figura 17).

Tabela 8. ANOVA de medidas repetidas (efeitos entre sujeitos) da motivação para parar de fumar.

\begin{tabular}{|c|c|c|c|c|c|c|c|c|c|}
\hline & $\begin{array}{l}\text { Correção de } \\
\text { Esfericidade }\end{array}$ & $\begin{array}{l}\text { Soma dos } \\
\text { Quadrados } \\
\end{array}$ & df & $\begin{array}{l}\text { Média dos } \\
\text { Quadrados }\end{array}$ & $\mathrm{F}$ & $\mathrm{p}$ & $\eta^{2}$ & $\eta^{2} \mathrm{p}$ & $\omega^{2}$ \\
\hline \multirow[t]{3}{*}{ Motivação } & None & 9.154 & 3.000 & 3.051 & 1.646 & 0.187 & 0.064 & 0.067 & 0.025 \\
\hline & Greenhouse-Geisser & 9.154 & 2.658 & 3.444 & 1.646 & 0.193 & 0.064 & 0.067 & 0.025 \\
\hline & Huynh-Feldt & 9.154 & 3.000 & 3.051 & 1.646 & 0.187 & 0.064 & 0.067 & 0.025 \\
\hline \multirow[t]{3}{*}{ Motivação $*$ grupo } & None & 6.556 & 3.000 & 2.185 & 1.179 & 0.324 & 0.046 & 0.049 & 0.007 \\
\hline & Greenhouse-Geisser & 6.556 & 2.658 & 2.467 & 1.179 & 0.323 & 0.046 & 0.049 & 0.007 \\
\hline & Huynh-Feldt & 6.556 & 3.000 & 2.185 & 1.179 & 0.324 & 0.046 & 0.049 & 0.007 \\
\hline \multirow[t]{3}{*}{ Residual } & None & 127.884 & 69.000 & 1.853 & & & & & \\
\hline & Greenhouse-Geisser & 127.884 & 61.130 & 2.092 & & & & & \\
\hline & Huynh-Feldt & 127.884 & 69.000 & 1.853 & & & & & \\
\hline
\end{tabular}

Nota. Tipo III Soma dos Quadrados

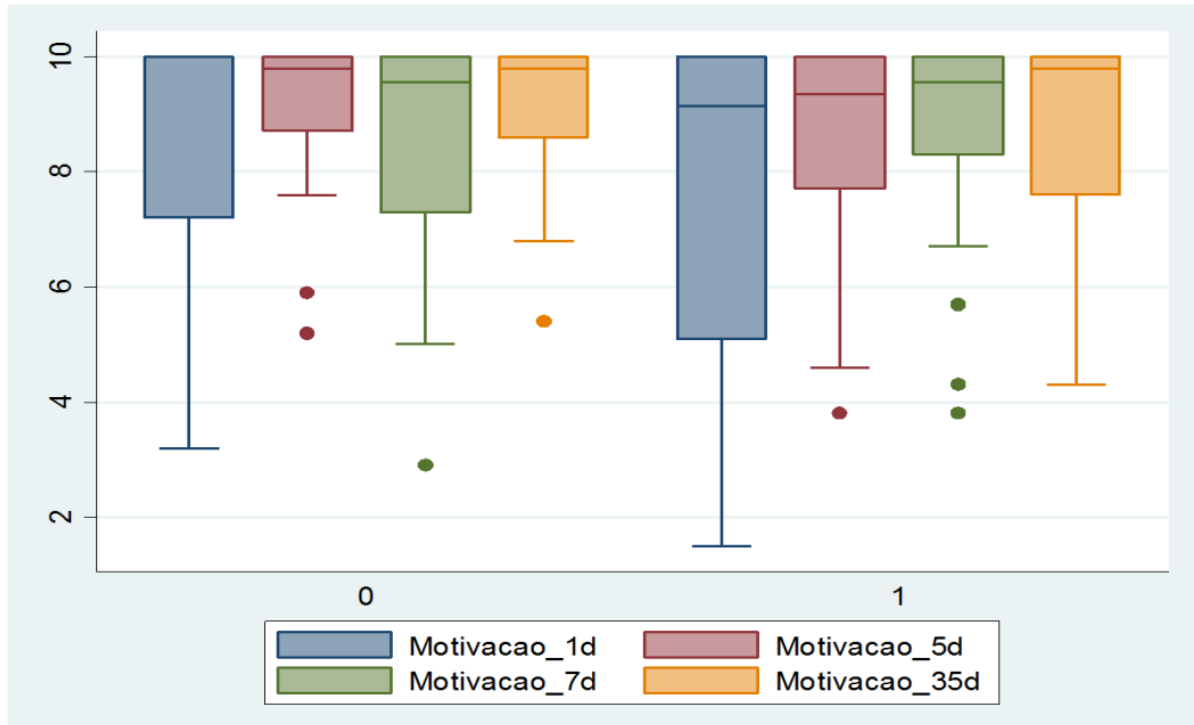

Figura 17. Boxplot da motivação dos grupos Sham-ETCC (0) e ETCC (1). 
$\mathrm{Na}$ análise da Regressão Linear, o coeficiente de determinação $\mathrm{R}^{2}$ da média de cigarros em relação à variável fissura foi de 0,062 e em relação à motivação foi de 0,093 (Figura 18 e Figura 19).

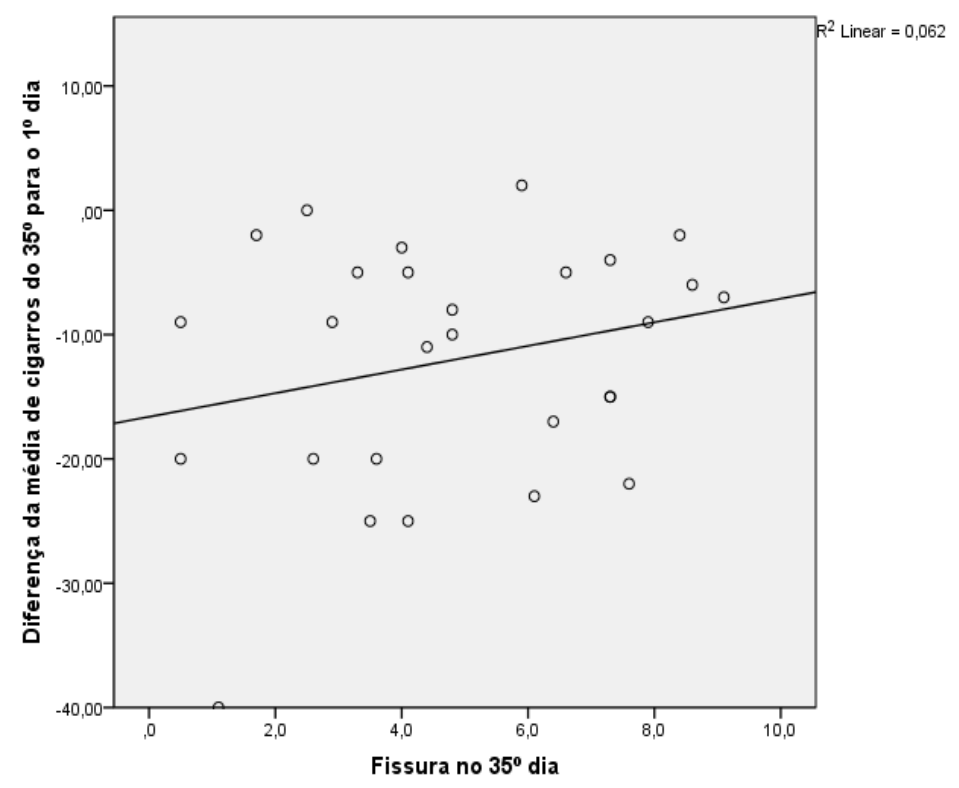

Figura 18. Diagrama de dispersão: cigarros $X$ fissura.

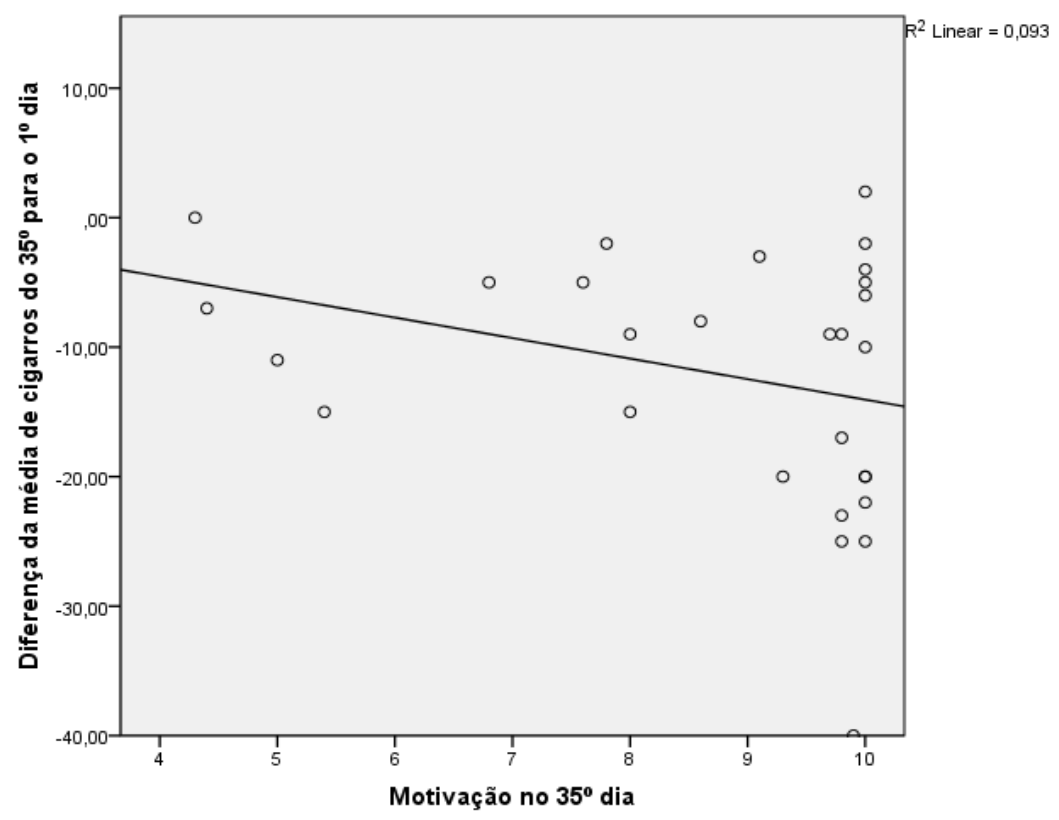

Figura 19. Diagrama de dispersão: cigarros X motivação. 


\section{Discussão}

Os resultado da amostra sugere um possível padrão de gravidade e complexidade da população estudada em relação ao tabagismo. A exemplo da literatura $(29,67)$ que evidencia que as mulheres procuram mais tratamento para tabagismo em comparação com os homens, no presente estudo, a maioria dos avaliados $(58,3 \%, n=21)$ era do gênero feminino. Estudos também sugerem que mulheres tabagistas têm maior dificuldade em parar de fumar, apresentam metabolização mais rápida da nicotina e maior prevalência de depressão do que homens $(7,29,68)$. Metade da amostra estudada - 50\% $(n=18)$ - já dizia ter algum tipo de comorbidade clínica.

O fator que mais contribui para o fracasso na cessação de fumar é a associação de tabagismo com transtornos psiquiátricos (29). As comorbidades psiquiátricas estavam presentes em 62,8\% ( $n=22)$ dos tabagistas no resultado da SCID e alguns tabagistas possuíam uma ou mais comorbidades psiquiátricas. Já no autorrelato, apenas $25 \%$ da amostra estudada $(n=9)$ diziam possuir alguma patologia psiquiátrica. Este resultado reforça a importância do uso de instrumentos específicos na detecção de patologias psiquiátricas em pesquisas com tabagistas. Os dados da literatura ressaltam que a prevalência de tabagismo na população psiquiátrica é significativamente maior que na população geral, em torno de 50\% daquela, em contraste com $25 \%$ desta (6). A probabilidade que uma pessoa com transtorno mental consuma cigarro é aproximadamente o dobro do que na população geral e a síndrome de abstinência à nicotina apresenta-se mais intensa do que nos demais tabagistas $(6,22,29)$. Vários autores demonstraram que o tratamento do tabagismo em pessoas com comorbidades psiquiátricas é menos eficaz mesmo quando combinados abordagens farmacológicas e comportamentais $(6,22,29)$. Pesquisas mostram que $50 \%$ dos tabagistas conseguem deixar de fumar, mas em pacientes com patologia psiquiátrica esta taxa cai para 15\% (29). Uma possibilidade para a elevada incidência de comorbidades psiquiátricas na amostra, pode ser o fato da divulgação do projeto de pesquisa ter ocorrido também em um ambiente hospitalar.

Quanto ao risco de ganho de peso, 41\% $(n=15)$ dos sujeitos estudados apresentavam medo de engordar ao parar de fumar. A literatura mostra que o ganho 
de peso é um fator importante que interfere no tratamento do tabagismo, principalmente entre mulheres. A maioria dos tabagistas ganhará $10 \%$ do seu peso em até cinco anos após o início da abstinência e cerca de um quinto dos tabagistas ganhará mais de $5 \mathrm{~kg}$. Mulheres tabagistas e tabagistas que consomem mais 25 cigarros ao dia apresentam maior risco para o ganho de peso. Este parece dever-se a um aumento da ingestão de alimentos e a um reajuste metabólico após a suspensão do tabagismo $(5,8)$.

Em relação ao início do uso do cigarro, que geralmente começa na adolescência; os resultados corroboraram os dados da literatura, na medida em que $52 \%(n=19)$ da amostra iniciaram o uso do cigarro antes dos 16 anos. No Brasil, o início do consumo de cigarro ocorre geralmente entre 13-14 anos. Quanto mais precocemente o início do uso do cigarro, maiores serão a gravidade da dependência e os problemas a ela associados $(8,29)$.

A média de anos de uso de cigarro amostra estudada foi de 28,3 (DP=11,3), 69,5\% ( $n=25)$ fumavam há mais de 20 anos e 19,4\% ( $n=7)$ fumavam há mais de 40 anos; a média do número de cigarros ao dia foi de 24,2 (DP=11,5) e 19,4\% (n=7) da amostra consumiam $\geq$ que 30 cigarros/dia; 41,6\% (n=15) relataram de 1 a 3 tentativas prévias para parar de fumar; $22 \%(n=8)$ nunca tentaram parar de fumar e $66,6 \%(n=24)$ nunca tinham parado de fumar completamente. A recaída é frequente ao longo do processo de cessação tabágica e estudos sugerem que são necessárias em média de cinco a sete tentativas prévias para que se atinja o sucesso $(5,6,8)$.

No TFDN a maioria $52,8 \%(n=19)$ foi considerada dependente de nicotina em grau elevado a muito elevado e destes, 27,8\% $(n=10)$ dependentes de nicotina em grau muito elevado (escore de Fagerström $\geq 8$ ). Segundo a literatura, quanto maior o número de cigarros fumados, maior será a gravidade da síndrome de abstinência e quanto mais dependente de nicotina for o fumante, maior será a possibilidade e/ou gravidade da síndrome da síndrome de abstinência durante a suspensão do cigarro $(7,8)$.

Nas perguntas referentes às questões motivacionais avaliadas pelo questionário da história tabagística, os resultados sugerem que os tabagistas se encontravam em estágios motivacionais diferentes, pois $83,3 \% \quad(n=30)$ dos 
tabagistas diziam querer parar de fumar (contemplativos), 13,8\% (n=5) dos tabagistas diziam que não tinham intenção de parar de fumar (pré-contemplativos), e um $(2,7 \%)$ dos tabagistas dizia ter aguardado o dia da estimulação para parar de fumar (ação). Além disso, 61,1\% ( $n=22)$ se diziam muito motivados, $25 \%(n=9)$ se diziam motivados e $13,8 \%(n=5)$ se diziam pouco motivados para abandonar 0 cigarro. A literatura indica que cerca de $70 \%$ dos tabagistas dizem estar planejando parar de fumar em algum momento; porém destes, apenas $5 \%$ conseguem fazê-lo por si mesmos e somente $2 \%$ a $8 \%$ conseguem sustentar a abstinência por 30 dias $(5,6,15)$. A motivação é uma condição imprescindível para iniciar o tratamento, sua ausência praticamente elimina as expectativas de cessação do tabagismo, sendo sua avaliação fundamental para determinar qual tratamento é mais adequado ao momento do paciente (6).

Prochaska diz que o sucesso no tratamento está diretamente relacionado ao estágio motivacional em que o paciente se encontra antes do tratamento e que tratar fumantes como se estivessem no mesmo estágio motivacional é simplório (30).

Um fator limitador do presente estudo é que não foram utilizadas escalas para averiguar os estágios motivacionais em que os paciente se encontravam. Algumas escalas, como a de Richmond, têm sido utilizadas em alguns estudos, como um instrumento específico para avaliar a motivação para a cessação do hábito de fumar (69).

Em relação à fissura, os resultados mostraram que tanto os pacientes do grupo ETCC: 8,0 (DP=1,5) quanto os do Sham-ETCC: 7,4 (DP=3,0) apresentavam fissura de moderada à elevada $(\geq 7)$, medida pela EVA no primeiro dia antes da estimulação, ocorrendo uma queda significativa após o $5^{\circ}$ dia $(F=17,35 ; p<0,001$ com tamanho de efeito médio: $\left.\eta^{2}=0,44\right)$. Estas reduções se mantiveram no seguimento de 30 dias, porém sem diferença entre os grupos ETCC - 5ำ dia: 5,3 $(\mathrm{DP}=2,6) / 35^{\circ} \mathrm{dia}: 5,1(\mathrm{DP}=2,3)$ e Sham-ETCC - 5이 dia: 4,9 (DP=2,3) / 35으 dia: 4,7 $(\mathrm{DP}=2,8) F=0,32 ; p=0,810$, com tamanho de efeito nulo $\left(\eta^{2}<0,01\right)$.

É interessante observar que apesar de não haver diferença significativa entre os grupos, o desejo pelo cigarro se manteve reduzido ao longo dos 35 dias do 
estudo, sugerindo que outros fatores possam ter favorecido a manutenção da redução desta variável.

Na literatura, até o presente momento, poucos estudos têm aplicado a ETCC para a dependência do cigarro. Estes estudos são altamente heterogêneos, tanto nos parâmetros da estimulação da ETCC, quanto no delineamento do estudo, tipo de amostra, dentre outros; o que prejudica tanto a comparação dos resultados obtidos quanto sua generalização (23).

Os estudos de Fregni et al. em 2008 (57) e de Boggio et al. em 2009 (58) observaram que a ETCC anódica no CPFDL tanto esquerdo quanto direito com catodo em CPFDL contralateral, com uma única sessão, e sessões continuadas de anodo no CPFDL esquerdo com contralateral direito, reduziu a fissura pelo cigarro no grupo ETCC comparada com o grupo sham-ETCC.

No estudo de Fecteau et al. em 2014 (60), o anodo foi posicionado no CPFDL direito e o catodo no CPFDL esquerdo, ocorrendo uma redução significativa da fissura pelo cigarro no grupo ETCC comparada com o Sham-ETCC.

Já o estudo de Xu et al. (59) a ETCC anódica no CPFDL esquerdo com catodo sobre a área supraorbital contralateral, não houve alteração da fissura pelo cigarro no grupo ETCC, comparado ao grupo Sham-ETCC.

A combinação dos parâmetros de estimulação da ETCC em relação ao posicionamento e ao tamanho dos eletrodos, à intensidade da corrente elétrica, à duração da estimulação, ao número total de sessões e ao intervalo entre elas, resulta em variadas cargas de corrente atingindo a área-alvo, e geram efeitos fisiológicos distintos (23).

Fatores como resistência da calota craniana, estruturas intracranianas (vasos sanguíneos, meninges, LCR), tecido cerebral e condições não fisiológicas também influenciam a quantidade da corrente elétrica. Outras variáveis também podem interferir, tais como atividades cognitivas, uso de substâncias psicoativas, medicações diversas, idade, gênero e devem ser considerados pois podem influenciar na neuromodulação da ETCC (23). 
O fluxo da corrente pode variar substancialmente, o que pode causar efeitos inconsistentes entre indivíduos. As variações de fluxo de corrente também podem estar associadas a efeitos paradoxais de estimulação, tal como representado por "estimulação catódica". Além disso, relatórios recentes sugerem que cerca de metade dos indivíduos saudáveis não apresenta um efeito excitatório esperado com a ETCC anódica (64).

Para o número de cigarros, nosso estudo trouxe como resultado uma redução em ambos os grupos no seguimento de 30 dias $(F=27,53 ; p<0,001$, com tamanho de efeito médio: $\left.\eta^{2}=0,53\right)$, porém não houve redução significativa quando comparado o grupo ETCC com o grupo Sham-ETCC ( $F=0,233 ; p=0,873$ com tamanho de efeito nulo: $\left.\eta^{2}<0,01\right)$. No entanto, o grupo ETCC apresentou uma redução de $55 \%$ do número de cigarros consumidos (1ํdia: 22,1 (DP=7,5) / 35ํdia: 9,9 (DP=8,8) enquanto o grupo Sham-ETCC reduziu em apenas $34 \%$ o número de cigarros (1ำ dia: 26,1 (DP=14,6) / 35으 dia: 17,2 (DP=11,0) ao longo de 35 dias, sugerindo um possível efeito da ETCC.

Um fator relevante é que o número de cigarros foi averiguado através do autorrelato dos fumantes, podendo ser tais informações imprecisas.

É importante salientar que alguns autores defendem a redução do número cigarros como uma estratégia inicial de tratamento para se alcançar a abstinência e que mesmo reduções já seriam benéficas e poderiam diminuir os efeitos nocivos do tabagismo $(69,74)$.

A redução é defendida também por alguns profissionais de saúde para os fumantes que não têm nenhuma intenção imediata de parar (pré-contempladores) ou aqueles que têm sido incapazes de abster-se $(69,74)$.

Os estudos indicam que a redução do número de cigarros promove a cessação em vez de desencorajá-la e uma vez alcançada, pode incentivar novos esforços para conseguir a cessação.

Os fumantes regulares apresentam neuroadaptações que levam a formação de relacionamentos condicionados entre estímulos ambientais e tabagismo. A redução do número de cigarros poderia perturbar estas relações e reverter as 
adaptações, diminuindo a gravidade dos sintomas de abstinência e fissura quando os fumantes absterem-se totalmente (70).

Nos estudos de Fregni et al. (57), Boggio et al. (58) e Fecteau et al. (60) além da redução da fissura, o número de cigarros fumados também reduziu de forma significativa no grupo ETCC comparada com o grupo sham-ETCC.

Meng et al. (61) observaram que os efeitos da ETCC catódica bilateral em ambos FPT em tabagistas reduziram o número de cigarros fumados no grupo ETCC comparada com o grupo sham-ETCC.

No estudo de Falcone et al. (62) os efeitos da ETCC anódica sobre o CPFDL esquerda com o cátodo na área supraorbital direita reduziram de forma significativa o número de cigarros no grupo ETCC comparado com Sham-ETCC.

Estes estudos são também altamente heterogêneos no que se refere a delineamento experimental, parâmetros da estimulação da ETCC e diferenças das amostras, o que dificulta a comparação entre os resultados obtidos.

No presente estudo, em relação à motivação medida por EVA, os resultados mostraram que os tabagistas se encontravam, tanto no grupo ETCC - 1 dia: 7,7 $(\mathrm{DP}=2,9)$ como no grupo sham-ETCC - 1ำ dia: 8,3 (DP=2,4) -, com motivação de moderada à elevada $(\geq 7)$ no primeiro dia antes da estimulação. Contudo, não houve diferença significativa no grupo ETCC - 35을 dia: 8,4 (DP=2,2) comparado com o Sham-ETCC - 35을 9 (DP=1,5) $(F=1,65 ; p=0,187$ com tamanho de efeito nulo: $\left.\eta^{2}=0,06\right)$, e também não houve diferença ao longo do tempo $(F=1,18 ; p=0,324$ com tamanho de efeito nulo: $\left.\eta^{2}=0,05\right)$ sugerindo que a estimulação da ETCC no CPFDL esquerdo, não modifica esta variável (Tabela 8 e Figura 17).

A motivação é estado de prontidão ou vontade de mudar, que pode flutuar de um momento para outro e de uma situação para outra $(71,72)$. Heather em 1992 disse que "os comportamentos aditivos são essencialmente problemas motivacionais", sinalizando a importância da motivação no processo de tratamento da dependência química. Muita discussão tem havido ao longo dos anos na tentativa de explicar a complexidade das motivações humanas (73). 
Evidências oriundas de pesquisas indicam que fatores algumas vezes denominados "não específicos" são determinantes fundamentais da ocorrência ou não da mudança e do modo como ela ocorre. Características dos pacientes influenciam a motivação para mudança e os resultados do tratamento (72).

De acordo com a Teoria do Comportamento Planeado (TCP) (Ajzen, 1991), o determinante mais relevante na mudança de comportamento do indivíduo é a intenção. Deixar de fumar é um processo complexo, que pode ser precedido por várias tentativas, acompanhadas de avanços e retrocessos (71).

Não existem estudos de ETCC avaliando o comportamento desta variável como desfecho principal, nem como secundário em tabagistas. Seria interessante a realização de estudos investigando esta variável, especialmente em populações clínicas.

$\mathrm{Na}$ análise de regressão linear, o resultado do coeficiente de determinação $\left(R^{2}\right)$, quando analisado o número de cigarros em relação à fissura $\left(R^{2}=0,062\right)$ e quanto à motivação $\left(R^{2}=0,093\right)$ mostrou que as duas variáveis não explicam a redução do número de cigarros. Dessa forma, infere-se que outros fatores possam estar envolvidos e contribuindo para a diminuição da quantidade de cigarros.

O tabagismo é um processo complexo envolvendo a interrelação entre fatores farmacológicos, psicológicos, comportamentais, ambientais e socioculturais, entre outros; sendo que o tabagista pode apresentar mais evidência de um determinado componente sobre os demais. Não existe um tratamento único para todos os tabagistas, sendo fundamental individualizar a abordagem, considerando todos os fatores e a peculiaridade de cada paciente $(6,7)$.

\section{Conclusões}

O presente estudo não foi capaz de demonstrar benefícios estatisticamente significativos do uso da ETCC anódica do CPFDL esquerdo para o tratamento do tabagismo. Entretanto, a técnica se mostrou segura e de fácil manejo. Mais estudos são necessários, com amostras maiores e em populações distintas, para determinar, entre outras coisas, quais os parâmetros ótimos de estimulação e as montagens de 
eletrodos que possam ser mais eficazes e bem toleradas, para confirmar a real utilidade da ETCC e a eficácia desta técnica como ferramenta clínica no tratamento do complexo fenômeno da dependência do tabaco.

\section{Sugestões de Pesquisas Futuras}

1. O uso de instrumentos específicos para avaliar estágios motivacionais.

2. Desenvolvimento de pesquisas avaliando efeito da ETCC na motivação em tabagistas.

3. Considerar sessões de ETCC comparando fumantes nos diversos estágios motivacionais no mesmo estudo.

4. O uso de métodos de mensuração do número de cigarros mais fidedignos como medida do monóxido de carbono exalado.

5. A utilização de entrevistas estruturadas para diagnosticar patologias psiquiátricas.

6. Considerar a aplicação de ETCC associada à técnicas psicoterápicas e / ou combinações farmacológicas.

7. O uso de exames de neuroimagem para:

a) compreender os processos neurais que eliciam comportamento de fumar cigarro levando à formação de relacionamentos condicionados entre estímulos ambientais e tabagismo;

b) melhor caracterizar a rede de conexões entre as regiões cerebrais que possam ser indiretamente alteradas (estriado dorsal, córtex cingulado anterior, núcleo accumbens, dentre outros);

c) e a identificação dos substratos neurais que são modulados por ETCC e estão associados especificamente com a redução do número de cigarros e motivação. 


\section{Referências Bibliográficas}

1. World Health Organization. Tobacco. [Online]. [cited 201512 17. Available from: http://www.who.int/mediacentre/factsheets/fs339/en/.

2. Rosemberg J. Nicotina: Droga Universal São Paulo: SES/CVE; 2003.

3. Das crenças e rituais indígenas: saiba como o tabaco tornou-se a mais importante cultura agrícola do planeta. [Online].; 2015 [cited 20151217. Available from: https://biografiadocigarro.wordpress.com/2015/05/03/o-cigarro-ea-cultura/.

4. Nogueira C. A História do Tabaco. [Online]. [cited 201512 17. Available from: http://www.charutos.com.br/artigos/art charutos 15.htm.

5. Silva LCCd. Tabagismo: Doença Que Tem Tratamento Porto Alegre: Artmed; 2012.

6. Gigliotti AdP, Presman S. Atualização no Tratamento do Tabagismo Rio de Janeiro: ABP-Saúde; 2006.

7. Viegas CAdA. Tabagismo - Do Diagnóstico à Saúde Pública São Paulo: Atheneu; 2007.

8. Campana A, Marques A, Gigliotti A, Baldisserotto G, Cruz M, Ferreira M, et al. Diretrizes básicas sobre a dependência de nicotina. In Achutti A. Guia Nacional de Prevenção e Tratamento do Tabagismo. Rio de Janeiro: Vitrô Comunicações \& Editora; 2001.

9. Protocolo da Rede de Atenção Psicossocial. Projeto Diretrizes. [Online].; 2015 [cited 201512 17. Available from:

http://www.projetodiretrizes.org.br/ans/diretrizes/tabagismo.pdf.

10. Seibel SD. Dependência de Drogas. 2nd ed. São Paulo: Atheneu; 2010.

11. Instituto Nacional de Câncer José Alencar Gomes da Silva (INCA). Observatório da Política Nacional de Controle do Tabaco. [Online]. [cited 201512 17. Available from:

http://www2.inca.gov.br/wps/wcm/connect/observatorio controle tabaco/site/hom e/convencao quadro/o que ehttp://www2.inca.gov.br/wps/wcm/connect/observa torio controle tabaco/site/home/convencao quadro/o que e.

12. Portal Brasil. País comemora redução no número de fumantes. [Online].; 2015 [cited 201512 17. Available from: http://www.brasil.gov.br/saude/2015/11/paiscomemora-reducao-no-numero-de-fumantes.

13. Instituto Nacional de Câncer José Alencar Gomes da Silva (INCA). Programa Nacional de Controle do Tabagismo. [Online]. [cited 2015 12 17. Available from: http://www2.inca.gov.br/wps/wcm/connect/acoes programas/site/home/nobrasil/p rograma-nacional-controle-tabagismo/promocao-da-saude.

14. Carmo JTd, Andrés-Pueyo A, López EÁ. La evolución del concepto de 
tabaquismo.

15. Zieher LM, Zubilete MZ. Tratado de Psicofarmacología y Neurociencia Adiciones Neurobiología y consideraciones diagnósticas Buenos Aires: Editorial Sciens; 2012.

16. American Psychiatric Association (APA). Manual Diagnóstico e Estatístico de Transtornos Mentais. 5th ed.: Artmed; 2014.

17. Nunes SOV, de Castro MRP. Tabagismo: abordagem, prevenção e tratamento: FapUNIFESP (SciELO); 2010.

18. Russo AC, Azevedo RCSd. Fatores motivacionais que contribuem para a busca de tratamento ambulatorial para a cessação do tabagismo em um hospital geral universitário.

19. Planeta CS, Cruz FC. Bases neurofisiológicas da dependência do tabaco.

20. Stahl SM. Psicofarmacología Esencial de Stahl Bases neurocientíficas y aplicaciones prácticas: Aula Médica; 2013.

21. Reichert J, de Araújo AJ, Gonçalves CMC, de Godoy I, Chatkin JM, Sales MdPU, et al. Diretrizes para cessação do tabagismo-2008. Jornal Brasileiro de Pneumologia. 2008; 34: p. 845-880.

22. Volkow ND, Koob GF, McLellan AT. Neurobiologic advances from the brain disease model of addiction. New England Journal of Medicine. 2016; 374: p. 363371.

23. Fregni F, Boggio PS, Brunoni AR. Neuromodulação Terapêutica, Princípios e Avanços da Estimulação Cerebral Não Invasiva em Neurologia, Reabilitação, Psiquiatria e Neuropsicologia Sáo Paulo: Sarvier; 2012.

24. Koob GF, Volkow ND. Neurocircuitry of Addiction. Neuropsychopharmacology. 2009 August; 35(1).

25. Purves D, Augustine GJ, Fitzpatrick D, Hall WC, LaMantia AS, McNamara JO, et al. Emoções. In Purves D, Augustine GJ, Fitzpatrick D, Hall WC, LaMantia AS, McNamara JO, et al. Neurociências. Porto Alegre: Artmed; 2010. p. 734-759.

26. Koob GF, Moal ML. Addiction and the Brain Antireward System. Annual Review of Psychology. 2008 January; 59.

27. Barboza JL, Patel R, Patel P, Hudmon KS. An update on the pharmacotherapeutic interventions for smoking cessation. Expert Opinion On Pharmacotherapy. 2016 Junho; 17(11).

28. Diehl A, Cordeiro DC, Laranjeira R. Tratamentos Farmacológicos para Dependência Química: Da Evidência Científica à Prática Clínica São Paulo: Artmed; 2011.

29. Diehl A, Cordeiro DC, Laranjeira R. Dependência Química São Paulo: Artmed; 2011.

30. Prochaska JO, DiClemente CC, Norcross JC. In search of how people change: Applications to addictive behaviors. American Psychologist. 1992 Sewtembro; 
47(9).

31. Stead LF, Koilpillai P, Fanshawe TR, Lancaster T. Combined pharmacotherapy and behavioural interventions for smoking cessation. Cochrane Database of Systematic Reviews. 2016 Março;(3).

32. Dantas DRG, Pinheiro AHB, Rossoni ALM, Prado LO, Barreira SN. Tratamento do tabagismo no Brasil, com bupropiona ou vareniclina: uma revisão sistemática. Revista Saúde \& Ciência. 2016 Janeiro-Abril; 5(1).

33. Issa JS. Tabagismo e Doença Cardiovascular São Paulo: Planmark; 2007.

34. McDonough M. Update on medicines for smoking cessation. Australian Prescriber. 2015 Agosto; 38(4).

35. Beard E, Shahab L, Cummings DM, Michie S, West R. New Pharmacological Agents to Aid Smoking Cessation and Tobacco Harm Reduction: What Has Been Investigated, and What Is in the Pipeline? CNS Drugs. 2016.

36. Houezec JL, Aubin HJ. Pharmacotherapies and harm-reduction options for the treatment of tobacco dependence. Expert Opinion on Pharmacotherapy. 2013 Outubro; 14(14).

37. Boggio PS. Efeitos da estimulação transcraniana por corrente contínua sobre memória operacional e controle motor. 2006..

38. Brunoni AR, Nitsche MA, Bolognini N, Bikson M, Wagner T, Merabet L, et al. Clinical research with transcranial direct current stimulation (tDCS): Challenges and future directions. Brain Stimulation. 2012 Julho; 5(3).

39. Piccolino M. Animal electricity and the birth of electrophysiology: The legacy of Luigi Galvani. Brain Research Bulletin. 1998.

40. Sabbatini RME. A História da Estimulação Elétrica Cerebral. [Online].; 2004 [cited 2016 Fevereiro 11. Available from: http://www.cerebromente.org.br/n18/history/stimulation p.htm.

41. Foerster ÁS. Estimulação transcraniana por corrente contínua associada à prática mental: efeitos dependentes dos parâmetros da estimulação sobre o aprendizado motor de indivíduos saudáveis. 2013.

42. Pelletier SJ, Cicchetti F. Cellular and Molecular Mechanisms of Action of Transcranial Direct Current Stimulation: Evidence from In Vitro and In Vivo Models. The international journal of neuropsychopharmacology. 2015 Janeiro; 18(2).

43. Berlim MT, Dias Neto V, Turecki G. Estimulação transcraniana por corrente direta: uma alternativa promissora para o tratamento da depressão maior? Rev. Bras. Psiquiatr. 2009 Maio; 31(Suppl 1).

44. Zheng X, Alsop DC, Schlaug G. Effects of transcranial direct current stimulation (tDCS) on human regional cerebral blood flow. Neurolmage. 2011 Junho.

45. Andrade SM, Oliveira EAd. Estimulação Transcraniana por Corrente Contínua no Tratamento do Acidente Vascular Cerebral: Revisão de Literatura. Revista 
Neurociências. 2015.

46. Baeken C, Brunelin J, Duprat R, Vanderhasselt MA. The application of tDCS in psychiatric disorders: a brain imaging view. Socioaffective Neuroscience \& Psychology. 2016.

47. Clark VP, Coffman BA, Trumbo MC, Gasparovic C. Transcranial direct current stimulation (tDCS) produces localized and specific alterations in neurochemistry: A ${ }^{1} \mathrm{H}$ magnetic resonance spectroscopy study. Neuroscience Letters. 2011 Agosto.

48. Antal A, Polania R, Schmidt-Samoa C, Dechent P, Paulus W. Transcranial direct current stimulation over the primary motor cortex during fMRI. Neurolmage. 2011 Março.

49. Bachtiar V, Near J, Johansen-Berg H, Stagg CJ. Modulation of GABA and resting state functional connectivity by transcranial direct current stimulation. eLife. 2015 Setembro.

50. Gbadeyan O, Steinhauser M, McMahon K, Meinzer M. Safety, Tolerability, Blinding Efficacy and Behavioural Effects of a Novel MRI-Compatible, HighDefinition tDCS Set-Up. Brain Stimulation. 2016 Julho-Agosto.

51. Gálvez V, Alonzo A, Martin D, Loo CK. Transcranial direct current stimulation treatment protocols: should stimulus intensity be constant or incremental over multiple sessions? International Journal of Neuropsychopharmacology. 2013 Fevereiro.

52. Brunoni AR, Amadera J, Berbel B, Volz MS, Rizzerio BG, Fregni F. A systematic review on reporting and assessment of adverse effects associated with transcranial direct current stimulation. International Journal of Neuropsychopharmacology. 2011 Setembro.

53. Carvalho CdC. Efeito da estimulação transcraniana com corrente DC na excitabilidade cortical - Estudo Experimental e Simulações numéricas. 2014.

54. Silva MEd, Shiozawa P, Fregni F, Cordeiro Q. Estimulação Magnética Transcraniana (EMT) e Estimulação Transcraniana por Corrente Contínua (ETCC) no tratamento da dependência química: revisão sistemática da literatura. Arquivos Médicos dos Hospitais e da Faculdade de Ciências Médicas da Santa Casa de São Paulo. 2013 Setembro-Dezembro.

55. Xu Y, Hou Qh, Russell SD, Bennett BC, Sellers AJ, Lin Q, et al. Neuroplasticity in post-stroke gait recovery and noninvasive brain stimulation. Neural Regeneration Research. 2015.

56. Fraser PE, Rosen AC. Transcranial direct current stimulation and behavioral models of smoking addiction. Frontiers in Psychiatry. 2012 Agosto.

57. Fregni F, Liguori P, Fecteau S, Nitsche MA, Pascual-Leone A, Boggio PS. Cortical Stimulation of the Prefrontal Cortex With Transcranial Direct Current Stimulation Reduces Cue-Provoked Smoking Craving: A Randomized, ShamControlled Study. The Journal of Clinical Psychiatry. 2008. 
58. Boggio PS, Liguori P, Sultani N, Rezende L, Fecteau S, Fregni F. Cumulative priming effects of cortical stimulation on smoking cue-induced craving. Neuroscience Letters. 2009 Setembro.

59. Xu J, Fregni F, Brody AL, Rahman AS. Transcranial direct current stimulation reduces negative affect but not cigarette craving in overnight abstinent smokers. Frontiers in Psychiatry. 2013 Setembro.

60. Fecteau S, Agosta S, Hone-Blanchet A, Fregni F, Boggio P, Ciraulo D, et al. Modulation of smoking and decision-making behaviors with transcranial direct current stimulation in tobacco smokers: A preliminary study. Drug and Alcohol Dependence. 2014 Julho.

61. Meng Z, Liu C, Yu C, Ma Y. Transcranial direct current stimulation of the frontalparietal-temporal area attenuates smoking behavior. Journal of Psychiatric Research. 2014 Julho.

62. Falcone M, Bernardo L, Ashare RL, Hamilton R, Faseyitan O, McKee SA, et al. Transcranial Direct Current Brain Stimulation Increases Ability to Resist Smoking. Brain Stimulation. 2016 Março-Abril.

63. Brunoni AR, Boggio PS, Ferrucci R, Priori A, Fregni F. Transcranial Direct Current Stimulation: Challenges, Opportunities, and Impact on Psychiatry and Neurorehabilitation. Frontiers in Psychiatry. 2013 Março; 4(19).

64. Yokoi Y, Sumiyoshi T. Application of transcranial direct current stimulation to psychiatric disorders: trends and perspectives. Neuropsychiatric Electrophysiology. 2015 Agosto; 1.

65. Shiozawa P, Silva MEd, Fregni F, Brunoni AR, Cordeiro Q. Estimulação craniana por corrente contínua (ETCC) no tratamento de distúrbios psiquiátricos: o que sabemos até agora? Arquivos Médicos dos Hospitais e da Faculdade de Ciências Médicas da Santa Casa de São Paulo. 2013.

66. Pietrobon RC, Barbisan JN, Manfroi WC. Utilização do Teste de Dependência à Nicotina de Fagerström como um Instrumento de Medida do Grau de Dependência. Hospital de Clínicas de Porto Alegre. 2007; 27(3).

67. Gandiga PC, Hummel FC, Cohen LG. Transcranial DC stimulation (tDCS): A tool for double-blind sham-controlled clinical studies in brain stimulation. Clinical Neurophisiology. 2006 Abril; 117(4).

68. Pereira CF, Vargas Dd. Perfil de mulheres que realizaram tratamento para cessação do tabagismo: revisão sistemática. Revista de Saúde Pública. 2015 Julho.

69. Barreto RB, Pincelli MP, Steinwandter R, Silva AP, Manes J, Steidle LJM. Tabagismo entre pacientes internados em um hospital universitário no sul do Brasil: prevalência; grau de dependência e estágio motivacional. 2012.

70. Begh R, Lindson-Hawley N, Aveyard P. Does reduced smoking if you can't stop make any difference? BMC Medicine. 2015 Outubro.

71. Afonso F, Pereira MG. Preditores da dependência nicotínica e do comportamento 
planeado para deixar de fumar. Análise Psicológica. 2013; 31(1).

72. Miller WR, Rollnick S. Entrevista Motivacional: preparando as pessoas para a mudança de comportamentos adictivos Porto Alegre: Artmed; 2001.

73. Edwards G, Dare C. Psicoterapia e Tratamento de Adições Porto Alegre: Artes Médicas; 1997.

74. Salamoni ACH, Pereira GBGdM, Santos LSd, Lima RKPd. Neurociências em Debate. [Online].; 2015 [cited 201512 17. Available from: http://cienciasecognicao.org/neuroemdebate/?p=2344.

75. Instituto Nacional de Câncer (INCA). Abordagem e Tratamento do Fumante Consenso 2001 Rio de Janeiro; 2001.

76. Datta A, Truong D, Minhas P, Parra LC, Bikson M. Inter-individual variation during transcranial direct current stimulation and normalization of dose using MRIderived computational models. Front. Psychiatry. 2012 Outubro; 3(91).

77. Sheffer CE, Mennemeier M, Landes RD, Bickel WK, Brackman S, Dornhoffer J, et al. Neuromodulation of delay discounting, the reflection effect, and cigarette consumption. Journal of substance abuse treatment. 2013 Agosto. 
ANEXO I. QUESTIONÁRIO COM DADOS SOCIODEMOGRÁFICOS, CLÍNICOS E ESCALAS ANALÓGICAS VISUAIS DE VONTADE/DESEJO E MOTIVAÇÃO 


\section{QUESTIONÁRIO COM DADOS SÓCIODEMOGRÁFICOS - CLÍNICOS E ESCALAS ANALÓGICAS VISUAIS DE VONTADE/DESEJO E MOTIVAÇÃO}

Profissional:

Data:

\section{Identificação}

Nome:

Data de nascimento: Sexo: ( ) Masc ( ) Fem

Naturalidade:

Tel:

Estado civil:

Endereço:

( ) Destro ou ( ) Canhoto

Escolaridade:

Profissão:

Tempo de uso de cigarro:

Tentativas anteriores de para de fumar:

Carga tabágica dia:

Comorbidades clínicas:

Comorbidades psiquiátricas:

Uso atual de medicações:

Uso atual de medicações para parar de fumar:

\section{1)Escala Visual Analógica de Vontade/Desejo pelo Cigarro}

\section{Qual a sua vontade/desejo pelo cigarro?}

Avalie, de 0 a 10, a sua vontade/desejo pelo cigarro ( 0 significa que não sente vontade/desejo pelo cigarro e 10 que está com intensa vontade/desejo pelo cigarro)

Pontuação máxima de 10. Pouca vontade/desejo se 0-3; Vontade/Desejo moderada se 4-7; Vontade/Desejo elevada se $\geq 8$.

\section{2) Escala Visual Analógica de motivacão para deixar de fumar}

\section{Qual a sua motivação para deixar de fumar?}

Avalie, de 0 a 10, a sua intenção atual para parar de fumar (0 significa que não tem vontade de parar e 10 que está verdadeiramente decidido a parar de fumar)

Sem nenhuma vontade de parar
Francamente decidido a parar

Pontuação Máxima de 10. Pouca Motivação se 0-3; Motivação Moderada se 4-7; Motivação Elevada se $\geq 8$. 


\section{ANEXO II. QUESTIONÁRIO DA HISTÓRIA DO TABAGISMO}




\section{QUESTIONÁRIO DA HISTÓRIA DO TABAGISMO}

1- Com que idade você começou a fumar?

2- Com quantos anos você começou a fumar regularmente( diariamente)?

3- Qual a média de cigarros por dia?

4- Quando você fuma muito, quantos cigarros fuma por dia?

5- Qual a marca do cigarro que fuma atualmente?

6- Em quais situações abaixo você fuma?
( ) em público
( ) em casa de não fumantes
( ) no seu carro na presença de não fumantes
( ) no trabalho
( ) em casa
( )no carro de outras pessoas
( ) na presença de certos familiar
( ) na presença de filhos
( ) em festas
( ) em restaurantes
( ) outros, especifique

7- Você fuma mesmo tendo problemas de saúde?

8- Em quais situações o cigarro está associado no seu dia-a-dia?
( ) ao falar ao telefone, celular.
( )após as refeições.
( ) com café.
( ) tristeza.
( ) com bebidas alcoólicas.
( ) no trabalho
( ) alegria
( ) ansiedade.
( ) nenhuma

Outras

9- Quantas vezes você consegui deixar de fumar?
( ) 01 a 03 vezes
( ) + de 03 vezes
( ) tentou, mas não conseguiu parar de fumar
( ) nunca tentou

10- Quando foi?

Última vez:

Apresentou algum sintoma de abstinência?

Qual(is):

Usou algum tipo de

medicação? Qual(is)?

Estava em algum tipo de tratamento $\mathrm{p} /$

tabagismo? Qual?

Por que voltou a

fumar?

Penúltima:

Apresentou algum sintoma de abstinência?

Qual(is)?

Usou algum tipo de

medicação?

Qual(is)? 
Estava em algum tipo de tratamento $\mathrm{p} /$

tabagismo? Qual?

Por que voltou a

fumar?

Antepenúltima

Apresentou algum sintoma de abstinência?

Qual(is)?

Usou algum tipo de

medicação?

Qual(is)?

Estava em algum tipo de tratamento para

tabagismo? Qual?

Por que voltou a

fumar?

11-Usou alguma vez na vida algum outro recurso para deixar de fumar?

( ) nenhum

( ) Outros,

especifique

12-Comparado com outras pessoas de sua idade, você acha que sua saúde está?

( ) excelente

( ) boa

( ) regular

( ) ruim

( ) péssima

13-Por que você quer deixar de fumar agora?

( ) porque está afetando minha saúde

( ) estou preocupado com minha saúde no futuro

( ) outras pessoas estão me pressionando

( ) porque meus filhos pedem

( ) pelo bem estar da minha família

( ) porque não gosto de ser dependente

( ) fumar é anti social

( ) fumar é um mal exemplo para as crianças

( ) porque gasto muito dinheiro com cigarro

( ) por conta das restrições de fumar em ambientes fechados

(

outros

14-Você convive com fumantes?

( ) Sim

Grau de parentesco

( ) Não

15-Você tem medo de engordar ao parar de fumar?

( ) $\mathrm{sim}$

( ) Não 
16-Você está pensando seriamente em parar de fumar?

( ) sim, inclusive já parei

( ) sim, nos próximos dias

( ) sim, nos próximos 30 dias

( ) sim, nos próximos 06 meses

( ) sim, no próximo ano

( ) indeciso

( ) sem planos para parar

17-Quanto você está motivado para parar totalmente de fumar?

( ) Não estou motivado

( ) Pouco motivado

( ) Motivado

( ) Bastante motivado

18-Se você já parou de fumar completamente, quando parou?

19-Você está pronto para marcar uma data?

( ) Sim. Data da parada:

( ) Não 


\section{ANEXO III. TESTE DE FARGESTROM PARA A DEPENDÊNCIA DE NICOTINA}




\section{TESTE DE FARGESTROM PARA A DEPENDÊNCIA DE NICOTINA}

1. Quanto tempo após acordar você fuma seu primeiro cigarro?

Dentro de 5 minutos $=3$

Entre 6-30 minutos $=2$

Entre 31-60 minutos $=1$

Após 60 minutos $=0$

2. Você acha difícil não fumar em lugares proibidos, como igrejas, ônibus, etc.?

Sim $=1$

Não $=0$

3. Qual cigarro do dia traz mais satisfação?

O primeiro da manhã $=1$

Outros

$=0$

4. Quantos cigarros você fuma por dia?

Menos de $10=0$

De 11 a $20=1$

De 21 a $30=2$

Mais de $31=3$

5. Você fuma mais frequentemente pela manhã?

$\mathrm{Sim}=1$

Não $=0$

6. Você fuma mesmo doente?

$\operatorname{Sim}=1$

Não $=0$

Conclusão sobre o grau de dependência:

$0-2$ pontos $=$ muito baixo

$3-4$ pontos $=$ baixo

5 pontos $=$ médio

$6-7$ pontos = elevado

$8-10$ pontos $=$ muito elevado

(Uma soma acima de 6 pontos indica que, provavelmente, o paciente sentirá desconforto (síndrome de abstinência) ao deixar de fumar). 


\section{ANEXO IV. ENTREVISTA CLÍNICA ESTRUTURADA PARA TRANSTORNOS DO EIXO I DO DSM-IV-SCID-I}




\section{ENTREVISTA CLÍNICA ESTRUTURADA PARA TRANSTORNOS DO EIXO I DO} DSM-IV-SCID-I

1. Caderno de perguntas - disponível no link:

http://files.getaufc.webnode.com.br/200000214-2b2742c211/entrevistaSCID.pdf.

2. Folha de Resposta - disponível no link:

https://xa.yimg.com/kg/groups/21689873/1470032809/name/folha+de+resposta+da+ $\underline{\text { SCID+CV.pdf }}$ 
ANEXO V. DOCUMENTO DE APROVAÇÃO PELO COMITÊ DE ÉTICA 




DECLARACÃO DE APROVAC̃̃̃ DE PROJETO DE PESQUISA

Registro do Projeto no CEP: 080/10

Título do Projeto: "Efeitos da Modulação do córtex pré-frontal através da estimulação transcraniana com corrente direta no desejo por tabaco em pacientes tabagistas".

Pesquisador Responsável: Raphael Boechat Barros

Data de Entrada: 01/07/10

Declaro para os devidos fins que o presente projeto foi aprovado em 13 de julho de 2010, conforme consta em nossos registros, como segue:

"Com base na Resolução 196/96, do CNS/MS, que regulamenta a ética em pesquisa com seres humanos, o Comitê de Ética em Pesquisa com Seres Humanos da Faculdade de Ciências da Saúde da Universidade de Brasília, após análise dos aspectos éticos e do contexto técnico-científico, resolveu APROVAR o projeto 080/10 com o título: "Efeitos da Modulação do córtex pré-frontal através da estimulação transcraniana com corrente direta no desejo por tabaco em pacientes tabagistas", analisado na $6^{\text {a }}$ Reunião Ordinária, realizada no dia 13 de julho de 2010

O pesquisador responsável fica, desde já, notificado da obrigatoriedade da apresentação de um relatório semestral e relatório final sucinto e objetivo sobre o desenvolvimento do Projeto, no prazo de 1 (um) ano a contar da presente data (item VII.13 da Resolução 196/96).

Brasília, 11 de agosto de 2010.

Prof. Volnei Garrafa Coordenador do CEP-FS/UnB"

Em 20 de maio de 2016

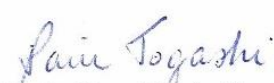

Profa. Dra. Marie Togashi

Coordenador - CEP/FS-UnB

Comitê de Ética em Pesquisa com Seres Humanos - Faculdade de Ciências da Saúde Universidade de Brasília - Campus Universitário Darcy Ribeiro - CEP. 70.910-900 Telefone: (61)=3107-1947 Email: cepfs@unb.br 


\section{ANEXO VI. TERMO DE CONSENTIMENTO LIVRE E ESCLARECIDO}




\section{TERMO DE CONSENTIMENTO LIVRE E ESCLARECIDO}

O (A) senhor(a) está sendo convidado(a) a participar da pesquisa: "Efeitos da modulação do córtex pré-frontal através da estimulação transcraniana com corrente direta contínua no desejo por tabaco em pacientes tabagistas" que será realizada sob a coordenação e orientação do Dr. Raphael Boechat Barros do Hospital Universitário de Brasília (HUB).

Este trabalho tem como objetivo analisar os efeitos da modulação de uma parte do cérebro com estimulação elétrica ( por meio de eletrodos) no desejo por tabaco em pacientes tabaco-dependentes e contribuir para a exploração deste método como alternativa terapêutica para a parada do fumo.

Os participantes serão submetidos a cinco sessões em dias consecutivos de estimulação elétrica transcraniana com duração de 20 minutos cada uma. Também serão aplicados questionários sobre dados gerais e dos hábitos tabágicos no primeiro dia, além de escalas sobre vontade/desejo e motivação. As escalas de vontade/desejo e motivação serão aplicadas no último dia de aplicação e nos seguimentos de 2 e 30 dias, após o último dia de aplicação.

Os participantes serão divididos em dois grupos, aleatoriamente( por ordem de chegada), um grupo receberá a estimulação real com corrente contínua e o outro receberá uma estimulação falsa, ou seja, o aparelho apenas será colocado na cabeça do paciente, porém estará desligado.

Para participar da pesquisa, não há necessidade de nenhum tipo de cirurgia ( não é invasivo) nem de raspagem do cabelo.

O(A) senhor(a) receberá todos os esclarecimentos necessários antes e durante a pesquisa e lhes asseguramos que o seu nome não aparecerá, sendo mantido o mais rigoroso sigilo através da omissão total de quaisquer informações que permitam identificá-lo(a).

Se o(a) senhor(a) concordar em participar da pesquisa, mas por algum motivo, mudar de ideia, o(a) senhor(a) terá todo o direito de sair a qualquer 
momento sem prejuízo. Esclarecemos ainda que esse termo encontra-se redigido em duas vias: uma cópia ficará com você e a outra será entregue ao pesquisador.

Os resultados da pesquisa serão divulgados no setor de saúde podendo, inclusive ser publicados posteriormente em revistas científicas especializadas, para que, desse modo, a pesquisa possa contribuir para a exploração deste método como alternativa terapêutica para a cessação tabágica. Os roteiros respondidos ficarão sob a guarda do coordenador da pesquisa.

Caso você tenha alguma dúvida sobre a pesquisa, estamos à disposição para quaisquer esclarecimentos.

\section{POSSÍVEIS EFEITOS COLATERAIS:}

- Irritações locais;

- Dor de cabeça ( transitória, cedendo a analgésicos comuns);

- Queimações leves e superficiais no couro cabeludo no local da aplicação do eletrodo.

Os possíveis efeitos colaterais serão minimizados com o aumento e diminuição gradual da corrente no início e final da aplicação, respectivamente.

Com o protocolo a ser utilizado estes efeitos se tornam muito improváveis pela baixa duração e tipo de corrente utilizada. Como o paciente estará sempre acompanhado por algum pesquisador da equipe o mesmo será orientado, caso sinta qualquer desconforto, a avisar o membro da equipe para que ele suspenda imediatamente a aplicação.

\section{CONTRA-INDICAÇÕES:}

- O paciente não poderá ter menos de 18 anos ou mais de 65 anos;

- Ser analfabeto;

- Incapaz de entender substancialmente o projeto ao qual está se submetendo;

- Estar grávida ou em risco de engravidar durante as aplicações;

- Ser portador de comorbidade clínica e/ou psiquiátrica importante que possa interferir no seguimento do projeto. 
Estou ciente de todas as informações acima e concordo em participar do referido projeto.

Nome:

Endereço:

Identidade:

Telefone para contato:

Brasília, de de 20

Assinatura:

Pesquisador responsável:

Dr. Raphael Boechat Barros, Ambulatório de Psiquiatria-UNB-DF

Dra Maria Célia Vitor de Souza Brangioni, Ambulatório de Psiquiatria-UNB-DF Telefone: 61-33072522 (Laboratório de Psiquiatria)

61-34485434 (Ambulatório de Psiquiatria)

Os pesquisadores estarão disponíveis para atendimento a qualquer momento 